\title{
3 Das RWI in der Kriegswirtschaft
}

\subsection{Die nationalsozialistische Wirtschaftslenkung}

\subsubsection{Die Organisation der NS-Wirtschaft}

Durch die vom NS-Regime forcierte „wehrwirtschaftliche“ Umgestaltung der Volkswirtschaft verschwand der dem kapitalistisch-marktwirtschaftlichen System innewohnende Konjunkturzyklus und damit auch der ursprüngliche Forschungsgegenstand sowohl des IfK als auch des Essener Instituts. Um die daraufhin eingeleitete Umorientierung des Berliner Mutterhauses und seines Essener Institutsablegers in die Kriegswirtschaft einzuordnen und zu verstehen, wird hier die Systemänderung der deutschen Wirtschaft erläutert. Die Organisation der NS-Wirtschaft brauchte nicht gegen die privaten Eigentümer der Produktionsmittel durchgesetzt zu werden wie in der zentral verwalteten Planwirtschaft sowjetischen Typs, ${ }^{1}$ sondern sie erfolgte zusammen mit den deutschen Unternehmen. Voraussetzung war die hochgradige Selbstorganisation der privaten Firmen in Großunternehmen, Kartellen und Branchenverbänden, die seit dem Kaiserreich und verstärkt in der Weimarer Republik wettbewerblich-marktwirtschaftliche Elemente zurückgedrängt oder ausgeschaltet hatten. Belohnt durch hohe Gewinne ließen sich diese privatwirtschaftlichen Organisationen ohne große Widerstände in die Lenkung und Ziele der NS-Wirtschaft einspannen. Eine stringente zentrale Planung wurde allerdings nie erreicht, zumal Machtkonflikte rivalisierender, den Unternehmen übergeordneter Institutionen sowie widersprüchliche direkte und indirekte Steuerungsmechanismen bestanden. ${ }^{2}$

Die Vorbereitung der deutschen Wirtschaft auf den geplanten Krieg vollzog sich innerhalb der nationalsozialistischen Autarkiepolitik mit ihren lenkungswirtschaftlichen Maßnahmen. ${ }^{3}$ Schon seit 1934 stellten die Überwachungsstellen ${ }^{4}$ zur Importkontrolle die Weichen zur Steuerung der industriellen Produktion unter Federführung des RWM. ${ }^{5}$ Die zunehmende Ressourcenbewirtschaftung begann mit einer Rohstoff-

1 Herbst weist darauf hin, dass der Systemcharakter der NS-Wirtschaft aus dem Blickfeld geriet, weil vor dem Hintergrund des Ost-West-Konfliktes lediglich die „liberale Marktwirtschaft“ gegen die „kommunistische Zentralverwaltungswirtschaft“ abgesetzt wurde. Herbst 2016, S. 611.

2 Die folgenden Ausführungen wurden im Rahmen eines Forschungsprojektes zur Geschichte des Bundeswirtschaftsministeriums erarbeitet. Siehe ausführlich Fremdling 2016a.

3 Hierzu die grundlegende Arbeit von Petzina (1968). Speziell zu den Lenkungsmaßnahmen vgl. ebd. S. 153ff.; vgl. auch Wagenführ 1963, S. 18 ff.; siehe zur Handelspolitik Kopper 2016 und Banken 2016. 4 Zu Schachts „Neuem Plan“ siehe Boelcke 1983, S. 100 ff. In den Überwachungsstellen, die seit 1939 Reichsstellen genannt wurden, arbeiteten Beamte des RWM mit Vertretern der Wirtschaftsverbände zusammen, Tooze 2001, S. 188; Ebi 2004, S. 130 ff.; Streb 2016, S. 536 ff. Nach Banken (2016) gab es die Strukturen der „Überwachungsstellen“ schon vor dem „Neuen Plan“.

5 Geer 1961, S. 30. Ebd. (S. 28 ff.) werden die rechtlichen Grundlagen und die Praxis erörtert. Siehe auch Herbst (2016, S. 613), der ganz klar die Verbindung von Importkontrolle und „der sich sukzessive entwickelnden Rohstofflenkung“ herstellt.

Ә OpenAccess. (c) 2018 Rainer Fremdling, publiziert von De Gruyter. (cc))BY-NC-ND Dieses Werk ist lizenziert unter der Creative Commons Attribution-NonCommercial-NoDerivatives 4.0 Lizenz. 
lenkung. Parallel und komplementär wurden Preise und Löhne, aber auch der Arbeitsmarkt immer stärker staatlich kontrolliert und gelenkt. Die privaten Firmen und ihre Interessenverbände stellten sich dieser Wirtschaftspolitik nicht entgegen, allerdings wurden sie in neue Zwangsverbände, z.B. die fachlich-gewerblichen Wirtschaftsgruppen, überführt. ${ }^{6}$ Nach Petzina war dies der Versuch, „eine staatlich reglementierte ,Kommandowirtschaft ${ }^{\star}$ auf der Grundlage eines privatkapitalistischen Systems“ zu errichten. ${ }^{7}$

Die zunehmende Ressourcenbewirtschaftung bot mit dem Zugriff an der untersten Stufe der Wertschöpfungskette über die Rohstoffe ein indirektes Steuerungsinstrument für die nachgelagerten Produktionsprozesse bis hin zum Endprodukt. Als „Rohstoff“ galten auch Zwischenprodukte auf einer unteren Produktionsstufe, z. B. Eisen und Stahl. Mit der forcierten Kriegsvorbereitung des Vierjahresplans ${ }^{8}$ ab 1936 wurde die indirekte Rohstoffbewirtschaftung zunehmend durch direkte Maßnahmen wie die Kontingentierung des Eisens abgelöst. Allerdings gelang die Lenkung der Wirtschaft nur mangelhaft. Die Unzulänglichkeiten dieser Bewirtschaftung lagen von Anfang an daran, dass sich keine klare und verbindliche Prioritätenliste durchsetzen ließ, die mit der tatsächlichen Produktion kompatibel war. Andauernd wurden Vorräte gehamstert, und im Vergleich zur Erzeugung waren immer zu viele Kontingente im Umlauf. Neue und verfeinerte Dringlichkeitsstufen änderten nichts an dem grundsätzlichen Dilemma. ${ }^{9}$

Das Lenkungssystem war kompliziert, widersprüchlich und zeigte selbst chaotische Züge. Seine Schwäche war die organisatorische Zuordnung der Betriebe seit Schachts Neuem Plan von 1934: ${ }^{10}$ Die Reichsstellen (vorher Überwachungsstellen) waren jeweils für Betriebe zuständig, die nach Rohstoffgruppen zusammengefasst waren. Für ein und dasselbe Unternehmen konnte eine Vielzahl von Lenkungsstellen verantwortlich sein, mit Reibereien bei den ständig veränderten Zuordnungen. Trotz aller Versuche, die Zuordnung der Betriebe zu reorganisieren, blieben in den

6 Geer 1961, S. 32, 36.

7 Petzina 1968, S. 11. Geer (1961, S. 122, 171f. u. passim) lehnt denn auch Begriffe wie „Planwirtschaft“ oder „Verwaltungswirtschaft“ zur Kennzeichnung der Wirtschaftsform ab, er schlägt „Programmwirtschaft“ für diese eher nach politischen Zielsetzungen gelenkte Wirtschaft vor.

8 Siehe die von Treue herausgegebene und kommentierte „Denkschrift Hitlers über die Aufgaben eines Vierjahresplans“, die wahrscheinlich im August 1936 verfasst wurde (Treue 1955). Hitler schloss die Denkschrift mit folgenden Forderungen: „Ich stelle damit folgende Aufgabe: I. Die deutsche Armee muß in 4 Jahren einsatzfähig sein. II. Die deutsche Wirtschaft muß in 4 Jahren kriegsfähig sein. “ Unter der Leitung Hermann Görings wurde daraufhin Ende 1936 die „Vierjahresplanbehörde“ geschaffen. Nach Herbst (2016, S. 637) „,setzte der Vierjahresplan lediglich die 1934 begonnene Aufrüstungs- und Industrialisierungspolitik fort.“

9 Müller 1988, S. $621 \mathrm{ff}$.

10 Boelcke 1983, S. 100 ff.; Tooze 2001, S. 264f. Die organisatorischen Schwächen hatte Wagenführ herausgearbeitet. 
Lenkungsbereichen ${ }^{11}$ des RWM Betriebe gleichzeitig mehreren Organisationen angeschlossen. ${ }^{12}$ Um die Mängel zu beseitigen, wurden immer weitergehende Lenkungsmaßnahmen eingeführt. Neben die Kontingentierung der Rohstoffe traten organisatorische Neuerungen wie die Reduzierung und Zentralisierung der Stellen. Gleichzeitig wurden aber unter Mitwirkung der Industrie (anfänglich allerdings auch gegen ihren Widerstand) weitere branchenorientierte Reichsvereinigungen zur Produktionslenkung geschaffen. Reichsbeauftragte führten und kontrollierten, während die Organisationen der gewerblichen Wirtschaft die Ausführungen verantworteten. ${ }^{13}$

Die Lenkung der verarbeitenden Industrie oblag den Wirtschaftsgruppen mit den nachgeordneten Fachgruppen und Fachuntergruppen. Die Gruppen waren aus der Selbstorganisation der Wirtschaft, den Verbänden und Kartellen hervorgegangen und deshalb nach gemeinsamen Betätigungsfeldern, wie sie sich in der Industrieklassifikation des StRA spiegelten, organisiert. Das geschah in Abstimmung mit dem RWM, womit die Kartelle staatlich sanktioniert waren. ${ }^{14}$ Zur weitgehenden Akzeptanz der Zwangsorganisationen trug bei, dass sie der privat organisierten Wirtschaft glänzende Gewinne bescherten: Nach der kürzlich fertig gestellten Berechnung des Bruttoinlandsprodukts für Deutschland im Jahre 1936, die zum ersten Mal nach der Entstehungsmethode erfolgte (also aufgrund der Wertschöpfungsdaten), zeigte sich bereits für dieses Stichjahr eine enorme Schieflage der Einkommensverteilung zugunsten der Gewinne. ${ }^{15}$ Für die Versorgung der Bevölkerung mit Konsumgütern waren die regional verankerten Landeswirtschaftsämter zuständig, die dem RWM unterstanden. ${ }^{16}$

Die Überwachungsstellen und Wirtschaftsorganisationen waren verpflichtet, die Ergebnisse ihrer internen statistischen Erhebungen dem StRA zur Verfügung zu stellen. ${ }^{17}$ Letztlich arbeiteten die Wirtschaftsorganisationen sogar eng mit den Trägern der

11 Darunter fielen Reichs- und Bewirtschaftungsstellen mit unterschiedlichen Bezeichnungen, siehe Wagenführ 1963, S. 43.

12 Siehe Beispiele für ausufernde Zuordnungen bei Wagenführ 1963, S. 41.

13 Siehe auch Herbst 2016, S. $638 \mathrm{f}$.

14 Geer 1961, S. 34 ff. Mit der Einbeziehung der Arbeitskräfte, des Energie- sowie des Verkehrssektors und der Investitionssteuerung hätte dann fast die gesamte Wirtschaft unter Kontrolle gestanden. Siehe auch Tooze 2008, S. 137.

15 Die Profitquote lag bei 48 Prozent, Fremdling/Staeglin 2014a, b. Das StRA führte solche Berechnungen nicht durch, seine internen Untersuchungen über die Gewinne der Rüstungsindustrie bestätigen dieses Ergebnis: BA R3102/2702 F. 1, 250 und 2701 F. 23 ff.; siehe auch Spoerer 2005, S. 423, 426 428 und Spoerer 1996.

16 Siehe Streb 2016, S. 538 ff.

17 Die Überwachungsstellen übermittelten ihre statistischen Erhebungen über den Produktionsumfang und die Bestände an das StRA. Siehe Schreiben des RWM vom 27.5.1936 an „sämtliche Überwachungsstellen“ (BA R3101/31274 F. 28) und die Erlasse des RWM vom 5.1. und 3.5.1935 (BA R3102/ 10003 F. 64). Entsprechende Erlasse, die ebenfalls an die Wirtschaftsorganisationen gerichtet waren, datieren vom 20.2. und 27.4.1937 (ebd.). Offensichtlich gab es auch schon vor den Erlassen eine große Bereitschaft, dem StRA produktionsstatistische Daten zu übermitteln. So schrieb die Fachgruppe Metallhalbzeugindustrie am 6.3.1937 als Antwort auf die Meldeverpflichtung durch den RWM vom 
amtlichen Statistik zusammen. Als das Reichsamt für Wehrwirtschaftliche Planung (RWP) und das StRA dasselbe fachliche Gliederungsprinzip wie die Wirtschaftsgruppen anwendeten, ließen sich die Ergebnisse der Produktionserhebungen ohne methodische Schwierigkeiten austauschen. Die „statistischen Erhebungen der Gliederungen der gewerblichen Wirtschaft“ gingen regelmäßig der Abteilung VII (Industrielle Produktionsstatistik) des StRA bzw. dem RWP zu. ${ }^{18}$ Ende der 1930er Jahre konzentrierte sich das RWP auf die Jahreserhebungen der industriellen Produktionsstatistik, während die Wirtschafts- und Fachgruppen der Reichsgruppe Industrie die Monatsstatistiken führten. ${ }^{19}$ Hier bahnte sich die spätere enge Verzahnung zwischen der Reichsgruppe Industrie und dem StRA bzw. der Statistischen Leitstelle auf der einen Seite und der Planstatistik des DIW im Auftrag des RWM und dann des Planungsamtes mit Rolf Wagenführ auf der anderen Seite an.

Während des Krieges funktionierte das Bewirtschaftungs- und Lenkungssystem ${ }^{20}$ für die Rüstungsplanung nicht mehr hinreichend. Daraufhin initiierte Rüstungsminister Speer ${ }^{21}$ im April 1942 eine neue Planungsorganisation für die Kriegswirtschaft, die „Zentrale Planung“ bei der Vierjahresplanbehörde. ${ }^{22}$ Mit dem übergeordneten Ausschuss „Zentrale Planung“ verfügte Speer über ein Instrument zur Lenkung der Rüstungswirtschaft. Im Ausschuss war auch das RWM vertreten, das für die zivile Produktion verantwortlich war. Die zentrale Planung wurde in gemeinsamen Sitzungen des Rüstungsministeriums, des RWM und der Vierjahresplanorganisation abgestimmt. Die zivile Produktionssteuerung lag also zunächst noch beim RWM, und zwar in der Hauptabteilung II (Industrie). Im April 1942 beauftragte Reichswirt-

20.2.1937, dass sie „,bereits seit Januar 1933“ ihre monatliche Produktionsstatistik dem StRA mitgeteilt habe (BA R3102/3006 F. 2).

18 Im Erlass des RWM vom 23.3.1938 mit Wirkung zum 1.4.1938 wurde die Abteilung VII des StRA (Industrielle Produktionsstatistik) zum RWP verselbständigt; mit dem Erlass des RWM vom 5.5.1940 wurde das RWP wieder als Abt. VIII (Industrielle Produktionsstatistik) in das StRA eingegliedert (BA R3102/3045). Siehe Brief Leisses an den Präsidenten des StRA vom 6.9.1937 (BA R3102/3572 F. 1f.) und mehrere Aktenstücke zu den Monatserhebungen (BA R3102/3625).

19 Bickert 1940, S. 1035; BA R3102/3586 F. 162; zur Rolle des RWP siehe Leisse 1940 und von Roeder 1940, S. 1018. Leisse (als Leiter) und von Roeder arbeiteten im RWP. Auch Bramstedt (1940, S. 1004f.) vom StRA diskutierte die Kooperation mit der Reichsgruppe Industrie.

20 Welter wies darauf hin, dass diese Begriffe nichts anderes als euphemistische Bezeichnungen für die „Rationierung“ auch der Produktionsmittel waren. Welter 1954, S. 85.

21 Das Ministerium wurde am 17.3.1940 geschaffen. Formell war Speer als „Generalbevollmächtigter für Rüstungsaufgaben im Vierjahresplan“ Göring unterstellt. Geer 1961, S. 151 ff. Ausführlich zu Speer siehe Tooze 2008, S. 634 ff.; Brechtken 2017.

22 „Erlaß des Reichsmarschalls des Großdeutschen Reiches über Errichtung einer ,Zentralen Planung“ im Vierjahresplan“, von Göring am 22.4.1942 unterzeichnet. Zitiert nach Eichholtz 1985, S. 82. Inhaltlich hatte sich dieser Ausschuss nach Geer schon lange vorher als „Kollegialgremium“ zur Aushandlung von Kompromissen bei der Bewirtschaftung gebildet. Dennoch sieht Geer im Jahre 1942 einen Wendepunkt bei den Lenkungsmethoden. Geer 1961, S. 120 f., 128. 
schaftsminister Funk auf Veranlassung Speers Hans Kehrl, ${ }^{23}$ der die Textilindustrie erfolgreich bewirtschaftete, die kriegswichtige Eisen- und Stahlindustrie zu reorganisieren. ${ }^{24}$ Unter der „Zentralen Planung“ wurde die Verteilung bzw. Kontingentierung von Eisen und Stahl zum Hebel, um die Kriegswirtschaft insgesamt zu lenken. ${ }^{25}$ Denn Eisen war zentraler „Grundstoff“ oder „Leitrohstoff“ (Kehrl) der Industrieproduktion. Nach Petzina „war die Geschichte der Rohstofflenkung zwischen 1936 und 1942 weitgehend mit der Geschichte der Eisenkontingentierung identisch." ${ }^{\text {"6 }}$ Zugleich übertrug das RWM Kehrl die Befugnis, die gesamte Rohstoffbewirtschaftung neu zu regeln. ${ }^{27}$

Parallel zu den Lenkungsbereichen des RWM schuf das Speersche Ministerium 1942 für die Rüstungsfertigung eine neuartige Gliederung in Ausschüsse und Ringe. ${ }^{28}$ Jeweils für die drei Wehrmachtsteile konzentrierten sich Ausschüsse auf Rüstungsendprodukte (Panzer, Schiffe, Waffen etc.), Ringe auf vorgelagerte Produktionsstufen (Ring Eisenverarbeitung, Elektrotechnik etc.). Nach diesem Organisationsprinzip ${ }^{29}$ wurden die Industrieunternehmen in neue zusätzliche Bezugseinheiten umgruppiert. „Das waren Zusammenschlüsse von Betrieben bzw. Betriebsabteilungen gleicher Fertigung unter autoritativer Führung eines anerkannten Industriefachmanns aus dem betreffenden Fertigungsgebiet.“30 Das heißt, sie agierten unter der „Selbstverantwortung der Industrie“. Führende Industrielle, Wirtschaftsleute, und nicht Militärs, waren verantwortlich für die Organisation der Ausschüsse und Ringe. ${ }^{31}$ Len-

23 Tooze 2008, S. 655 ff. Zu Hans Kehrl siehe Herbst 1982, S. 257, Anm. 8 und Herbst 2016, S. 639; ausführlich Müller 1999a u. 1999b. Hans Kehrl (1900 -1984), Tuchfabrikant und Mitglied zahlreicher Aufsichtsräte, war seit 1934 u. a. führend in der Rohstoffbewirtschaftung (Textilreferat im Vierjahresplan) tätig, seit 1938 leitete er im RWM die Textilabteilung und ab November 1942 die Hauptabteilung II (Industrie). Im RMRuK stand er ab September 1943 dem Planungsamt vor. 1939 wurde er SS-Oberführer und 1944 SS-Brigadeführer. Nach der Internierung und Verurteilung als Kriegsverbrecher wurde er 1951 begnadigt und war als Wirtschaftsberater in der BRD tätig.

24 Hensler 2008, S. 59 ff. Die Aufgaben Kehrls lassen sich aus einem internen Papier des DIW mit „Stichworten“ für eine Sitzung mit Wagemann ablesen. Darin hatte Wagenführ am 14.7.1943 u.a. folgende Punkte notiert: „Ausgangspunkt der Kehrlarbeiten, a) Organisationswirrwarr, [...] b) Wirrwarr der Planung c) Wirrwarr der Statistik“. Danach folgten Stichworte zur Neuordnung: ,je Betrieb eine Lenkungsstelle, [...] Keine Rohstoffplanung sondern Fertigwarenplanung, [...] Einschaltung erfolgreicher Unternehmer“. BA R3/1796 F. 34.

25 Eichholtz 1996, S. $126 \mathrm{ff}$.

26 Petzina 1968, S. 154. Siehe ausführlich dazu Geer (1961) und Hensler (2008).

27 Wagenführ 1963, S. 43 ff.; Eichholtz 1985, S. 84; Tooze 2001, S. 260; Streb 2016, S. $542 \mathrm{ff.}$

28 Siehe „Speers Schema für die Reorganisation der Rüstungswirtschaft vom Februar 1942“ bei Müller 1988, S. 681; siehe das Verzeichnis der Ausschüsse und Ringe (Stand Mitte Juli 1943) bei Eichholtz 1985, Beilage 2; Geer 1961, S. 93 Anm. 8.

29 Tatsächlich wurde das Organisationsprinzip nicht konsequent durchgesetzt: „In Wirklichkeit liefen Ringe und Ausschüsse durcheinander.“ Wagenführ 1963, S. 41, dort konkrete Beispiele.

30 Wagenführ 1963, S. 40.

31 Eichholtz 1996, S. 12; Geer 1961, S. $151 \mathrm{ff}$. 
kungstechnisch waren sie wiederum in eine Hierarchie von Haupt- und Unterausschüssen bzw. Ringen eingebunden.

Die beiden Organisationsmodelle des RWM und des Rüstungsministeriums waren nicht kompatibel. Da beide Gliederungssysteme weiter nebeneinander bestanden, war eine eindeutige und ausschließliche Zuordnung der Betriebe im Lenkungssystem prinzipiell unmöglich. Bereits bestehende Organisationen, wie die Wirtschaftsgruppen, blieben erhalten, und viele Einzelbetriebe konnten gleichzeitig einer Vielzahl von Ausschüssen, Ringen und Wirtschaftsgruppen und den jeweilig hierarchisch untergeordneten Untergliederungen angehören. Mit der weiteren Aufspaltung nach regionalen Gesichtspunkten und schließlich wechselnden Zuordnungen im Zeitablauf waren unübersichtliche Zustände und Verwicklungen programmiert. ${ }^{32}$

Im Herbst 1943 wurde mit dem „Planungsamt“ die Kriegswirtschaft, die ja die Produktion für zivile Zwecke einschloss, organisatorisch vollständig zentralisiert, um sie ganz auf die militärischen Bedürfnisse zuzuschneiden. Schon vorher hatte sich zwar abgezeichnet, dass die Rüstungsproduktion den Kern der Kriegswirtschaft ausmachte und Ausgangspunkt aller Lenkungsmaßnahmen war. Jedoch hatte es, durch die blitzartigen Kriegserfolge vor 1943 lediglich verzögert, begrenzte organisatorische Änderungen für den zivilen Teil gegeben. Anders sah es im militärischen Bereich aus: Anfangs lag die Beschaffung von Kriegsgerät in der Verantwortung der Wehrmacht, wurde ihr aber organisatorisch und fertigungstechnisch nach und nach entzogen. ${ }^{33}$ Seit 1942 fiel sie in den Zuständigkeitsbereich des Speerschen Rüstungsministeriums. ${ }^{34}$ Die Verlagerung der Verantwortung trat deutlich zutage, als die Rüstungsorganisation des Oberkommandos der Wehrmacht, das Rüstungsamt, im Laufe des Jahres 1942 in das Rüstungsministerium verschoben wurde. ${ }^{35}$

Um die Zweiteilung des Lenkungssystems in militärische und zivile, aber auch überlappende Zuständigkeiten beider Ministerien und damit das Nebeneinander und Überschneidungen der Planungsinstanzen zu beenden, wurde die zivile Produktionssteuerung des RWM (Hauptabteilung II Industrie) unter der Leitung Kehrls mit dem Führererlass vom 2. September $1943^{36}$ komplett in die Verantwortung Speers überführt. ${ }^{37}$ Diese Abteilung wurde mit den erweiterten Zuständigkeiten für die Waffenproduktion das Planungsamt im Rüstungsministerium, das damit die Komman-

32 Wagenführ 1963, S. 40 ff.; Geer 1961, S. 136 ff.; Welter (1954, S. 115ff.) gibt anschauliche Beispiele. 33 Siehe dazu Wagenführ 1963, S. 39 ff.; Eichholtz 1985, S. 64 ff.; Müller 1988, S. 664 ff.; Welter 1954, S. $115 \mathrm{ff}$.

34 Zum Folgenden Herbst 1982, S. 255 ff.; siehe auch das „Kapitel 4. Entmachtung des Reichswirtschaftsministeriums“ bei Boelcke 1983, S. $297 \mathrm{ff}$.

35 Erlass Hitlers vom 7.5.1942; der gänzliche Übergang fand schließlich ein halbes Jahr später mit der Entmachtung von General Thomas statt, siehe Eichholtz 1985, S. 70 f.; diese Umorientierung hing auch mit dem Scheitern der Blitzkriegsstrategie an der Ostfront zusammen, siehe Müller 1983, S. $1022 \mathrm{ff}$. 36 Im Erlass vom 16.9.1943 umriss Speer die Aufgaben und Kompetenzen des Planungsamtes, BA R3102/3589 F. 46 f. oder BA R3102/3569. Siehe auch Herbst (1982; S. 255ff.) und Streb (2016, S. 547 ff.) zu den Hintergründen über die „Konzentration der Kriegswirtschaft“ und den Führererlass vom 2.9.1943. 37 Roth 1996, S. $522 \mathrm{ff}$. 
dozentrale der deutschen Wirtschaft bis zum Kriegsende bildete. Im Kern wurde damit also auch die Lenkung der „zivilen“ Zulieferindustrien (Rohstoffe, Industrie) für die Rüstungsproduktion dem Speerschen Ministerium einverleibt. ${ }^{38}$ Die Reorganisation der deutschen Kriegswirtschaft war damit abgeschlossen. ${ }^{39}$ Nach Müller war Kehrl „in der letzten Kriegsphase als quasi ,Generalstabschef ${ }^{\star}$ Speers der eigentliche Organisator der deutschen Kriegswirtschaft und Rüstung. “40

\subsubsection{Operationale Einbindung der empirischen Wirtschaftsforschung in die Kriegswirtschaft - Die Industrieabteilung des DIW}

Anders als ein dezentrales, sich selbst über Knappheitspreise regulierendes Marktsystem erfordert eine zentralisierte Planungs- und Bewirtschaftungsstruktur prinzipiell andere Mechanismen. ${ }^{41}$ Im Archiv des RWI finden sich zwei Akten vom Mai 1943, die das „System Kehrl“ (RWM) und das „System Speer“ (Rüstungsministerium) gegenüberstellen. ${ }^{42}$ Die jeweiligen Organisationsprinzipien werden mit textlichen und schematischen (u.a. Grafiken) Erläuterungen über die Abgrenzung und Aufgabenverteilung genau beschrieben. Beigefügt ist der Erlass des Rüstungsministeriums „über die Aufgabenverteilung in der Kriegswirtschaft vom 29. Oktober 1943“. Es ist nicht klar, ob diese rudimentären RWI-Archivstücke Teil einer Auftragsarbeit waren oder zur internen Orientierung in der verwirrenden Organisation der Kriegswirtschaft dienten. Darüber hinaus lässt sich aufgrund der mangelhaften Quellenüberlieferung für das RWI nicht sagen, inwieweit das Essener Institut selbst direkt in die Organisation der Kriegswirtschaft eingebunden war. Auf jeden Fall müssen das Mutterhaus in Berlin und seine Töchter, und damit auch das RWI, während des Krieges mit Wagemann an der Spitze als organisatorische Einheit gesehen werden. Darin lieferten das RWI und andere Tochterinstitute der Berliner Zentrale laufend Material zu und waren so in die kriegswirtschaftlichen Arbeiten des DIW eingebunden. Wie bereits im Abschnitt über die Verselbständigung des RWI ausgeführt, erfüllten nach dem Selbstverständnis des DIW die regional verankerten Tochterinstitute organisatorisch „ähnliche Aufgaben“ wie die „Mittelstufe der Reichsverwaltung“ und leisteten dem „Zentralinstitut bei der Bearbeitung regionaler Wirtschaftsfragen und zentraler Son-

38 Boelcke 1983, S. 297 f. Nach dem Urteil von Herbst entsprach dieser formale Kompetenzverlust des RWM lediglich längst praktizierter Handhabung, Herbst 1982, S. 256.

39 Abelshauser 1999, S. 529.

40 Müller 1999b, S. 196.

41 Siehe allerdings die grundlegende Arbeit von Geer (1961), der am Beispiel der Eisenbewirtschaftung aufzeigt, wie planwirtschaftliche („verwaltungswirtschaftliche“) Elemente durch marktwirtschaftliche (,verkehrswirtschaftliche“) ergänzt oder ersetzt wurden.

42 RWI-Archiv: Akten RWI 121-4 u. 5. Mai 1943. 
derprobleme [...] wertvolle Hilfe. “43 Die unten erörterte Ernennung Wagemanns zum Leiter der „Arbeitsgemeinschaft für empirische Wirtschaftsforschung im Reichsforschungsrat" durch Göring im August $1944^{44}$ war denn auch explizit an das von Wagemann „geleitete Deutsche Institut für Wirtschaftsforschung mit seinen ihm angeschlossenen Zweiginstituten“ [Hervorhebung R.F.] gerichtet. Und schon mehr als drei Jahre zuvor hatte Däbritz im „Tätigkeitsbericht der Abteilung Westen für die Jahre 1939 und 1940“ darauf verwiesen, dass das Berliner Mutterhaus Essen für „Sonderuntersuchungen kriegswirtschaftlicher Art“ beanspruchte..$^{45}$ Auch wenn das RWI selbst nicht direkt für die laufende kriegswirtschaftliche Planung tätig gewesen zu sein scheint, lässt sich die empirische Wirtschaftsforschung aller von Wagemann geleiteten Institute während des Krieges nur dann hinreichend verorten, wenn man die planungsstatistische und operationale Integration der Industrieabteilung des DIW in die Kriegsmaschinerie erörtert.

Für die Planungstechnik engagierte Kehrl neben Fachleuten aus der Ministerialbürokratie technokratische Manager aus der mittleren und oberen Führungsebene großer Unternehmen. ${ }^{46}$ Darüber hinaus arbeiteten aber auch Wissenschaftler (Statistiker und Ökonomen) aus angegliederten oder selbständigen Forschungseinrichtungen wie Ferdinand Grünig von der Reichswirtschaftskammer und Bernhard Benning ${ }^{47}$ von der Volkswirtschaftlichen Abteilung deutscher Großbanken mit. Vor allem wurde Wagemanns DIW mit der gesamten Industrieabteilung unter der Leitung von Rolf Wagenführ ${ }^{48}$ als strategischer Partner gewonnen. ${ }^{49}$

43 Siehe die Denkschrift zu den „Aufgaben des Deutschen Instituts für Wirtschaftsforschung“ von November 1944, BA R3601/216.

44 Brief des Reichsmarschalls des Grossdeutschen Reiches (gez. Göring) vom 26.8.1944 an den Präsidenten des DIW, Professor Dr. Ernst Wagemann, BA R3/156 F. 27.

45 WA-LWL 722/55.

46 Siehe die Namensliste bei Eichholtz 1985, S. 149.

47 Siehe den Geschäftsverteilungsplan des Planungsamtes von Juni 1944, BA R3 108 F. 32.

48 Rolf Wagenführ (1905-1975), Dipl.-Volkswirt (1927), Dr. rer. pol. 1928 (Dissertation: Geschichte und Theorie der Konjunktur in Rußland); 1928-1945 Mitarbeiter des IfK, zunächst „,wissenschaftlicher Hilfsarbeiter“, später Leiter der Industrieabteilung; Mitglied in der NSDAP seit dem 20.2.1940 (BA R1/ 31XX T0034, 3200 Y006). Mit Wagenführ an der Spitze wurde die gesamte Industrieabteilung des DIW „dem Reichswirtschaftsministerium für planungsstatistische Arbeiten zur Verfügung“ gestellt (Schreiben des Reichsbankpräsidenten Funk, der zugleich Wirtschaftsminister war, vom 30.7.1942 an den DIW-Präsidenten Wagemann, BA R3/1969 F. 150). Ab September 1943 mit der Verlagerung der zivilen Produktionssteuerung des RWM (Hauptabteilung II Industrie) in das Speersche Rüstungsministerium war Wagenführ Leiter der Hauptabteilung V Planstatistik des Planungsamtes (BA R3102/3589 F. 15 RS). Nach dem Krieg arbeitete er für die Statistischen Behörden in der sowjetischen („Statistisches Zentralamt“ in Berlin, BA DE2/43397) und britischen Besatzungszone („Statistisches Amt für die Britische Besatzungszone“ in Minden). Ab Mitte 1948 bis 1952 leitete er das wirtschaftswissenschaftliche Institut der Gewerkschaften in Köln. 1952-1958 Direktor der Statistischen Abteilung der Hohen Behörde der Europäischen Gemeinschaft für Kohle und Stahle (EGKS) und 1958-1966 Generaldirektor des Statistischen Amtes der Europäischen Gemeinschaft (EGKS, EWG und Euratom, später Eurostat) in Brüssel und Luxemburg; ab 1957 ordentlicher Professor für Statistik an der Universität Heidelberg. Quellen: Einleitung zum Findbuch N 10 Nachlass Rolf Wagenführ (privater Nachlass von Wagenführ, 
Wagenführ und seine Mitarbeiter brachten die jahrelange Erfahrung des IfK bzw. des DIW auf dem Gebiet der Industriestatistik ein. Kehrls Zusammenarbeit mit dem DIW hatte bereits vor seinem Eintritt in das Rüstungsministerium, also noch im RWM, begonnen: ${ }^{50}$ Aus dem Schreiben des Reichsbankpräsidenten Funk, der zugleich Wirtschaftsminister war, vom 30. Juli 1942 an den DIW-Präsidenten Wagemann geht hervor, dass mit Wagenführ an der Spitze die gesamte Industrieabteilung des DIW „dem Reichswirtschaftsministerium für planungsstatistische Arbeiten zur Verfügung“ gestellt wurde. Kehrl und Wagemann sprachen ab, dass „die Herren [...] Angestellte des Instituts [blieben], [...] jedoch in den Aufbaustab für die Neuordnung der Bewirtschaftung im Reichswirtschaftsministerium [...] eingereiht" wurden. ${ }^{51}$

Wie Müller ausführte, hatte sich Kehrl damit ein Team jüngerer Spezialisten herangezogen, die sich nicht scheuten, planwirtschaftliche Konzeptionen sowjetischen Typs anzuwenden..$^{52}$ Wagenführs Selbstdarstellung über sein Wirken im DIW bestätigt diese Aussage. ${ }^{53}$ Letztlich entwickelte die Gruppe mit mengenmäßigen InputOutput-Koeffizienten ein Planungsinstrument zur Ressourcenverteilung. Grundlage waren Rohstoff- und Fertigwarenbilanzen. Mit mehrstufigen Bilanzen oder Flussdiagrammen wurde versucht, eine Kette von Verarbeitungsstufen darzustellen. Die Verbindung zwischen den Stufen wurde über die sogenannten „Einsatzschlüssel“, den Materialverbrauch pro Fertigungseinheit, erfasst. Dieser Zugriff auf den kompliziert verflochtenen Produktionsapparat einer Volkswirtschaft war nach Wagenführ von Grünigs Arbeiten ${ }^{54}$ über den Wirtschaftskreislauf (1933) und einer „volkswirtschaftli-

Wirtschaftsarchiv Baden-Württemberg (WABW), Stuttgart-Hohenheim); Bundesarchiv (BA), R1 NSDAPMitgliederkartei, R3 Reichswirtschaftsministerium, R3102 Statistisches Reichsamt, DE2 Statistisches Zentralamt; Wagenführ 1963; Krengel 1986; De Michelis/Chantraine 2003; Stahmer 2010.

49 Roth 1996, S. 523 ff.; Tooze 2001, S. 261 ff.; Kehrl 1973, S. 267 ff. Zum DIW siehe auch Krengel 1986. In Krengels Institutsgeschichte bleibt Wagenführs Rolle für die Kriegswirtschaft unterbelichtet. Krengel (1986, S. 67-72) beschränkte sich in dessen Darstellung im Wesentlichen auf eine Reihe langer Zitate aus Wagenführs Buch (1954/63) über „Die deutsche Industrie im Kriege“.

50 Zum folgenden Absatz vor allem Müller 1999a, S. 88 ff.

51 Es bestanden keinerlei Bedenken, dass das DIW die bei diesen Arbeiten gewonnenen Erkenntnisse „wissenschaftlich und publizistisch“ auswertete. Die Dienstleistung des DIW wurde mit 120.000 RM für das laufende Jahr vergütet, BA R3/1969 F. 150. Siehe auch Stäglin/Fremdling 2016a.

52 Wagenführ gehörte wohl zu der im Jahr 1931 von Friedrich Lenz und Arvid Harnack (Widerstandskämpfer in der „Roten Kapelle“) gegründeten „Arplan“, der Arbeitsgemeinschaft zum Studium der Planwirtschaft. Jedenfalls war er als Angehöriger des IfK dabei, als die Arplan-Gesellschaft im Sommer 1932 in einer dreiwöchigen Studienreise die Sowjetunion besuchte (Kettelhake 2008, S. 267). Die Beobachtung und Analyse der sowjetischen Planwirtschaft, z.B. des Preissystems, gehörte zu den regelmäßigen Aktivitäten des DIW. Siehe den Arbeitsbericht des DIW (April 1943 bis Juni 1944) BA R3101/32126 F. 33- 40.

53 Wagenführ 1963.

54 Grünigs Einfluss auf den „Wirtschaftsstab“ innerhalb der NSDAP erwähnt Geer 1961, S. 113. Grünig leitete die „Abteilung für Zentrale Wirtschaftsbeobachtung“ bei der Reichswirtschaftskammer. In einem Vortrag vom 15.1.1943 über „Die volkswirtschaftliche Bilanz als Hilfsmittel der Wirtschaftslenkung“ wies Grünig darauf hin, dass sich seine Abteilung „schon seit Jahren mit dem Problem der volkswirtschaftlichen Bilanzierung mit dem Ziel, die für die wirtschaftspolitischen Entscheidungen 
chen Bilanz“ der zentralstatistischen Verwaltung der Sowjetunion (1924) beeinflusst worden.

Das DIW hatte in seiner beratenden Tätigkeit für die Industrie bereits 1941 diese neuen Lenkungsmethoden erprobt und z.B. zusammen mit der neugeschaffenen Reichsvereinigung Kohle einen Kohlenplan konzipiert, der die Förderung, den Absatz nach Inland und Ausland sowie die Aufteilung des Inlandsverbrauchs einbezog, um „von da aus den Gesamtkohlenplan durchzurechnen“. Kehrl hatte das DIW Anfang/ Mitte 1942 beauftragt, Pläne für die einzelnen Rohstoffe und Fertigwaren aufzustellen. „[...] mit Hilfe von sog. Rohstoffbilanzen, die eine Art volkswirtschaftliche Einnahmeund Ausgabenrechnung darstellen und zeigen, wie der einzelne Rohstoff aufkommt (Quelle der Herkunft, ob aus Inlandserzeugung, Einfuhr, Lagerabbau usw.) und wie er verwendet wird (Wehrmacht, sonstige Kriegswirtschaft, Ausfuhr)“, waren nach Wagemann einheitliche Ansätze für die Lenkung der Rohstoffe im gewerblichen Sektor geschaffen worden. „Größter Wert wird auch hier darauf gelegt, eine vernünftige Rückschau mit einer möglichst detaillierten Vorschau zu koppeln. Aus dem Vergleich von Ist und Soll lassen sich dann allmählich Verbesserungen in den Methoden der Rohstoffvoranschläge finden“. Gleichzeitig wurden auch methodische Grundlagen für die komplizierteren Fertigwarenbilanzen entwickelt. Auch sie mussten die Produktionsvoraussetzungen für die Versorgung der Zivilbevölkerung anzeigen können. „Sind Rohstoffbilanzen und Fertigwarenbilanzen erst einmal in größerem Umfange verfügbar, dann ist damit auch ein wichtiger Schritt getan, um den Gesamtkreislauf der deutschen Wirtschaft in seiner konkreten Form besser zu erkennen. Der wichtigste Grundsatz der Wirtschaftsforschung, wie sie in meinem Institut betrieben wurde, war immer der, dass die Wirtschaft ein Gesamtprozess ist und es darauf ankommt, den Zusammenhang der einzelnen Teilerscheinungen zu begreifen. Mitten im Kriege nähern wir uns in gewaltigen Schritten diesem Arbeitsziel. Mehr denn je wird daran gearbeitet, eine Gesamtbilanz der Volkswirtschaft aufzustellen. Erst dann kann eine Lenkung der Wirtschaft - ob es sich nun um die Regelung des Arbeitseinsatzes, des Rohstoffverbrauchs, der Lagerbewegung, der Investitions- und Verbrauchslenkung usw. handelt - einsetzen. “55 Das DIW dürfte schon vor dem Engagement seiner gesamten Industrieabteilung für das RWM von Kehrl mit planerischer Entwicklungsarbeit beauftragt worden sein, die vom Kreislaufgedanken für die Gesamtwirtschaft ausging.

Unter der Leitung Wagenführs arbeitete die Statistikabteilung im RWM und schließlich im Planungsamt mit der Leitstelle im StRA zusammen, um die Wirt-

erforderlichen Zahlenunterlagen in übersichtlicher Form bereitzustellen“, beschäftigte. Siehe das Vortragsmanuskript mit Zahlen zur VGR für die unmittelbare Vorkriegszeit, BA R11/118 F. 22-42.

55 BA R3/1796, Vortrag Wagemanns ohne Datum, wohl Mitte 1942. Zitiert nach Stäglin/Fremdling 2016 . 
schaftsstatistiken für die Lenkung der Kriegswirtschaft aufzubereiten. ${ }^{56}$ Neben dem unverzichtbaren Datenbestand des Industriezensus von 1936 und den Erhebungen des StRA selbst mussten aktuelle Zahlen der Lenkungsbereiche weitergeleitet werden: Nachdem der RWM im September 1943 seine Anweisung zur Einrichtung der Statistischen Leitstelle gegeben hatte, die zum 1. November 1943 in Kraft trat, wies Kehrl in seinem Schreiben ${ }^{57}$ vom 20. November 1943 alle Reichsstellen und Reichsvereinigungen darauf hin, dass die Leitstelle „für die Arbeit der Hauptabteilung Planstatistik [des Planungsamtes] [...] - Leiter Dr. Wagenführ - zur Verfügung“ stehe. „Ihre Aufgabe ist es, alle bei den Dienststellen der Lenkungsbereiche und bei anderen Stellen anfallenden wirtschaftsstatistischen Daten über Erzeugung, Verbrauch, Ein- und Ausfuhr, Lagerhaltung, über Erzeugungspläne, über Herstellungsanweisungen und deren Erfüllung usw. systematisch zu sammeln, zu überprüfen, untereinander abzustimmen und zusammenfassend auszuwerten.“ Kehrl bat darum, „daß den Sachbearbeitern der Leitstelle auf Anforderung alle statistischen Daten zugänglich gemacht werden.“ Zur Beschleunigung sollten Daten selbst „unverzüglich fernmündlich - erforderlichenfalls unter Tarnbezeichnungen -“ übermittelt werden. ${ }^{58}$ „Das anfallende Zahlenmaterial ist systematisch [...] zu statistischen Monats- oder Vierteljahresheften zusammenzustellen. “59

Die Anforderungen des RWM und schließlich des Planungsamtes banden Wagenführs DIW-Abteilung fast vollständig. Der Arbeitsbericht des DIW von April 1943 bis Juni 1944 schilderte die Einspannung dieser Abteilung: ${ }^{60}$

Die industriewirtschaftlichen Arbeiten des Instituts dienten im abgelaufenen Jahr fast ausschließlich der organisatorischen Vervollkommnung der deutschen Rüstungswirtschaft, und zwar zunächst im Auftrage des Generalreferats des Reichswirtschaftsministeriums und später im Auftrage des Planungsamts beim Generalbevollmächtigten für Rüstungsaufgaben. Hauptaufgabe des Instituts war es dabei, zur einheitlichen Ausrichtung der Lenkungsbereiche, insbesondere der Reichsstellen, allgemein verwendbare Methoden und Richtlinien für die Planung und Statistik aufzustellen. Zu diesem Zweck wurden unter dem Titel: „Die Planung und Statistik in den Lenkungsbereichen“ in Zusammenarbeit mit anderen Dienststellen Anweisungen ausgearbeitet und im Sommer 1943 vom Reichswirtschaftsministerium herausgegeben. Darüber hinaus wurde ein einheitliches Schema für die Erstellung von Rohstoffbilanzen entworfen, die unter genauer Aufgliederung der Aufkommens- und Verwendungsseite die Möglichkeiten der Erzeugungslenkung und der Zuteilung über längere Zeiträume hinweg erkennbar machen. Im Rahmen der

56 Siehe z.B. das ausgeklügelte Organisationsschema (Flussdiagramm) für die Beschäftigtenmeldung, den Erhebungsbogen und die Lochkarte während des Krieges, zum Schreiben vom 8.4.1943, BA R3/25 F. 23, 40 u. 88.

57 BA R3102/3589 F. 39. Zuvor, praktisch parallel zu Funks Anweisung vom 10.9.1943 zur Einrichtung der Leitstelle, hatte Kehrl mit dem Erlass vom 16.9.1943 die Lenkungsbereiche („Hauptausschüsse, Hauptringe bzw. Wirtschaftsgruppen“) zu monatlichen „Eilmeldungen der Soll- und Ist-Produktionszahlen“ verpflichtet. Abgedruckt bei Wagenführ 1963, S. $206 \mathrm{f}$.

$58 \mathrm{Zu}$ einigen „Quellen für das Zahlenmaterial der Schnellberichte“ mit genauen Adressen, Telefonnummern und den Namen der Bearbeiter siehe für mehrere Erzeugnisse BA R3102/3589 F. $6 \mathrm{f}$.

59 BA R3102/3472 (1) F. $1 \mathrm{f}$.

60 BA R3101/32126 F. $34 \mathrm{f}$. 
Rohstoffplanung wurden für besondere Engpassprodukte (z.B. Kautschuk, industrielle Fette, Schmierseife, Bekleidung, Schuhe) auch eingehendere Gutachten angefertigt, die die Grundlage für entsprechende Maßnahmen der wirtschaftspolitischen Führung bildeten.

In Weiterführung dieser industriewirtschaftlichen Arbeiten handelt es sich nach deren weitestgehender Ausrichtung auf die Bedürfnisse des Planungsamts vor allem darum, Gesamtüberblicke über Bedarf und Erzeugung auf den wichtigsten Gebieten des industriellen Bereichs in der Form von Bilanzen zu gewinnen und die Entwicklung der Fertigung bei den einzelnen Rüstungsgütern in ihren bestimmenden Faktoren zu verfolgen. Die Aufstellung der Indexreihe für die gesamte deutsche Rüstungsproduktion wurde vervollständigt und laufend ergänzt. Zur laufenden Unterrichtung des Herrn Reichsministers für Rüstung und Kriegsproduktion werden regelmässig Schnellmeldungen mit den wichtigsten statistischen Daten abgefasst. ${ }^{61}$

In einem methodischen Aufsatz, der nach dem Krieg, 1952, erschien, behandelte Wagenführ die von ihm im Planungsamt verwendeten Mengenbilanzen in einer resümierenden Rückschau. Er stellte sie als nützliche Ergänzung der sich nach dem Krieg auch in Deutschland durchsetzenden Volkswirtschaftlichen Gesamtrechnung auf Basis von Wertgrößen dar. Die „mengenmäßige Betrachtung“ sah er als hilfreich bei „Engpaßsituationen“ und betonte, dass „während des zweiten Weltkrieges [...] praktisch alle großen Volkswirtschaften auf dem Gebiet der mengenmäßigen Rohstoffbilanzierung weitreichende Erfahrung gesammelt“ hätten. ${ }^{62}$ Alle Zahlenbeispiele, die Wagenführ in seinem Beitrag für die verschiedenen Bilanztypen anführte, stützten sich auf den Industriezensus von 1936 und damit auf die Arbeit des RWP, das „nicht weniger als 384 [Rohstoff]Bilanzen“ erstellt hatte. Die einfachste Form einer Rohstoffbilanz erfasste auf der Aufkommensseite die Erzeugung und die Einfuhr und auf der Verwendungsseite den Verbrauch und die Ausfuhr. Die Mengenbilanz glich sich über die Vorratsänderung und den ungeklärten Saldo aus. Beim Aufkommen nach Erzeugungsquellen ergaben sich Untergliederungen nach Werken und Sorten, bei der Verwendung nach Verbrauchern wurden Branchen erfasst, beim Außenhandel wurde nach Ländern differenziert. Wenn verschiedene Branchen dasselbe Produkt erzeugten oder wenn Roh- und Grundstoffe über zahlreiche Zweige verteilt verbraucht wurden, erschwerte sich die bilanzmäßige Erfassung. Zudem nahm „mit aufsteigender Produktionsstufe [...] die Anzahl der verschiedenartigen Erzeugnisse rasch zu“ ${ }^{63}$ Hier wurde dann mit mehrstufigen Bilanzen oder „Fließbildern“ bzw. Flussdiagrammen

$61 \mathrm{Zu}$ den Rohstoffbilanzen siehe die noch im Februar 1945 zusammengefassten „Rohstoffbilanzen der deutschen Kriegswirtschaft 1942 bis 1944“ im Wagenführ-Archiv WABW N10 Bü 32. Zu der Berechnungsmethode der Indexziffern siehe Wagenführ 1963, S. $208 \mathrm{ff}$., zu den Indexziffern S. $178 \mathrm{ff}$.; zu den aus den Unterlagen des Planungsamtes übernommenen Indexziffern der Wagenführ-Abteilung (in anderer Zusammenstellung und auch leicht abweichend) siehe USSBS Oct. 1945, S. 140 (Graphic), 275 (Table 100), 286 (Table 115). Zu den „Schnellmeldungen“ siehe die „Statistischen Schnellberichte zur Kriegsproduktion“ im Bundesarchiv BA R3102/3147.

62 Wagenführ 1952.

63 Siehe die Beispiele bei Wagenführ 1952, S. $128 \mathrm{ff}$. 
versucht, eine Kette von Verarbeitungsstufen darzustellen. ${ }^{64}$ Die Verbindung zwischen den Stufen wurde über die sogenannten „Einsatzschlüssel“ erfasst. Dieser Materialverbrauch pro Fertigungseinheit ${ }^{65}$ war nichts anderes als ein technischer Input-Output-Koeffizient. Wagenführ wies selbst darauf hin, dass diese technischen Produktivitätsmaße „im Laufe der Zeit nicht unbeträchtlichen Veränderungen unterliegen können“. Tatsächlich dürfte Wagenführ im Planungsamt mit den Koeffizienten des Industriezensus von 1936 gearbeitet haben, denn in dem hier herangezogenen Artikel verwies er auf seine Arbeit für die britische Zone mit 1936er Einsatzschlüsseln. ${ }^{66}$ In den Fertigungsbilanzen wurde der umgekehrte Weg verfolgt, um die Einsatzschlüssel für Endprodukte zu bestimmen. „Bei der oft verwirrenden Vielzahl von verschiedenartigen Materialien, die bei einer Fertigung zusammenzuwirken haben, wurde zwischen „Leit- und Nebenrohstoffen“ einerseits und „Vorlieferungen, Unterlieferungen und Zulieferungen“ andererseits unterschieden. Schließlich grenzte Wagenführ noch „konstruktionsgebundene“, einseitig einsetzbare Zulieferungen (z. B. „Motoren für Schiffe“) von solchen „mit allgemeinem Verwendungszweck“ (z.B. „Schrauben, Wälzlager“) ab, die „sich in der Regel einer bilanziellen Betrachtung entziehen“. Das Aggregationsproblem war über die Mengenbetrachtung nicht lösbar.

Im Arbeitsplan des DIW von Juli 1944 wurde auch auf die Bedeutung des Schaltoder „Schachbretts“ für eine Gesamtplanung hingewiesen: „Für die Industriepolitik erscheint die Erarbeitung von ,Methoden der Plankoordination“ und der ,Aufbau eines Schaltbretts der deutschen Industrieproduktion` besonders dringlich. Diese Arbeiten, die im besonderen Auftrag für die Zwecke des Planungsamts erstellt werden, sollen systematisch und statistisch den organisatorischen Aufbau und die Arbeitsteilung innerhalb der Industriewirtschaft durchleuchten. ${ }^{67}$

Wagenführ und seine Mitarbeiter dürften angestrebt haben, die umfangreichen Einzelbilanzen für Branchen und Sektoren zu einem „Gesamtaufwandsplan“ oder dem „Schachbrett“ für die deutsche Wirtschaft zu verdichten, um Ressourcenengpässe zu überwinden. ${ }^{68}$ Nach Welter soll es allerdings erst Ende 1944 einen „notdürftigen güterwirtschaftlichen Gesamtplan“ gegeben haben. ${ }^{69}$ Dieser Gesamtaufwandsplan war allerdings noch weit von einer ausgereiften Input-Output-Tabelle

64 Wagenführ (1952, S. 135) zeigt das Flussdiagramm für Kali. Vom RWP gezeichnete Diagramme sind reproduziert in Fremdling/Stäglin 2003 für Kalk; in Fremdling 2005 und in Fremdling/Stäglin 2007 für Papier und Holz.

65 „In unserem Beispiel [Lederwirtschaft] würde man also errechnen, wieviel Häute gebraucht werden, um beispielsweise ein Kilo Leder herzustellen; ebenso wieviel Kilo Leder - und damit wiederum ebenso wieviel Kilo Häute - für ein Kilo Schuhe benötigt werden usw. “ Wagenführ 1952, S. 134ff. (dort auch alle folgenden Zitate).

66 Wagenführ 1952, S. 134 Anm. 1.

67 Kuratorium des DIW, 15. Juli 1944, Quelle: BA R3101/32126.

68 Tooze 2001, S. 276ff. Siehe dort (S. 277) die Ende Mai 1944 entwickelte Tabelle des m.E. eher dürftigen Gesamtplans für das dritte Vierteljahr 1943.

69 Welter 1954, S. 95. 
entfernt. ${ }^{70}$ Zwar konnten einige Input-Mengen (Arbeitskräfte, Stahl und Kohle in Tonnen, Strom in kWh) für Endprodukte noch quantifiziert werden, jedoch ließ sich mit diesem physischen Ansatz die Zwischenproduktion mit ihrer Verflechtung nicht erfassen. Wagenführ selbst war sich dieser Unzulänglichkeit bewusst. Im September 1944 thematisierte er dieses Erfassungsproblem auf einer Arbeitskreissitzung mit Industriellen: ${ }^{71}$ „Eine von den Wirtschaftsgruppen angestellte Analyse (Beispiel: Maschinenbau) kann im allgemeinen nur angeben, in welche Kanäle die Vor-, Unter- und Zulieferungen fließen; nicht aber, wieviel dieser Lieferungen mengenmäßig und arbeitsstundenmäßig im Enderzeugnis stecken. “Er fuhr fort, dass sich für Kriegsgeräte „unter Umständen wert- und mengenmäßige Anteile der Vor-, Unter- und Zulieferungen im Enderzeugnis ermitteln lassen.“ Allerdings gäben sie keinen „Aufschluß über die Kanäle, woher diese Lieferungen fließen“. „Als letzte Möglichkeit ergibt sich die Schaffung von Bedarfsgruppennummern“, um die Lieferströme zu erfassen. Wagenführ verwarf jedoch die Möglichkeit der maschinellen Datenverarbeitung (Hollerith-Verfahren), weil „in zwischengeschalteten Lägern bei Erzeugern und Verteilern“ und ,insbesondere von den Klein- und Mittelbetrieben die exakte Durchführung der Nummerung nicht zu erwarten ist.“ Wagenführ schloss zwar nicht aus, dass eine Kombination der aufgezeigten Wege schließlich das gewünschte Ergebnis erbringen könnte, schlussfolgerte allerdings: „Augenblicklich kann sich die Planung nur auf die unvollkommenen Angaben der Industrieberichterstattung stützen.“

Nicht nur im Herbst 1944, sondern überhaupt wäre es unmöglich gewesen, ein umfassendes Mengengerüst über alle Produktionsstufen hin $\mathrm{zu}$ berechnen. ${ }^{72}$ Die Verbindung zwischen dem Bewirtschaftungskreis „Urproduktion“ und dem Bewirtschaftungskreis „Fertigwaren“ konnte nicht lückenlos geschlossen werden. ${ }^{73}$ Damit

70 Kurt Werner von der Statistischen Leitstelle des StRA hatte allerdings im Dezember 1943 Berechnungen über den Arbeitseinsatz in Zulieferindustrien vorgelegt. Die Berechnungen seiner Abteilung stützten sich auf sukzessive Lohnquoten, also Wertgrößen, immer weiter vorgelagerter Industriezweige. Seine „deduktive“, also hypothetische, „Beleuchtung“ verknüpfte er mit beispielhaften Berechnungen anhand des Zahlenmaterials des Industriezensus von 1936. Im Anschreiben bezweifelte Werner die Übertragbarkeit der 1936er Zahlen auf die Gegenwart, weil die Endfertigung der Rüstungsindustrie ,immer mehr den Charakter einer bloßen Montage“ angenommen hatte und weil „die zahlreichen Neubauten an Fertigungswerkstätten in der Rüstungsindustrie“ nicht „durch die verwendete Rohstoffquote“ berücksichtigt werden konnten (BA R3102/3472 (2) F. $473 \mathrm{ff}$.; siehe auch BA R3102/3589 F. 49, 53f.). Vermutlich scheiterten weitergehende Versuche, wenn das StRA sie denn überhaupt noch unternahm.

71 „Protokoll über die Sitzung des Arbeitskreises Dr. Krähe am Mittwoch, den 20.9.44“, BA R3/1847 F. 176.

72 Welter 1954, S. $68 \mathrm{ff}$. Siehe ebenfalls die knappe Zusammenfassung über diese entscheidende Schwäche des Planungssystems, wie sie die Briten (Kaldor war federführend) unmittelbar nach dem Krieg analysierten, Wagenführ-Archiv WABW N 10 Bü 48. Nach Tooze (2001, S. 231f.) war daran das RWP schon 1939 gescheitert.

73 Geer (1961, S. 88-95, 114 ff.) schilderte dieses Problem detailliert für die Zwischenprodukte zwischen der Eisenschaffung („Urproduktion bis zur ersten Verformungsstufe“) und Eisenverarbeitung („Letztverbraucher der Fertigwaren bis zum Eisen- und Stahlhandel“). Für Zwischenprodukte bildete 
fehlten der Planung die schlüssigen Glieder zwischen der Lenkung der Grundstoffe und der Endprodukte. ${ }^{74}$

Die Anlage zur Denkschrift über die Aufgaben des DIW vom 8. November 1944 führt die in Arbeit befindlichen Themen und damit die Tätigkeiten der Industrieabteilung des Instituts im Zweiten Weltkrieg auf:

1. Aufstellung von Rohstoffbilanzen für die wichtigsten Gebiete der Industrieproduktion.

2. Anfertigung von Grundbüchern zur Darstellung der Struktur und der Planungsvoraussetzungen für wichtige industrielle Produktionsgebiete (zurzeit in Arbeit für: Elektroindustrie, Schwefelsäure, Leder).

3. Aufbau einer sogenannten Koordinationsstatistik zur Darstellung der gegenseitigen Verzahnung bei den Produktionsplanungen der einzelnen industriewirtschaftlichen Bereiche (zurzeit in Arbeit für: Schuhe, industrielle Fette, Kautschuk, Soda, Elektroden).

4. Statistische Schnellberichterstattung über die Produktionsentwicklung auf den wichtigsten Gebieten der Rüstungsfertigung und der zivilen Bedarfsdeckung (zur Kriegsproduktion monatlich etwa 200 Reihen, zur Rüstungsendfertigung monatlich 300 Reihen).

5. Organisation von Schnellmeldungen für bestimmte Engpassgebiete der Rohstoffproduktion (zurzeit für Eisen und Mineralöl).

6. Berechnung einer Indexziffer der Rüstungsendfertigung und monatliche Darstellung der Rüstungsendfertigung in Kurven.

7. Zusammenfassende Ermittlungen über die Produktionsentwicklung in den Bereichen der einzelnen Ämter des Rüstungsministeriums (Rohstoffamt, Rüstungslieferungsamt, Produktionsamt) und Berechnung einer Indexziffer für die Gesamtproduktion.

8. Berichterstattung über die Luftkriegsschäden in der Industrie. ${ }^{75}$

„Der kriegswirtschaftliche Apparat unter Leitung des Reichsministeriums für Rüstung und Kriegsproduktion blieb bis spät in den Herbst 1944 weitgehend intakt [...] es gelang den Rüstungsverantwortlichen, die Produktion von Waffen und Kriegsgerät auf erstaunlicher Höhe zu halten und die Fronten auch unter katastrophalen Bedingungen mit dem Allernötigsten zu versorgen. ${ }^{\text {"76 }}$ Allerdings war nach Wagenführ in den beiden letzten Kriegsjahren eine Produktionssteigerung nicht mehr möglich gewesen, sodass sich die Lenkung auf kaum mehr als die Beseitigung wechselnder Engpässe richtete. Um Prioritäten für die Zuteilung zu setzen, führte Wagenführs Gruppe die bereits geschilderte analytische Trennung der Zulieferströme nach allgemein verwendbaren Vor- oder Zwischenprodukten und konstruktionsgebundenen, einseitig verwendbaren durch. Für ein abschließendes Urteil über die Effizienz der Gesamt-

sich pragmatisch ein eigener kreativer Bewirtschaftungskreis als Puffer heraus, den Geer allerdings als Befangener (er war für die Eisenbewirtschaftung mitverantwortlich) als „Lösung des Problems“ sah, ebd. S. 93 ff. und Anm. 8.

74 Tooze 2001, S. 278 ff. Auch das maschinelle Berichtswesen (MB) mit dem Hollerith-Verfahren und der „Nummerung der Produktion“ konnte die Informationslücke nicht schließen, Wagenführ 1963, S. 64.

75 Kuratorium des DIW, 8. November 1944, Quelle: BA R3601/216.

76 Eichholtz 1996, S. 5. 
planung müssten die Planvorgaben der letzten Kriegsjahre mit dem Produktionsergebnis verglichen und das Zurechnungsproblem gelöst werden.

Bis zum Kriegsende leitete Wagenführ die Hauptabteilung Planstatistik des Planungsamtes. Im Winter 1945, als sich Wagemann nach Clausthal-Zellerfeld zurückzog, übernahm Wagenführ als dessen Stellvertreter die Leitung des DIW in Berlin, die er nach der deutschen Kapitulation im Mai 1945 an Ferdinand Friedensburg als den ersten Nachkriegspräsidenten des DIW übertrug. ${ }^{77}$ Wagenführ arbeitete nicht mehr im DIW, sondern war unmittelbar nach dem Krieg für die Sowjetische Militäradministration mit dem Aufbau der Planstatistik des Statistischen Zentralamtes in der SBZ beschäftigt. $^{78}$

\subsection{Von der Konjunkturforschung zur Raumforschung}

Da die Konjunkturforschung in der NS-Wirtschaft obsolet geworden war, fragt es sich, wie das IfK und seine Tochterinstitute auf die fundamental geänderten Bedingungen für ihre Gutachter- und Beratertätigkeit reagierten. Als Erstes fällt die relativ späte Namensänderung auf, die als nach außen sichtbares Zeichen die Abwendung von der Konjunkturforschung dokumentiert. Hierin folgte die Tochter in Essen ihrem Berliner Mutterinstitut. Vor allem während der Kriegswirtschaft vollzog die Zentrale des IfK/DIW jedoch eine andere inhaltliche und funktionale Umorientierung als die Zweigstelle: Während die Berliner Zentrale sehr stark direkt in die Kriegswirtschaft eingebunden war, ${ }^{79}$ konzentrierte sich Essen auf die ebenfalls „kriegswichtige“ Raumforschung und über den rheinisch-westfälischen Raum hinaus auf die „Westlandforschung“.

Neben der Neuorientierung der Forschung auf „Sonderuntersuchungen kriegswirtschaftlicher Art" ${ }^{\text {80 }}$ verselbständigte sich die Abteilung Westen des DIW am 29. Januar 1943 als eingetragener Verein (Eintragung ins Vereinsregister am 27. Mai 1943) mit dem Namen „Rheinisch-Westfälisches Institut für Wirtschaftsforschung in Essen“. 81

\subsubsection{Namensänderung: Vom IfK zum DIW}

Am 18. September 1941 schrieb Däbritz der „Wirtschaftskammer für Westfalen und Lippe, Dortmund“: „Wir geben Ihnen davon Kenntnis, daß wir in Übereinstimmung

77 Krengel 1986, S. 74, 78 f.

78 Fremdling 2016b und 2016c.

79 Fremdling 2016a, S. 277-300; Stäglin/Fremdling 2016a.

80 „Tätigkeitsbericht der Abteilung Westen für die Jahre 1939 und 1940“ vom 6.2.1941, WA-LWL 722/55.

81 Siehe die Gründungssatzung mit den Unterschriften der Gründer und dem Eintragungsvermerk des Amtsgerichts Essen. RWI-Archiv Akte Chronik. 
mit der kürzlich vorgenommenen Namensänderung unseres Berliner Zentralinstituts nunmehr die Bezeichnung „Deutsches Institut für Wirtschaftsforschung, Abteilung Westen“ führen."82 In Berlin war die überfällige programmatische Umbenennung, also die Abkehr von der Konjunkturforschung, im Namen schon einige Monate zuvor auf der Kuratoriumssitzung ${ }^{83}$ vom 18. Juni 1941 vollzogen worden. ${ }^{84}$ Wagemanns Ausführungen dazu wurden folgendermaßen protokolliert:

Schon seit vielen Jahren trage sich die Institutsleitung mit dem Gedanken, den Namen des Instituts abzuändern, da das Wort „Konjunktur“ mehr und mehr in der öffentlichen Meinung seines wissenschaftlichen Charakters entkleidet und zu einem politischen Begriff geworden sei. Das habe, zumal in den ersten Jahren der Machtübernahme, wiederholt zu Angriffen gegen das Institut von verschiedenen Seiten her geführt. Dazu komme aber noch, daß in der Tat der Begriff ,Konjunktur' nicht mehr den tatsächlichen Arbeitsbereich des Instituts umreiße. Das habe in letzter Zeit, wie erwähnt, auch dem Herrn Reichswirtschaftsminister wieder Anlaß zu der Anregung gegeben, den Namen des Instituts jetzt abzuändern, und es als ,Deutsches Institut für Wirtschaftsforschung' zu bezeichnen. Präsident Wagemann glaubt, daß diese Änderung nicht nur aus rein formalen Gründen, sondern auch aus sachlichen Erwägungen zweckmäßig sei; denn die Arbeiten des Instituts umfaßten doch den Bereich der öffentlichen und privaten Wirtschaft in weitestem Umfange. Der neue Name werde daher geeignet sein, auch den Kreisen, denen nicht durch eine laufende Zusammenarbeit oder aus regelmäßigem Studium der Veröffentlichungen die Institutsarbeiten genauer bekannt seien, eine richtige Vorstellung von den Aufgaben und Zielen des Instituts zu vermitteln.

Wagemann konnte in seinen Ausführungen vage bleiben, weil allen beteiligten Kuratoriumsmitgliedern klar war, dass die aktuelle Kriegswirtschaft, oder die auf Kriegsvorbereitung ausgerichtete Kommandowirtschaft ${ }^{85}$ zuvor, im Wesentlichen durch administrative Organe, also durch eine staatliche Lenkung und durch die privatwirtschaftlichen Zwangskörperschaften, die Reichs- und Wirtschaftsgruppen, gesteuert und reguliert wurde. Der klassische Konjunkturzyklus, der einer primär marktwirtschaftlich-kapitalistischen Wirtschaftsordnung eigen ist, war damit in Deutschland verschwunden.

Eine programmatische Abhandlung über „Gesichtspunkte für den Ausbau des Konjunkturinstituts Essen“ vom 15. Oktober $1940,{ }^{86}$ die vermutlich von Däbritz stammt,

82 Däbritz an Bornemann (Hauptgeschäftsführer der Wirtschaftskammer für Westfalen und Lippe, Dortmund), 18.9.1941, WWA K1 Nr. 2080.

83 Im Kuratorium, das nach der Satzung nur juristische Personen umfasste, waren u.a. mehrere Ministerien, öffentlich-rechtliche Banken, die Reichswirtschaftskammer, die Deutsche Arbeitsfront, die I.G.-Farbenindustrie A.-G. sowie mehrere der in den Wirtschaftsgruppen zwangszusammengeschlossenen Wirtschaftsverbände vertreten, BA R11/111, F. 93. Die Satzung des DIW vom 14.7.1941 ist im Vereinsregister des Registergerichts beim Amtsgericht Berlin-Charlottenburg (Gesch. Nr. 581) einzusehen.

84 Protokoll über die Sitzung des Kuratoriums des Instituts für Konjunkturforschung, BA R11/111, F. $88-89$.

85 Petzina 1968, S. 11.

86 RWI-Archiv Akte Chronik. 
erörterte das künftige Arbeitsprogramm. Zunächst wurde festgestellt, dass die „Herausgabe der bisher periodisch erscheinenden Konjunkturberichte der Abteilung Westen [...] seit Kriegsbeginn eingestellt worden“ sei. Die den Berichten zugrundeliegende Konjunkturstatistik hingegen solle nach wie vor erhoben werden: „Das Essener Institut wird vielmehr nach wie vor Wert darauf legen müssen, eine Zentrale zur Sammlung des wirtschaftsstatistischen Materials für den rheinisch-westfälischen Industriebezirk zu bleiben.“ Es verfüge über Statistiken, die „ihm allein anvertraut“87 würden, und es sei die „einzige Stelle, die dieses Material unter übergeordneten Gesichtspunkten“ zusammenfasse. Verwiesen wurde auf die periodischen Veröffentlichungen „Wirtschaftszahlen Westen“. Zudem hätten sich „Betriebe, Verbände, Verwaltungen u.ä. [...] daran gewöhnt, [...] sich beim Institut Informationen zu holen.“ Die empirische Basis für die regional ausgerichtete Forschungstätigkeit und Dienstleistungsfunktion als Informationsvermittler $^{88}$ solle nicht aufgegeben werden, wohl aber die Beschäftigung mit dem Konjunkturphänomen.

Anders als Wagemann auf der Kuratoriumssitzung der Berliner Zentrale begründete Däbritz die Namensänderung für die Essener Zweigstelle in der programmatischen Abhandlung von 1940 inhaltlich schlüssig: ${ }^{89}$ „Seit dem nationalsozialistischen Umbruch“ sei an „stelle der freien Unternehmerschaft“ eine vom „Staat gelenkte Wirtschaft getreten. Damit wurden die konjunkturellen Reaktionen als dem Innern der Wirtschaft entstammende und gleichsam selbsttätig wirkende Bewegungsvorgänge weitgehend zurück gedrängt. Statt ihrer sind für den Ablauf der Gesamtwirtschaft die Planungen und Zielsetzungen des Staates und die Maßnahmen der Staatsorgane entscheidend geworden, die überwachend, lenkend, regelnd in die Wirtschaft eingreifen.“ Damit sei für die Konjunkturinstitute das „Phänomen der Konjunkturen in den Hintergrund gerückt.“ Ihre Forschungen seien vielmehr auf diese „neue Wirtschaftspolitik“, die „sich aus einer umfassenden staatlichen Wirtschaftslenkung“ ergäben, ausgerichtet. Die Abhandlung stellte die Raumforschung als konzeptionelle Alternative zur Konjunkturforschung und als spezifische Ausprägung der Regionalforschung der Abteilung Westen vor. ${ }^{90}$

87 Siehe z. B. den Brief von Däbritz an Hugo (1. Syndikus der IHK Bochum) vom 31.12.1935, in dem er darum bat, dem Essener Institut „Zahlenangaben über die Fehlbeträge sowie über die Steuereinnahmen und die Wohlfahrtslasten der Großstädte“ zu besorgen. Für die Konjunkturberichte sollten die Gemeindefinanzen im rheinisch-westfälischen Industriebezirk zwischen 1932 und 1935 untersucht werden. WWA K2 Nr. 254.

88 Im „Tätigkeitsbericht der Abteilung Westen für die Jahre 1939 und 1940“ vom 6.2.1941 (WA-LWL 722/55) verwies Däbritz darauf, dass „,neben Arbeiten grösseren Umfangs die Abteilung Westen weiterhin aus den Kreisen der Wirtschaft in beträchtlichem Masse für die Beschaffung von Einzelmaterial und für Auskünfte verschiedenster Art in Anspruch genommen“ werde.

89 RWI-Archiv Akte Chronik: Gesichtspunkte für den Ausbau des Konjunkturinstituts Essen vom 15.10. 1940.

90 Allgemeiner dazu Däbritz 1940. 


\subsubsection{Raumforschung im RWI}

Raumforschung und Raumplanung erlebten in der NS-Zeit einen enormen Aufschwung, da sich räumliche Erklärungsmuster für sozialökonomische Entwicklungen mit der völkisch-rassistischen Lebensraumideologie des Nationalsozialismus verbinden ließen. ${ }^{91}$ In der Raumforschung und Raumplanung rangen verschiedene staatliche Stellen, Parteiinstanzen und Wissenschaftler (Köln) um eine dominierende Position. ${ }^{92}$ Die 1935 gegründete Reichsstelle für Raumordnung (RfR) sollte dieses Kompetenzgerangel beenden. Als interministerielle Koordinationsinstanz war sie keinem Ministerium direkt zugeordnet. Der Reichsstelle unterstanden die zur regionalen Staatsverwaltung gehörenden Landesplanungsgemeinschaften (LPG) und die Reichsarbeitsgemeinschaft für Raumordnung. ${ }^{93}$ Über Forschungsaufträge, Mittelzuweisungen und „Dienstverpflichtung der Hochschulen“ sollte die Reichsarbeitsgemeinschaft die Wissenschaft für die Ziele der Reichsstelle (RfR), also für die Aufrüstung und die raumplanerische Vorbereitung des Krieges sowie letztlich auch für die räumlichen Ausdehnungs- und Unterwerfungspläne des NS-Regimes, instrumentalisieren. ${ }^{94}$ Zur „planmäßige[n] Zusammenfassung und Ausrichtung aller wissenschaftlichen Kräfte für die Raumforschung“95 wurden deshalb die Hochschularbeitsgemeinschaften für Raumforschung (HAG) geschaffen. Mit diesen „Arbeitsgemeinschaften“ verleibte sich das nationalsozialistische Herrschaftssystem die Wissenschaft der Raumforschung ein.

Mit dem Kölner Ordinarius für Wirtschaftsgeschichte und Wirtschaftsgeographie Bruno Kuske als treibende Kraft war die Wirtschafts- und Sozialwissenschaftliche Fakultät der Kölner Universität beispielhaft für die Etablierung der Hochschularbeitsgemeinschaften für Raumforschung an einer Universität. Belegt durch seine zahlreichen Veröffentlichungen stand Kuske für eine völkisch ausgerichtete Sozialund Wirtschaftsraumforschung, die unverblümt rassistische Erklärungsmuster für die unterschiedliche wirtschaftliche Entwicklung von Regionen, Ländern und Ländergruppen heranzog. ${ }^{96}$ Das Reichswissenschaftsministerium beauftragte ihn 1936, die

91 „Die drei Grundpfeiler der nationalsozialistischen Weltanschauung waren die Lebensraumideologie, der Rassegedanke sowie der Antisemitismus." Loose 2016, S. 361.

92 Engels 2007, S. 140 ff.; siehe auch Däbritz 1940, S. $802 \mathrm{ff}$.

93 Siehe bereits 1936 den Hinweis des Essener Instituts auf die „,vor kurzem geschaffene Reichsstelle“ in den KB 1936/37, H. 1, S. 46.

94 Die Reichsarbeitsgemeinschaft für Raumordnung wurde 1940 bei den „bisherigen Geldgebern der Abteilung Westen“ aufgeführt. Siehe RWI-Archiv Akte Chronik: Gesichtspunkte für den Ausbau des Konjunkturinstituts Essen vom 15.10.1940.

95 Erlass des zuständigen Reichswissenschaftsministeriums (Reichs- und Preußisches Ministerium für Wissenschaft, Erziehung und Volksbildung, REM), zitiert bei Engels 2007, S. 141.

96 Bruno Kuskes Wirken bildet den Schwerpunkt des Buches von Marc Engels (2007) über die „Wirtschaftsgemeinschaft des Westlandes“ mit dem Untertitel: „Bruno Kuske und die wirtschaftswissenschaftliche Westforschung zwischen Kaiserreich und Bundesrepublik“. „Kuske [schuf] Raumkonstrukte, die verschiedene Wirtschaftsräume integrierten und denen er seit 1933 zunehmend expansionistische Züge gab. Auf dem Höhepunkt des Zweiten Weltkrieges [1942] beschrieb Kuske im 
Hochschularbeitsgemeinschaft (HAG) in Köln einzurichten, und in den folgenden Jahren etablierte er die Raumforschung als Schwerpunkt in der Fakultät, u.a. als Dekan mit entsprechender Berufungspolitik. ${ }^{97} \mathrm{Zu}$ den zahlreichen disziplinübergreifenden Mitgliedern der HAG an der Kölner Universität gehörte auch von Anfang an Däbritz. ${ }^{98}$ Nachdem die Konjunkturforschung überhaupt und damit auch ihre regionale Ausprägung als Forschungsgegenstand als überholt galten, erschloss sich die Abteilung Westen des IfK mit der Raumwirtschaftsforschung ein neues Betätigungsfeld.

Däbritz erörterte die programmatische Umorientierung der Essener Abteilung in seiner Abhandlung von 1940: ${ }^{99}$ Für die „Regionalforschung, wie sie von der Abteilung Westen gepflegt“ wurde, hätten „sich damit [d.h. mit der Abwendung von der Konjunkturforschung] neue Gesichtspunkte eröffnet. “100

Das erfordere „monographische Untersuchungen über die naturgegebenen Grundlagen der verschiedenen Wirtschaftsgebiete, ihre Bevölkerungsstruktur, die Produktions- und Absatzbedingungen, die Verkehrsverhältnisse, die Ein- und Ausfuhrabhängigkeit, den Arbeitseinsatz, Einkommens- und Kapitalbildung, Verbrauch und Investitionen, Siedlung und Städtebildung usw. usw. Im ganzen handelt es sich mithin um Strukturanalysen und Verflechtungsuntersuchungen allgemeiner wie spezieller Art, die nach einheitlichem Plan zu entwerfen sind.“ Der Untersuchungsgegenstand war also ausgesprochen breit angelegt und liest sich wie das Inhaltsverzeichnis der damals in den Statistischen Jahrbüchern des Deutschen Reichs behandelten Themen. Die geplante Analyse wurde nicht weiter spezifiziert. Der Adressatenkreis der Forschungsergebnisse hingegen sehr wohl: Seien doch die „Staatsführung wie die Wirtschaft“ [...] ,,an ihren Ergebnissen interessiert. Soweit es sich um die Regionalforschung handelt, kommen insbesondere die Organe der Landesplanung und Raumordnung, die Landesarbeitsämter, die Kommunalverwaltungen, die Verkehrsträger, die Regionalorganisationen der Wirtschaft wie Industrie- und Handelskammern, Wirtschaftskammern, Bezirksgruppen u.a.m. in Betracht.“

Erst der folgende längere Abschnitt widmete sich den hegemonialen Zielen des nationalsozialistischen Deutschlands mit der Ausweitung des vom Reich beherrsch-

\footnotetext{
Anschluss an seine Vorkriegsarbeiten die „Wirtschaftsgemeinschaft des Westlandes“; dieses Raumgebilde legitimierte [...] die deutsche Hegemonie über Westeuropa." Engels 2007, S. 15. Zu Kuske siehe unten in diesem Band Teil II ausführlich Toni Pierenkemper, der auch dessen Biografie zusammenfasst.

97 Engels 2007, S. $142 \mathrm{ff}$.

98 Siehe die Details bei Engels 2007, S. 150 ff. Däbritz war seit 1927 Privatdozent und seit 1938 Honorarprofessor an der Wirtschafts- und Sozialwissenschaftlichen Fakultät der Kölner Universität. Vgl. dazu unten in diesem Band Teil II.

99 Schon 1936 hatte die Abteilung „Westen“ in ihren Konjunkturberichten (1936/37, H. 1, S. 42-55) in einem programmatischen Aufsatz über die „Aufgaben der regionalen Konjunkturforschung“ die Hinwendung zur „Raumforschung“ bzw. „Regionalforschung“ thematisiert. Ebd. S. 46, 54.

100 RWI-Archiv Akte Chronik: Gesichtspunkte für den Ausbau des Konjunkturinstituts Essen vom 15.10.1940.
} 
ten Wirtschaftsraums nach Westen. Er wurde im Herbst 1940 verfasst, als Deutschland nach den militärischen Eroberungen im Westen die Niederlande, Belgien, Luxemburg und große Teile Frankreichs besetzt hielt. Die expansionistischen Großraumvorstellungen, die u.a. der Kölner Ordinarius Kuske propagierte, waren damit auch programmatische Grundlage für die Forschung des Essener Instituts. ${ }^{101}$ Der folgende Abschnitt wird ungekürzt zitiert: ${ }^{102}$

Die Notwendigkeit derartiger Untersuchungen wird neuestens durch einen weiteren Umstand verstärkt. Der Neubau der großdeutschen Wirtschaft als Folge der politischen Geschehnisse der jüngsten Zeit verändert an entscheidenden Stellen die Grundlagen des bisherigen wirtschaftlichen Schaffens und eröffnet ihm neue Perspektiven. Für den rheinisch-westfälischen Industriebezirk wirkt sich dies wegen seiner Grenzlage besonders nachhaltig aus. Es ergeben sich für ihn über die bisherigen Reichsgrenzen hinaus nach Westen und Südosten, d.h. nach Holland, Belgien, Luxemburg, Lothringen und das übrige Frankreich neue Beziehungen grösster Tragweite.

Schon jetzt werden die Umrisse eines neuen wirtschaftlichen Großraums sichtbar, innerhalb dessen der rheinisch-westfälische Industriebezirk sich mit den westlich anschließenden Gebieten zu einem nicht mehr durch politische Grenzen getrennten Gebilde zusammenfügt. Es sei auf die in diesem Großraum charakteristische Ausstattung mit Bodenschätzen (Kohlen und Eisenerze) und an die auf ihnen aufgebauten Gewinnungs- und Verarbeitungsindustrien verwiesen, die in Hinblick auf ihre verschiedenartige Abstufung aufeinander eingestellt werden müssen und zu einer sehr viel engeren und intensiveren Arbeits- und Funktionsteilung kommen werden, als dies bisher der Fall war. In Verbindung hiermit entstehen in Zukunft ganz neue Verkehrsprobleme zu Lande und zu Wasser. Auch auf die Neuorientierung des Absatzes ist hinzuweisen, ferner auf Bevölkerungs-, Arbeiter-, Siedlungs- und andere Gesichtspunkte. Es eröffnen sich hier Probleme und Aufgaben von einer Grösse, Vielfalt und Reichweite, die noch kaum abzusehen sind, und ihre Lösung wird nicht wie unter früheren Verhältnissen der Initiative der einzelnen Unternehmer überlassen bleiben, sondern die Staatsführung wird sie einheitlich anfassen, und mit konzentrierter Kraft, darum auch wesentlich schneller und konsequenter nach grossen übergeordneten Gesichtspunkten lösen.

Indem die Forschung die Daten liefert, die zu der Vorbereitung dieser Neuordnung notwendig sind, indem sie die vorhandenen Zusammenhänge klärt und die sich daraus ergebenden Möglichkeiten aufzeigt, indem sie weiterhin nach durchgeführter Neuordnung die hierauf einsetzende Entwicklung verfolgt, kann sie Staat und Wirtschaft in ihren Zentral- und Regionalstellen abermals wertvolle Unterlagen liefern.

Bei der Bearbeitung dieser Westfragen kommt der Abteilung Westen eine besondere Bedeutung zu.

101 Engels (2007, S. 17) charakterisierte diese „Forschung“ folgendermaßen: „Die Westforschung, wie sie zwischen 1919 und 1945 praktiziert wurde, schuf, transportierte, legitimierte und modifizierte insbesondere antifranzösische Feindbilder. Indem die Westforschung den deutschen Hegemonialanspruch in Westeuropa untermauerte, nahm sie Partei in einem Konflikt, der auf ökonomischer, politischer und militärischer Ebene die europäische Geschichte der ersten Jahrhunderthälfte prägte. Teil dieser konfrontativen Wissenschaftsstrategie war aber auch der Versuch, die westeuropäischen Nachbarstaaten Belgien, Niederlande, Luxemburg und die Schweiz in Allianzen gegen Frankreich und Großbritannien zu ziehen, die auf rassischer, völkischer, historischer und kultureller Verwandtschaft oder ökonomischen Interessen gründeten.“

102 RWI-Archiv Akte Chronik: Gesichtspunkte für den Ausbau des Konjunkturinstituts Essen vom 15.10.1940, S. 3-5. 
Mit dieser programmatischen Standortbestimmung wurden für das „Essener Institut“ neue Arbeitsfelder abgesteckt, welche die Konjunkturforschung durch die Raumforschung ersetzten: ${ }^{103}$

a) In seinem Arbeitsprogramm werden die Konjunkturberichte bisheriger Art zurücktreten.

b) Statt ihrer hat es sich vorwiegend monographischen Arbeiten im Sinne von Strukturanalysen und Verflechtungsuntersuchungen zuzuwenden und sein Arbeitsgebiet ist hierbei über den rheinisch-westfälischen Industriebezirk auf die ihm angrenzenden Westgebiete zu erweitern.

c) Die Konjunkturstatistik im bisherigen Sinn ist beizubehalten; sie ist jedoch ebenfalls auf den angrenzenden Westraum auszudehnen.

Einige Monate später, im Februar 1941, ${ }^{104}$ erwähnte Däbritz eine in „Bearbeitung befindliche Untersuchung“, die genau zu dem ambitionierten Arbeitsprogramm passte: „Die wirtschaftlichen Verflechtungen zwischen Holland und Deutschland mit besonderer Berücksichtigung des deutschen Westens“. Diese Arbeit, an der „in besonderem Masse die Reichsstelle für Raumordnung, Berlin, interessiert“ gewesen sei, wurde jedoch in der umfassenden Form nicht als selbständiges Heft der Institutsreihe fertiggestellt. Im Tätigkeitsbericht 1939/40 vom Februar 1941 wurde diese laufende Untersuchung in die ,bereits erfolgte bzw. noch im Gange befindliche staatliche und wirtschaftliche Neuordnung in den westlichen Nachbargebieten“ eingeordnet: „Aus dem veränderten Verhältnis zu Holland, Belgien sowie Nord- und Ostfrankreich ergeben sich für den rheinisch-westfälischen Industriebezirk künftighin neue grosse Perspektiven. Damit ist auch das Essener Institut darauf verwiesen worden, sein Beobachtungs- und Aufgabengebiet über die deutsche Westgrenze hinaus zu erweitern.“ Mit der „angewandten Kriegswirtschaftsforschung“ konzentrierte sich das Essener Institut seit 1941 auf die wirtschaftlichen Konsequenzen, welche die Besetzung und Neuordnung der westeuropäischen Länder für Deutschland und vor allem den rheinisch-westfälischen Raum bedeuten würde. ${ }^{105}$

In der räumlichen Ausdehnung des Untersuchungsgebietes nach Westen folgte die Essener Tochter dem Expansionsdrang des Mutterinstituts nach Osten und Südosteuropa. ${ }^{106}$ Explizit verwies Däbritz in seiner Abhandlung von $1940^{107}$ auf die „an-

\footnotetext{
103 In der rückblickenden Darstellung von Däbritz aus dem Jahr 1956 erscheint die Umorientierung der Forschungstätigkeit des RWI während des Krieges weniger dramatisch: Nachdem die „Konjunkturberichterstattung bisheriger Art inzwischen hinfällig geworden war [...], ging das Institut dazu über, größere Einzeluntersuchungen durchzuführen. Sie betrafen Grundprobleme der rheinisch-westfälischen Wirtschaft, Arbeitseinsatz, Ernährung, Produktion, Verkehr, die Entwicklung wichtiger Einzelindustrien im Kriegsverlauf, vergleichsweise auch diejenigen anderer deutscher und ausländischer Montanreviere.“ Däbritz/Stupp 1956, S. 21.

104 „Tätigkeitsbericht der Abteilung Westen für die Jahre 1939 und 1940“ vom 6.2.1941, WA-LWL 722/ 55.

105 Engels 2007, S. 310.

106 Siehe den Abschnitt 2.2 über die Verselbständigung der Essener Abteilung als RWI.

107 RWI-Archiv Akte Chronik: Gesichtspunkte für den Ausbau des Konjunkturinstituts Essen vom 15.10.1940, S. 5 f.
} 
deren Aussenstellen des Berliner Instituts“ und hob hervor, dass das „Berliner Institut“ in letzter Zeit dazu übergegangen sei, „Aussenstellen im Osten aufzubauen.“ Genannt wurden die „Institute in Breslau und Wien, neuerdings in Danzig und evtl. Krakau“. Zu erwägen sei, „daß auch im Westen die Zahl der Beobachtungsstellen vermehrt“" werde. Konkret wurde hierfür Folgendes vorgeschlagen:

a) Das Essener Institut erhält zu seinem bisherigen Beobachtungsgebiet Holland, Belgien, Luxemburg zugewiesen.

b) Es wird die Errichtung einer weiteren Aussenstelle im Südwesten in Aussicht genommen, die im Saargebiet (Saarbrücken) oder in Lothringen (Metz) ihren Sitz nimmt und das Saarrevier und Lothringen-Nordfrankreich als Domäne erhält.

c) Zwischen diesen beiden Weststellen ist in ähnlicher Weise eine Zusammenarbeit vorzusehen wie diese zwischen Danzig, Breslau, Krakau und Wien geplant ist.

Unmissverständlich ordnete sich damit die Essener Zweigstelle mit ihrem Forschungsprogramm in die expansionistische Großraumkonzeption des nationalsozialistischen Herrschaftssystems ein. ${ }^{108}$ Trotz dieser ideologischen Fixierung und damit Instrumentalisierung für die Ziele des Regimes fällt der eher sachliche Ton der programmatischen Ausführungen auf. Anders als bei Kuskes ${ }^{109}$ Ausführungen sind in dieser Abhandlung völkische oder rassistisch-ideologische Konnotationen m. E. nicht zu erkennen. Das rheinisch-westfälische Gebiet war in seiner Geschichte schon immer grenzüberschreitend eher nach Westen als nach dem Osten (auch Deutschlands) ausgerichtet und für eine völkisch-rassistische Überlegenheitsideologie gegenüber den unmittelbaren westlichen Nachbarn gab es keinen Nährboden. ${ }^{110} \mathrm{Zu}$ fragen bleibt, wie noch während des Krieges die „Gesichtspunkte für den Ausbau des Konjunkturinstituts Essen“ umgesetzt wurden.

\subsubsection{Forschung und Publikationen im Krieg}

Um die Forschungen und Publikationen des RWI einzuordnen, sind die Rahmenbedingungen in der Kriegswirtschaft, die für jedes einzelne Projekt galten, zu umreißen. „Nach einer Anordnung des Vorsitzenden des Statistischen Zentralausschusses [zählt]

108 Siehe z.B. die Haltung der Ruhrindustrie gegenüber den westeuropäischen Produzenten, mit denen man schon vor der NS-Zeit und Besatzung durch internationale Kartellabsprachen verbunden gewesen war. Ernst Poensgen (Vorstandsvorsitzender der „Vereinigte Stahlwerke AG“) formulierte 1940 „Kriegsziele“, die pragmatisch von Kollaboration und der Schaffung einer westeuropäischen Stahlunion ausgingen, statt auf Raub oder Konfiszierung zu setzen. Allerdings gab es Konflikte mit Industriellen (Flick, Röchling, Pleiger), die dieser Linie nicht folgten (Gillingham 1986, S. 391ff.; Donges 2014, S. 380 -392). Zur Einbindung der westeuropäischen Stahl- und Kohleindustrie in die deutsche Kriegswirtschaft siehe vor allem die einschlägigen Arbeiten Gillinghams (1985, 1986, 1991).

109 Ausführlich zu Kuske: Engels 2007.

110 „Der Ruhr kommt zumindest ein Teil des Verdienstes daran zu, daß Westeuropa kein zweites Polen wurde.“ Gillingham 1986, S. 390; siehe auch Donges 2014, S. 380. 
die Abteilung Westen zu denjenigen Instituten [...], die auch für die Dauer des Krieges mit Wirtschaftsstatistiken beliefert werden dürfen. “111 Darüber hinaus muss das RWI auf jeden Fall wie das DIW und seine anderen Tochterinstitute grundsätzlich einen privilegierten Zugriff auf unveröffentlichtes bzw. geheimes und internes Material des StRA, der staatlichen Verwaltung wie auch der privatwirtschaftlich organisierten Lenkungsstellen gehabt haben: Wagemann als Person und das DIW als Forschungsinstitution waren vom RWM in einer Auseinandersetzung mit Himmler als „kriegswichtig“ eingestuft worden, ${ }^{112}$ sodass davon auszugehen ist, dass diese Einordnung analog auch für die „kriegswichtigen Strukturuntersuchungen“113 des RWI galt. Wagemann war schließlich auch dessen Präsident.

In Ermangelung entsprechender Materialien für den „Westen“ sei der Vorgang angeführt, mit dem sich Wagemann als „Vorstand und wissenschaftliche Leitung“ des „Ober-Schlesischen Instituts für Wirtschafts- und Konjunkturforschung“ im Brief vom 3. November 1941 an den RWM (Bergbauabteilung) befasste: ${ }^{114}$ Danach habe das Oberbergamt Breslau ,seit längerer Zeit einen Materialaustausch mit dem Schlesischen Institut für Wirtschafts- und Konjunkturforschung in Breslau durchgeführt.“ Dieses habe „die Materialangaben des Oberbergamts zur Ausführung der ihm vom Landeswirtschaftsamt Schlesien, von der Wirtschaftskammer Schlesien und von der Rüstungsinspektion Breslau erfolgten Aufträge verwendet, zu denen vor allem auch die Erstattung der wirtschaftlichen Lageberichte gehört. “"115 Mit der Annektierung OstOberschlesiens und der damit verbundenen neuen Verwaltungseinteilung, einer „verwaltungsmäßigen Teilung der Provinz Schlesien“, wurde der Aufgabenbereich der DIW-Tochter in Breslau auf Niederschlesien beschränkt, und in Kattowitz wurde für Oberschlesien eine weitere DIW-Dependance errichtet. Um in Kattowitz wie in Breslau „kriegswirtschaftlich wichtige Aufträge des Landeswirtschaftsamts, der Wirtschaftskammer und der Rüstungsinspektion auszuführen“, war das Oberbergamt Breslau

111 „Tätigkeitsbericht der Abteilung Westen für die Jahre 1939 und 1940“ vom 6.2.1941, WA-LWL 722/ 55. Der Statistische Zentralausschuss kontrollierte seit 1939 sämtliche amtlichen und nichtamtlichen statistischen Erhebungen.

112 Schreiben des RWM Funk vom 7.3.1944 an den Reichsführer SS Himmler gegen eine Abberufung Wagemanns als Präsident des DIW, BA NS19/20531. Zu den Hintergründen siehe Stäglin/Fremdling 2016a und Wietog 2001, S. 48, Anm. 100. Auch Göring stufte Wagemann und das DIW so ein: „In Würdigung der Leistungen und der Kriegswichtigkeit des Instituts ist sein Präsident durch den Herrn Reichsmarschall als Bevollmächtigter für empirische Wirtschaftsforschung in den Reichsforschungsrat berufen worden.“ Siehe „Aufgaben des Deutschen Instituts für Wirtschaftsforschung“ von November 1944, BA R3601/216, F. 55 f.

113 Siehe RWI-Archiv Akte Chronik: Institut für Konjunkturforschung Essen, 11.1.1941.

114 „Betr.: Materialaustausch zwischen dem Oberbergamt Breslau und dem Oberschlesischen Institut für Wirtschaftsforschung in Kattowitz.“ Breslau, 3.11.1941, BA R3101/31275 F. 150 f.

115 Weiter im Zitat: „Es hat seinerseits die Arbeiten des Oberbergamts nach Möglichkeit durch Bereitstellung von eigenem Material zu unterstützen versucht.“ Das Breslauer Institut erstellte also die detaillierten monatlichen Lageberichte über die wirtschaftliche Situation des Verwaltungsbezirks für den Oberpräsidenten. Wie auch die anderen Oberpräsidenten Deutschlands hatte er sie an das RWM zu liefern. 
„grundsätzlich bereit“, den „bewährten Materialaustausch“ auch mit dem neuen Institut in Kattowitz durchzuführen. Wagemann erbat eine „schriftliche Einverständniserklärung der Bergbauabteilung des Reichswirtschaftsministeriums“ und „bemerkte ergänzend, daß auch das oberschlesische Institut für Wirtschaftsforschung in den vorsorglichen Geheimschutz einbezogen“ sei. Im überlieferten Briefentwurf des RWM $^{116}$ an das Oberbergamt Breslau (OBA) wollte es neben der Auffassung des OBA zum Anliegen Wagemanns „über Umfang und Handhabung des Materialaustausches für Niederschlesien sowie die dabei gemachten Erfahrungen kurz unterrichtet“ werden. Durchgestrichen stand folgender Absatz im Briefentwurf: „Grundsätzliche Bedenken gegen einen Materialaustausch habe ich nicht; es erscheint mir sogar erwünscht, daß die Unterrichtung des Instituts über die Entwicklung auf bergbaulichem Gebiet in erster Linie durch das OBA in dem von diesem für zweckmäßig gehaltenen Umfang erfolgt.“ Im Antwortbrief lobte das $\mathrm{OBA}^{117}$ die „enge, von gegenseitigem Vertrauen getragene Zusammenarbeit“. Für die Erstellung der Lageberichte bekomme das Institut „sämtliche beim Landeswirtschaftsamt und bei der Wirtschaftskammer Schlesien eingehenden, für die Beurteilung der wirtschaftlichen Lage wichtigen Berichte und Unterlagen zur Verfügung gestellt.“ Dem OBA gingen „Abdrucke der Lageberichte des Oberpräsidenten [...] regelmäßig zu.“ Darüber hinaus habe das „Breslauer Institut in den letzten Jahren verschiedene größere Gutachten, so unter anderem eines über die Probleme der oberschlesischen Eisenindustrie für den Gauleiter oder die Wirtschaftskammer Schlesien erstattet.“ Diese Gutachten seien allen Interessierten, darunter auch dem OBA, zugeleitet worden. „Soweit in diesen Gutachten bergbauliche Fragen berührt worden sind, sind die Bearbeiter vorher mit dem Oberbergamt in mündlichen Gedankenaustausch getreten und haben, soweit dies erforderlich war, ihre gutachterliche Stellungnahme der des Oberbergamtes angeglichen. [...] Da sich die Zusammenarbeit mit dem Breslauer Institut für beide Teile als wertvoll erwiesen hat, möchten wir in gleicher Weise mit dem neu entstandenen Kattowitzer Institut in Materialaustausch treten. “ Der RWM teilte Ende Dezember dem OBA und dem „Präsidenten des Oberschlesischen Instituts für Wirtschafts- und Konjunkturforschung“ mit, dass er einverstanden sei, mit dem neuen Institut in Kattowitz zusammenzuarbeiten. ${ }^{118}$

In Analogie dazu dürfte somit auch das RWI auf geheime wirtschaftsstatistische Daten zugegriffen haben. Darüber hinaus stellten natürlich all die Gebietskörperschaften und andere staatliche bzw. semistaatliche Organisationen und Institutionen wie auch Unternehmen, welche die Dienste und Publikationen des RWI in Anspruch nahmen, selbstverständlich Datenmaterial und weitere Informationen für die Forschungstätigkeit des RWI bereit. Trotz der restriktiven Geheimhaltungsvorschriften während des Krieges konnte sich also die „kriegswichtige“ Forschung des RWI 
wahrscheinlich ohne gravierende Einschränkungen auf amtliche und nicht-amtliche Statistiken stützen.

Allerdings wurde die Weitergabe von Rüstungsstatistiken deutlich restriktiv gehandhabt. So hatten nicht alle Abteilungen des DIW gleichermaßen Zugang zu den geheimen Daten über den militärischen Komplex: Während die Industrieabteilung unter Wagenführs Leitung ${ }^{119}$ bei der Arbeit für das Speersche Planungsamt direkt in die Produktionsplanung der Rüstungsgüter einbezogen war, beklagte Wolf ${ }^{120}$ für die Auslandsabteilung des DIW, dass der britische und amerikanische Stand der Rüstungsproduktion und der Produktionsreserven zwar einzuschätzen sei, jedoch „über die Höhe der deutschen Rüstungsproduktion keinerlei Angaben vorliegen“. ${ }^{121}$

Unverändert galt das Veröffentlichungsverbot des RWM, das aus kriegswirtschaftlichen Gründen immer weitergehende Anordnungen traf, die Publikation statistischer Daten zu beschränken oder ganz zu verbieten. ${ }^{122}$ Für die dennoch veröffentlichten Statistiken verfügte das RWM aber immer wieder: Es „sollen sämtliche Veröffentlichungen nach wie vor der Wahrheit entsprechen. In Zweifelsfällen soll die Veröffentlichung statistischer und sonstiger Angaben eher unterbleiben als daß falsche Angaben gemacht werden. ${ }^{\text {“123 }}$ Alle statistischen Zusammenstellungen unterlagen demnach Geheimhaltungsvorschriften. Umso erstaunlicher war es, dass die „Spezialuntersuchungen“, die mit Kriegsbeginn die „laufende Konjunkturforschung“ abgelöst hatten, als „kriegswirtschaftlich wichtige [...] Arbeiten [des RWI] doch vertraulich gedruckt und publiziert" ${ }^{\text {"124 }}$ wurden. Die gedruckten oder hektographierten Hefte der RWI-Schriftenreihe durften zwar nicht öffentlich verbreitet werden, waren aber in limitierter Auflage einem begrenzten Kreis „nur für den Dienstgebrauch“ zugänglich. Manchmal galt eine noch höhere Geheimhaltungsstufe, und in der Regel

119 Ausführlich dazu Fremdling 2016a, S. $283 \mathrm{ff}$.

120 Vor dem IfK/DIW war Eduard Wolf im StRA angestellt: Nach dem Geschäftsverteilungsplan des StRA Ende September 1930 war „Dr. Wolf, Hilfsreferent“ unter Langelütke im Referat „Statistik der internationalen Verflechtungen“ beschäftigt (BA R3102/6210 F. 245). Im Januar 1934 (12.1.1934) wurde er im StRA als ,ausgeschieden“ vermeldet (BA R3102/3586 F. 74). Er war 1934-1948 im IfK/DIW Leiter der Abteilung „Auslandswirtschaft“ und danach bei der Bank Deutscher Länder/Deutsche Bundesbank (Direktoriumsmitglied) tätig. Vgl. Stahmer 2010, S. 186, Anm. 70; Nützenadel 2005, S. 100, Anm. 59; Krengel 1986, S. 60.

121 Bericht über die Besprechung im [Deutschen] Institut für Wirtschaftsforschung am 4. Oktober 1944, BA R3101/32126, F. 67.

122 Das Veröffentlichungsverbot vom 2.10.1939 galt „für alle Darstellungen bis zurück zum August 1914“. „Beschränkungen und Verbote von Statistischen Veröffentlichungen wirtschaftlicher Art“, BA R3102/3082. Siehe dazu auch die umfangreichen Akten des RWM, in denen es als zuständiges Ministerium konkrete Fälle zur Veröffentlichung oder die Weitergabe von Daten zu prüfen hatte: BA R3101/31274 und 31275. Darin (31275 F. 3-11, 45-48 u. passim) finden sich z. B. detaillierte „Richtlinien für die Veröffentlichung von Wirtschaftszahlen aus dem Gebiet des Bergbaus und der Mineralölwirtschaft“. Sie wurden wahrscheinlich schon 1936 im RWM formuliert.

123 Zusammenfassung von Richtlinien für die Beschränkung von Veröffentlichungen im Bereich der gewerblichen Wirtschaft, Februar 1939, BA R3101/31275 F. 33-44.

124 Siehe RWI-Archiv Akte Chronik: Brief von Däbritz vom 26.2.1943 an Dr. von Dryander, DIW. 
waren weitergegebene Arbeiten nummeriert, sodass das RWI belegen konnte, wer welche Kopie erhalten hatte. ${ }^{125}$ Rückblickend aus dem Jahr 1956 kennzeichnete Däbritz etwas vage die Verbreitung der Forschungsergebnisse während des Krieges folgendermaßen: „Ihre Ergebnisse konnten unter dem Zwang der Verhältnisse allerdings nur einem engeren Kreis von Interessenten zugänglich gemacht werden. “126

Über Geheimhaltungsvorschriften hinaus wurden Veröffentlichungen ohnehin grundsätzlich zensiert. Hier galt auch für das RWI, was im Mutterhaus in Berlin auf einer Besprechung des Instituts am 4. Oktober 1944 in der Auslandsabteilung beklagt wurde. ${ }^{127}$ Wegen der gesunkenen Zahl der wissenschaftlichen Mitarbeiter könne eine „Grundsatzforschung [...] daher neben den laufenden Untersuchungen nicht mehr durchgeführt werden“. ${ }^{128}$ Deshalb erwog man, „wieweit die kurzfristigen Untersuchungen und ,Propagandaarbeiten ${ }^{129}$ zugunsten einer langfristigen Forschung eingeschränkt werden könnten.“ Trotz der festgestellten Einschränkungen „trat Dr. Wolf für seine derzeitigen Arbeitsaufgaben nachdrücklich ein: Es sei hier die Möglichkeit gegeben, von der Wissenschaft her einfach durch die Tatsachen die Propaganda zu beeinflussen und $u$.a. sogar zu lenken; allerdings gab er zu, dass die Berichte infolge ihrer Themenstellung leicht eingefärbt sein könnten, wenn es auch nach Möglichkeit vermieden würde. Das trifft nur für die Berichte $\mathrm{zu}$, nicht aber für die Veröffentlichungen des Instituts, wurde sogleich ausdrücklich hinzugesetzt. Bedauerlicherweise unterliegen aber die Veröffentlichungen des Instituts einer sehr scharfen Zensur. Der Maßstab, der an die Arbeiten des Instituts gelegt würde, sei darum besonders

125 Bei den hier im Einzelnen aufgeführten Arbeiten wird die Geheimhaltungsstufe nur noch in Ausnahmefällen erwähnt. Zu den restriktiven Richtlinien über die „Weitergabe statistischen Materials“ siehe die Verfügung des „Statistischen Zentralausschusses“ vom 29.9.1939, BA R3101/31275 F. 66-68. „Institute, die im Auftrag von obersten Reichsbehörden Untersuchungen durchzuführen haben“ (31275 F. 67) durften grundsätzlich „statistische Ergebnisse“ erhalten, die unter das Veröffentlichungsverbot fielen.

126 Däbritz/Stupp 1956, S. 21.

127 Die Auslandsabteilung arbeitete „in der Hauptsache für das Ministerium für Rüstung und Kriegsproduktion, das Auswärtige Amt und das Propagandaministerium aber auch für Parteistellen.“ Bericht über die Besprechung im Institut für Wirtschaftsforschung am 4. Oktober 1944, BA R3101/32126, F. $67 \mathrm{f}$. Hervorhebung R.F.

128 Die Ernennung Wagemanns zum Leiter der neugegründeten Arbeitsgemeinschaft für empirische Wirtschaftsforschung im Reichsforschungsrat (Erlass Görings vom 26.8.1944) wurde dann in der Denkschrift zu den „Aufgaben des Deutschen Instituts für Wirtschaftsforschung“ von November 1944 (BA R3601/216, F. 57) als Chance bzw. „Forschungsauftrag“ begriffen, wieder vermehrt „Grundlagenforschung“ betreiben zu können.

129 Allerdings hatte das IfK 1933/34 bis zum Kriegsbeginn die Beobachtung der UdSSR „nicht weiter durchgeführt. [...] Hier sei die Themenstellung so eindeutig propagandistisch gewesen, dass das Institut es abgelehnt habe, darüber zu arbeiten.“ (BA R3101/32126, F. 68.) „Beiträge zur Wirtschaftspropaganda“ gehörten allerdings ausdrücklich zum Arbeitsprogramm des DIW: „Diese bestehen in international vergleichenden Gutachten, in Glossen über bestimmte Wirtschaftsvorgänge und in kürzeren Aufsätzen verschiedener Art mit dem Ziel der Versorgung des Propagandadienstes oder auch der Aufzeigung propagandistischer Möglichkeiten.“ Denkschrift zu den „Aufgaben des Deutschen Instituts für Wirtschaftsforschung“von November 1944, BA R3601/216 F. 56. 
streng, weil man in seinen Veröffentlichungen gewissermaßen eine offizielle Stelle sehe."

Als Beispiel für den privilegierten Zugriff des RWI auf Originalunterlagen des StRA sei auf die Volks-, Betriebs- und Berufszählung von 1939 verwiesen. Das RWI verarbeitete die Daten für diese Zusammenstellungen bereits, als die Auswertung der 1939er Zählung vom StRA wahrscheinlich noch nicht abgeschlossen war. ${ }^{130}$ Auch die nicht-amtlichen Wirtschaftsstatistiken, die also nicht vom StRA, sondern vielfach von den privaten Wirtschaftsorganisationen und Lenkungsorganen (Wirtschaftsgruppen, Reichsstellen, Ringen, Ausschüssen, Arbeitskreisen etc.) erhoben wurden, standen seit 1939 unter strenger Kontrolle des StRA. Es hatte mit dem unter der Geschäftsführung des StRA-Präsidenten stehenden „Statistischen Zentralausschuß“ die Aufsicht über den gesamten statistischen Kontrollapparat an sich gezogen. ${ }^{131}$ Der Ausschuss war im Februar 1939 eingerichtet worden, um alle „nicht-amtlichen“ Erhebungen zu kontrollieren und zu genehmigen. ${ }^{132}$ Von Anfang an wurde das RWI bzw. die Abteilung Westen im rheinisch-westfälischen Raum von Firmen, Handelskammern, Gebietskörperschaften und weiteren Institutionen mit Datenmaterial versorgt. In seinem Vortrag über die „Aufgaben des Instituts für Konjunkturforschung, Abteilung Westen“ vor der „Geschäftsführerkonferenz der Vereinigung der Industrie- und Handelskammern des rheinisch-westfälischen Industriebezirks“133 hatte Däbritz bereits im Mai 1926 das damalige Ziel angegeben, „statistisches Material unter dem Gesichtspunkt der Konjunkturempfindlichkeit zu sammeln.“ Dabei gehe es nicht darum, eigene Statistiken zu erheben und damit die „vorhandenen wertvollen statistischen Stellen überflüssig zu machen“, sondern man müsse analog zur Arbeitsteilung des „Berliner Instituts“ mit dem StRA auf das lokale und regionale Datenmaterial des Reviers zurückgreifen können. ${ }^{134}$ Fünfzehn Jahre später, am 11. Januar

130 Einige Ergebnisse sind nie, auch nicht für interne Zwecke zum „Dienstgebrauch“, zusammengestellt und ausgedruckt worden, z. B. der geplante Band 567 der Statistik des Deutschen Reichs mit den Reichsergebnissen der nichtlandwirtschaftlichen Betriebsstätten. Zu Details über die Veröffentlichungen zur Betriebs- und Berufszählung von 1939 siehe Fremdling/Staeglin 2014a, S. 287-289.

131 Siehe die vom Präsidenten des StRA Reichardt erlassene „Verfügung zur Einrichtung einer Geschäftsstelle des Statistischen Zentralausschusses" vom 17.3.1939, BA R3102/2945 F. 4, 11. Siehe z. B. das Protokoll einer Sitzung des Zentralausschusses vom 21.8.1939, BA R3102/8915 F. 1-8.

132 Es ging um die „Verordnung zur Vereinfachung der Wirtschaftsstatistik vom 13. Februar 1939“, gez. vom Beauftragten für den Vierjahresplan, Göring, am 9.3.1939, BA R3102/2945 F. 1f.; Reichardt 1940, S. 88 ff.; Jacobs 1971, S. 292f.; siehe auch die Akte BA R3102/2948, die sich auf Vorgänge zu der Verordnung während des Krieges bezog, z. B. „Verordnung zur Vereinfachung der Wirtschaftsstatistik“ oder Antragsformulare und Erhebungsformblätter.

133 Siehe RWI-Archiv: Vortrag Nr. 2, S. $16 \mathrm{ff}$.

134 In der Denkschrift zu den „Aufgaben des Deutschen Instituts für Wirtschaftsforschung“ von November 1944 (BA R3601/216 F. 54) wurde diese Positionierung bekräftigt: „Die Tätigkeit des Instituts grenzt sich auch gegenüber der Arbeit der statistischen Erhebungsstellen eindeutig ab. Es ist nicht Aufgabe des Instituts, selbst statistische Erhebungen durchzuführen, und auch statistisches Urmaterial hat es nur in Ausnahmefällen selbst aufzuarbeiten." Als Ausnahme wurde die Einbindung des DIW in das Planungsamt genannt. 
1941, erläuterte Däbritz in vertraulichem Kreis die veränderte Aufgabenstellung des Essener Instituts auch gegenüber dem Mutterinstitut und den inzwischen ausgegründeten Zweigstellen des DIW, um die Verselbständigung der Essener Abteilung als RWI vorzubereiten: Nachdem er die „regionale Konjunkturforschung“ als bisherigen Schwerpunkt herausgearbeitet hatte, beschrieb er die Abkehr davon mit der Umorientierung: „Seit Ausbruch des Weltkrieges ist das Essener Institut alsdann mit kriegswichtigen Strukturuntersuchungen betraut worden. Derartige Strukturanalysen sind aber von vornherein den genannten neuen Instituten zugedacht.“135

Die folgende Darstellung und Einordnung der Forschungsergebnisse des Essener Instituts basiert vor allem auf den Tätigkeitsberichten des RWI ${ }^{136}$ für die Geschäftsjahre 1942/43 und 1943/44 sowie dem Arbeitsplan für das Geschäftsjahr 1944/45. ${ }^{137}$

Im Geschäftsjahr 1942/43 „galt die Haupttätigkeit nach wie vor wissenschaftlichen Untersuchungen kriegswichtiger Fragen.“ Ohne Nennung der Verfasser wurden die Arbeiten aufgeführt, die meistens auch im Bericht für das folgende Geschäftsjahr 1943/44 auftauchten. Nicht mehr erwähnt wurden in den hier herangezogenen Tätigkeitsberichten die Hefte 1, 2, 2a und 3 der Schriftenreihe des Instituts, die alle vor 1942 fertiggestellt waren. Ohne Erscheinungsjahr und Verfasser verzeichnete Däbritz die Hefte 1 bis 301947 in einer Liste:138

Heft 1, Wirtschaftsstruktur und Krisenfestigkeit in 30 rheinisch-westfälischen Städten. ${ }^{139}$

In der Einleitung dieses Heftes wird festgestellt, dass das „Krisenproblem“ kein „akutes Problem“ mehr sei. Wegen der erreichten Vollbeschäftigung sei es vielmehr

135 Siehe RWI-Archiv Akte Chronik: Institut für Konjunkturforschung Essen, 11.1.1941. Im vertraulichen Brief von Däbritz vom 26.2.1943 an Dr. von Dryander, DIW (RWI-Archiv Akte Chronik) hieß es: „Seit Kriegsausbruch gaben wir [...] die laufende Konjunkturforschung auf und wandten uns stattdessen kriegswirtschaftlich wichtigen Spezialaufgaben zu.“

136 Däbritz datierte den Tätigkeitsbericht auf den 16. Juni 1943. Zu diesem Zeitpunkt war das Institut bereits als RWI (Rheinisch-Westfälisches Institut für Wirtschaftsforschung) gegründet (Januar/Februar 1943) und ins Vereinsregister eingetragen (31.5.1943). Auch wenn im Bericht (S. 3) die „Umwandlung des Deutschen Instituts für Wirtschaftsforschung, Abteilung Westen, in ein Rheinisch-Westfälisches Institut für Wirtschaftsforschung e.V.“ als „nur nahezu abgeschlossen“ bezeichnet wurde, war die Überschrift des Berichts als „Deutsches Institut für Wirtschaftsforschung, Abteilung Westen“ bereits überholt. Siehe RWI-Archiv Akte Chronik.

137 Tätigkeitsbericht des Deutschen Instituts für Wirtschaftsforschung, Abteilung Westen, für das Jahr 1942/43 vom 16.6.1943, RWI-Archiv Akte Chronik: Rheinisch-Westfälisches Institut für Wirtschaftsforschung, Essen; Tätigkeitsbericht für das Geschäftsjahr 1943/44 und Arbeitsplan für das Geschäftsjahr 1944/45 vom 19.9.1944, WWA K1 Nr. 2080. Der dünne, dreiseitige Tätigkeitsbericht für 1939 und 1940 vom 6.2.1941 wird für einige Werke der Schriftenreihe zusätzlich herangezogen. WA-LWL 722/ 55

138 Däbritz 1947, S. $33-35$.

139 Wirtschaftsstruktur und Krisenfestigkeit in 30 rheinisch-westfälischen Großstädten (Institut für Konjunkturforschung, Abteilung „Westen“), hektographiert, Essen Dezember 1939 [im Nachhinein von Däbritz als Heft 1 der Schriftenreihe eingeordnet]. Schon dieses erste Heft wurde in durchnummerierten Exemplaren als „Nur für den Dienstgebrauch“ klassifiziert. 
„ein Gegenstand rückschauender Betrachtung geworden“, deren „Einsichten und Erkenntnisse“ dazu dienten, „der Wirtschaftsführung Hinweise für ihr künftiges Handeln zu vermitteln. “ In die Untersuchung gingen 14 Städte der Rheinprovinz und 16 Westfalens ein. Vor allem auf der Basis der detaillierten Volks-, Berufs- und Betriebszählung von 1933 entstand ein differenziertes Bild über die Krisenanfälligkeit der wirtschaftlich unterschiedlich strukturierten Städte. Orte mit einem hohen Anteil an „konjunkturreagiblen“ und „großbetrieblichen“ Produktionsmittelgüterindustrien (Gladbach, Gelsenkirchen) erwiesen sich als „empfindlicher“ als Städte mit vorwiegend vielfältigen Verbrauchsgüterindustrien (Gütersloh, Lüdenscheid). „Das Thema dieser Arbeit ist in Verbindung mit den Landesplanungsgemeinschaften Westfalen, Rheinland und dem Siedlungsverband Ruhrkohlenbezirk ${ }^{140}$ als Landesplanungsgemeinschaft für den Ruhrkohlenbezirk formuliert worden“. Im Tätigkeitsbericht 1939/ 40 wurde zudem „,in enger Fühlung“ die „Reichsstelle für Raumordnung“ genannt. Den „genannten Stellen [sollten] praktisch verwertbare Materialien für ihre Planungsaufgabe“ geliefert werden. ${ }^{141}$

Heft 2, Der oberschlesische Wirtschaftsraum. Ein Vergleich mit dem Ruhrbezirk. ${ }^{142}$

Im Vorwort dieser Arbeit Helmrichs ${ }^{143}$ vom Juni 1940 führte Däbritz aus, dass mit der „Neuordnung des deutschen Ostens [...] deutsche Landesteile“ heimgekehrt seien und „weitere Gebiete der Oberhoheit des Reiches unterstellt wurden.“ Damit seien die „bisher selbständigen und zum Teil einander entgegenwirkenden industriellen Teilbezirke des oberschlesischen Wirtschaftsraumes nunmehr in einheitliche Verwaltung genommen worden“ und damit sei „die Möglichkeit geschaffen, dieses ganze Gebiet zu einer schwerindustriellen Einheit zusammenzufassen. “ Ziel der Untersuchung war, „der organischen Einheit im Westen des Reiches, [also dem] Ruhrbezirk [...] die Struktur und Verflechtung des oberschlesischen Wirtschaftsraumes“ gegenüberzustellen. „Aus der politischen Neugliederung im östlichen Mitteleuropa“ erwartete Helmrich in seiner „Schlußbetrachtung“ glänzende Absatzmöglichkeiten für den „Wirtschaftsraum Großoberschlesien“.

Heft 2a Der Ausbau der Ruhrindustrie seit dem Weltkriege unter besonderer Berücksichtigung der Freisetzung und des Bedarfs an Arbeitskräften. ${ }^{144}$

140 „Der Siedlungsverband Ruhrkohlenbezirk (SVR) wurde durch Gesetz vom 5. Mai 1920 (Preuss.Ges.S.S.286) als öffentlich rechtliche Körperschaft geschaffen. Dem Verband gehören 18 kreisfreie Städte und 9 Landkreise an. Das Verbandsgebiet erstreckt sich im allgemeinen im Süden bis zur Ruhr, im Norden bis zur Lippe, im Westen bis zur holländischen Grenze, im Osten bis in die Gegend von Hamm, geht an einzelnen Punkten jedoch über diese Grenzen hinaus.“ Quelle: Landesarchiv NRW Abteilung Rheinland Findbuch-Eintrag Signatur: 216.01.01.

141 WA-LWL 722/55.

142 Helmrich, Wilhelm, Der oberschlesische Wirtschaftsraum. Ein Vergleich mit dem Ruhrbezirk (Schriften des Instituts für Konjunkturforschung, Abteilung Westen, Sonderheft 2), Essen 1940.

143 Engels (2007, S. 240 ff.) belegt die enge Zusammenarbeit Helmrichs mit Kuske in der „Westlandforschung“. Helmrich arbeitete von 1938 bis 1941 im Essener Institut.

144 Helmrich, Wilhelm, Der Ausbau der Ruhrindustrie seit dem Weltkriege unter besonderer Berücksichtigung der Freisetzung und des Bedarfs an Arbeitskräften, Bearbeitet auf Veranlassung des 
Aus dem Vorwort vom August 1940 dieser vom Ruhrsiedlungsverband beauftragten Studie geht hervor, dass diese Untersuchung Helmrichs von der „Reichsstelle für Raumordnung“ initiiert worden war. Das 65 Seiten umfassende hektographierte Heft spannt zeitlich einen Bogen von der gewerblichen Betriebszählung 1933 bis zurück zu den Gewerbezählungen Preußens in der Mitte des 19. Jahrhunderts: „Tabellen und amtliche Nachrichten über den Preussischen Staat“ von 1849. Nach Engels ${ }^{145}$ diente diese Arbeit dazu, gegen „Absiedlungspläne“ von Arbeitskräften aus dem Ruhrgebiet „zum Aufbau der Ostgebiete“ zu argumentieren. Wegen eines Arbeitskräftemangels des Ruhrgebiets selbst könnten Arbeitskräfte von dort nicht zur Ost- oder Westexpansion abgezogen werden.

Heft 3 Die Versorgung des niederrheinisch-westfälischen Industriebezirks mit Fleisch und Fleischwaren. ${ }^{146}$

Im Vorwort vom März 1941 beschrieb Däbritz die Quellen, die erst von den im Rahmen der gelenkten Wirtschaft 1935 und 1936 entstandenen „Marktverbänden“ zusammengestellt werden konnten. Mit diesem Zahlenmaterial aus den örtlichen Untergliederungen der „Hauptvereinigung der Deutschen Viehwirtschaft“ ließen sich erstmals Städte des Reviers miteinander vergleichen. Daneben wurde „umfangreiches statistisches Material der Reichsstelle für Tiere und tierische Erzeugnisse“ und der „Reichsstelle für Milcherzeugnisse, Öle und Fette“ herangezogen. Die „Untersuchung erfolgte im Einvernehmen mit dem Provinzialernährungsamt der Rheinprovinz in Bonn.“ Man erwartete, dass die „Ergebnisse der Arbeit“ nicht nur für „kriegswirtschaftliche Maßnahmen“, sondern „darüber hinaus auch nach der Wiederkehr des Friedenszustandes nutzbringende Verwendung finden werden.“

Bis auf diese oben beschriebenen Hefte tauchen die weiteren in der Kriegszeit entstandenen Arbeiten aus der Däbritz-Liste von 1947 in den hier herangezogenen Tätigkeitsberichten von 1942/43 und 1943/44 sowie dem Arbeitsplan 1944/45 in der Regel nur mit dem Arbeits- oder Publikationstitel auf. Darüber hinaus werden sie hier inhaltlich nur knapp vorgestellt und mit kurzen Erklärungen in einen breiteren Zusammenhang eingeordnet. Um den authentischen historiographischen Kontext zu erhalten, ${ }^{147}$ werden die Hefte des RWI in derselben Reihenfolge, wie sie in den Tätigkeitsberichten des RWI aufgeführt wurden, erläutert.

An erster Stelle verwies der Tätigkeitsbericht des RWI für das Geschäftsjahr 1942/ 43 auf die Arbeit „Die Schwerindustrie im Raume Saarland-Lothringen-Luxemburg“.

Ruhrsiedlungsverbandes im Institut für Konjunkturforschung, Abteilung Westen, hektographiert, Essen 1940.

145 Engels 2007, S. 244f. Siehe auch den Tätigkeitsbericht 1939/40, WA-LWL 722/55.

146 Chandon, Emil, Die Versorgung des niederrheinisch-westfälischen Industriebezirks mit Fleischund Wurstwaren (Schriften des Instituts für Konjunkturforschung, Abteilung Westen, Sonderheft 3), Essen 1941.

147 Erscheinungsjahr, Heftnummer und erstes Erwähnen des Themas verliefen nicht synchron. 
Helmrich hatte sie „im Vorjahr“, also 1942, abgeschlossen. ${ }^{148} \mathrm{Im}$ Vorwort führte Däbritz aus: „Aus der Darstellung der Vergangenheit leitet sie [die Untersuchung] die künftigen Entwicklungsmöglichkeiten des in der Entstehung begriffenen Gesamtbezirks ab.“ Däbritz erwartete also, dass dieser schwerindustrielle „Gesamtbezirk“ mit dem Ruhrgebiet ohne behindernde Grenzen zusammenwachsen würde. Diese Arbeit Helmrichs, wie auch die meisten anderen Forschungen des RWI, war historisch mit starker Quantifizierung angelegt, während ein explizit wirtschaftstheoretischer Bezugsrahmen fehlte. Engels ordnet Helmrichs Werk in die Großraumideologie Kuskes und als Auftragsarbeit, u.a. vom Stahlindustriellen Röchling, ein, um den deutschen Zugriff auf die lothringischen Minetteerze zu untermauern. ${ }^{149}$

Eine Reihe weiterer Arbeiten war „ganz oder nahezu fertiggestellt“:

1. „Die Landwirtschaft der Niederlande mit besonderer Berücksichtigung ihrer Beziehungen zu Rheinland und Westfalen." ${ }^{150}$

Diese Untersuchung war ,in Verbindung mit regionalen Stellen des Reichsnährstandes“ erstellt worden, und neben „sonstigen deutschen und niederländischen Dienststellen“ hatte man dazu „die zuständigen Stellen des Reichskommissars für die besetzten Niederlande“ eingeschaltet. ${ }^{151}$ Nach Engels war sie ein Projekt aus dem von der Deutschen Forschungsgemeinschaft geförderten Forschungsprogramm der Reichsarbeitsgemeinschaft für Raumordnung „Die Germanische Forschungsaufgabe“. ${ }^{152}$ Im Vorwort der gedruckten Fassung vom August 1944, also ein Dreivierteljahr vor Kriegsende, behandelte Däbritz die im Mai 1940 mit der Besetzung der Niederlande durch deutsche Truppen eingeleitete „wirtschaftliche Neuordnung“ und die Eingliederung der „niederländischen Industrie und Landwirtschaft [...] je länger je mehr in den kontinentaleuropäischen Raum“. „Im Vordergrund [der Untersuchung] stand [...] die niederländische Landwirtschaft als wichtige Lieferantin für den massiven Nahrungsmittelbedarf der dicht gesiedelten Bevölkerung von Rheinland-Westfalen [...] und ihre Verflechtung mit dem rheinisch-westfälischen Industriegebiet.“

148 Siehe Helmrich, Wilhelm, Die Schwerindustrie im Raum Saarland-Lothringen-Luxemburg (Schriften des Instituts für Konjunkturforschung, Abteilung Westen, Sonderheft 4), Essen 1942.

149 Engels 2007, S. 245 f.; zu Röchlings Haltung siehe Gillingham 1986, S. 391 ff.

150 Siehe Cless, Herta, Die Landwirtschaft der Niederlande unter besonderer Berücksichtigung ihrer Beziehungen zu Rheinland und Westfalen (Rheinisch-Westfälisches Institut für Wirtschaftsforschung Essen, H. 13), Essen 1944. Diese Arbeit war bereits im Brief von Däbritz vom 27.9.1941 an „Gauleiter Bornemann, Hauptgeschäftsführer der Wirtschaftskammer Westfalen und Lippe“ als „in Bearbeitung“ angekündigt worden. WWA K1 Nr. 2080.

151 Im Vorwort werden sie genannt: „Oberregierungsrat Dr.-Ing. habil. Roloff, Abteilung Planung beim Reichskommissar für die besetzten niederländischen Gebiete, Den Haag [...] Dr. Herbig, Hauptgeschäftsführer der Deutschen Handelskammer für die Niederlande“. Weiterhin waren mehrere „Reichsstellen“, d.h. Lenkungsstellen der Kriegswirtschaft, an der Datenerhebung beteiligt: „Reichsstelle für Eier, [...] für Milcherzeugnisse, Öle und Fette“ sowie die entsprechenden regionalen Wirtschaftsverbände.

152 Zu den Hintergründen siehe Engels 2007, S. 303 ff.; Engels (2007, S. 306) erwähnt noch ein weiteres RWI-Projekt in diesem Rahmen, das in den Tätigkeitsberichten des RWI nicht erwähnt wurde: „Einsatz der belgischen Wirtschaftskapazität zur Stärkung des deutschen Kriegspotentials“. 
Damit schimmern wenige Monate vor Kriegsende und der absehbaren Niederlage Deutschlands noch immer die imperialen Ansprüche gegenüber den Niederlanden durch. ${ }^{153}$

Däbritz entwickelte damit weder originelle Vorstellungen noch war seine Orientierung auf die Nachkriegswirtschaft einzigartig. Sowohl im RWM als auch vom Leiter des Speerschen Planungsamtes, ${ }^{154}$ Hans Kehrl, angeregt, wurde eine europäische Wirtschaftsordnung für die Zeit nach dem Krieg, selbstredend unter deutscher Führung, konzipiert. Der Leiter der Außenwirtschaftsabteilung der Reichsgruppe Industrie, Karl Albrecht, und der von ihm geleitete Außenwirtschaftskreis erörterten im Sommer 1944 mit dem RWM (Ohlendorf) Außenwirtschaftsfragen in dieser Richtung. ${ }^{155}$ Beim Außenwirtschaftskreis fällt die Parallelität zu Hans Kehrls Europa-Kreis auf. ${ }^{156}$ Dieser Kreis existierte schon länger und überschnitt sich sowohl personell (Hermann Josef Abs, Karl Blessing) ${ }^{157}$ als auch thematisch mit Plänen und Aktivitäten des Außenwirtschaftskreises bzw. des RWM. ${ }^{158}$

2. „Statistische Zusammenstellungen“. Das ist ein Tabellenwerk, das für den als Raumplanungsbehörde fungierenden „Siedlungsverband Ruhrkohlenbezirk - Essen auf Grund der Volks-, Berufs- und Betriebszählung 1933 und 1939 sowie anderer Unterlagen“ erarbeitet worden war. ${ }^{159}$ „Die Ergebnisse der Zählungen wurden für den Raum des Siedlungsverbandes Ruhrkohlenbezirk zusammengestellt.“

Diese „Statistischen Zusammenstellungen“ wurden schließlich erst kurz nach dem Ende des Zweiten Weltkriegs im Mai 1945 in der Schriftenreihe des RWI veröffentlicht. ${ }^{160}$ Im Vorwort pries Däbritz den Nutzen dieser Daten von 1939 für den Wiederaufbau: „Obwohl sie mithin die Vorkriegsverhältnisse wiedergeben und in der Zwischenzeit tiefgreifende Veränderungen vor sich gegangen sind, dürfen sie nicht als

153 Der von Hans Kehrl initiierte Arbeitskreis (Europa-Kreis) schwadronierte zu der Zeit allerdings noch unverhüllt über deutsche Machtansprüche gegenüber den Niederlanden. Hermann Josef Abs, der spätere Vorstandssprecher der Deutschen Bank, war im „Kehrl-Kränzchen“ der Ansprechpartner für die Niederlande. BA R3/1941 F. 29, 32, 245-250.

154 Das Planungsamt war die Kommandozentrale der deutschen Kriegswirtschaft.

155 Herbst 1982, S. 388; Roth 1996, S. 573.

156 BA R3/1941, vgl. den umfangreichen Aktenbestand mit weiteren Protokollen und weiteren einschlägigen Schriftstücken. Ausführlich dazu Roth 1996, S. 524-538.

157 BA R3 1941, F. 29, „Protokoll Nr. 4 der Monatsbesprechung“ des Arbeitskreises vom 30.4.1944 mit Blessing und Abs als Teilnehmern.

158 BA R3 1941, F. 245-250, siehe den „Arbeitsplan für Europakreis“.

159 Im Tätigkeitsbericht des Instituts für das Geschäftsjahr 1943/44 (WWA K1 Nr. 2080) wurden als Heft 10 bzw. 11 der „Schriftenreihe des Rheinisch-Westfälischen Instituts für Wirtschaftsforschung Essen“ zwei Arbeiten als „gegenwärtig abgeschlossen und ausgegeben“ erwähnt, welche ebenfalls die Volks-, Berufs- und Betriebszählung von 1939 auswerteten: „Die Westdeutschen Gaue. Darstellung und Vergleich von Struktur und Bedeutung nach dem Stand der Volks-, Berufs- und Betriebszählung vom 17.5.1939. Heft 10.“ und „Zahlen zu Bevölkerung und Wirtschaft des Ruhrbezirks 1939. Ergebnisse der Volks- und Betriebszählung vom 17.5.1939. Heft 11.“

160 Siedlungsverband Ruhrkohlenbezirk, Statistische Zusammenstellungen (Rheinisch-Westfälisches Institut für Wirtschaftsforschung Essen, H. 19), Essen 1945. 
gegenstandslos gelten. Vielmehr können sie gerade deshalb für den künftigen Wiederaufbau wertvolle Erkenntnisse liefern und insbesondere den Gemeinden des Ruhrkohlenbezirks durchgehende Vergleiche liefern.“ Däbritz behielt Recht: Nach dem Krieg griffen sowohl die Besatzungszonen als auch die beiden deutschen Staaten (BRD und DDR) in erheblichem Maße auf die Statistiken der NS-Zeit und auf die daran beteiligten Statistiker zurück. ${ }^{161}$

3. „Zahlen zum Wirtschaftsverlauf im rheinisch-westfälischen Industriebezirk 1938-1942“. Damit wurden „zu einem gewissen Grade die früheren „KonjunkturBerichte des Instituts“ fortgeführt, in welche die „wichtigsten Daten zur Beurteilung des wirtschaftlichen Ablaufs“ eingingen. Auch hier wurde geheimes Material vom „Rüstungsobmann für den Wehrkreisbezirk VI b zur Verfügung gestellt.“ Diese Datensammlung sollte „weitergeführt und ausgebaut“ werden.

4. „Denkschrift über die wirtschaftliche und verkehrsmässige Einheit des rheinisch-westfälischen Industriegebietes“. ${ }^{162}$ Das RWI lieferte das quantitative Material, die Unterlagen für die Karten und beriet den „Siedlungsverband Ruhrkohlenbezirk Essen“, der die Denkschrift verfasste. Sie diente „den Zwecken des zuständigen Reichsverteidigungskommissars.“

5. „Die Beschäftigungslage im Ruhrbezirk“. Die „Arbeitsbucherhebungen 1938 und 1942“ bildeten die statistische Grundlage, die für den Siedlungsverband Ruhrkohlenbezirk zusammengestellt worden waren.

6. „Kreisbeschreibungen“. Gegenstand war der „Emscher-Lippe-Raum“, Auftraggeber waren der „Siedlungsverband Ruhrkohlenbezirk - Essen“ und die „Reichsstelle für Raumordnung - Berlin“. Die „seit längerem laufende Darstellung wurde einstweilen zurückgestellt und die Arbeit auf Materialsammlung beschränkt.“ Im Tätigkeitsbericht für 1939/40 war die Arbeit noch „im engen Zusammenhang mit den vom Führer angeordneten [...] vorbereitenden Planungsmassnahmen für das nach Kriegsende durchzuführende soziale Wohnungsbau-Programm“ eingeordnet. Im Bericht für das Geschäftsjahr 1943/44 wurde für die Rückstellung als „Grund: nicht kriegswichtig“ genannt.

7. „Die Struktur des Planungsraumes Ruhrkohlenbezirk“. In der „Arbeit aus Text und Statistiken“ ging es um „Gebiet und Bevölkerung, das räumliche Gefüge, Funktion und Bedeutung.“ Als „Auftraggeber“ fungierten wiederum der „Siedlungsverband Ruhrkohlenbezirk - Essen“ und die „Reichsstelle für Raumordnung - Berlin“. Eine Drucklegung war geplant.

8. „Der Pendelverkehr der Berufstätigen im Ruhrgebiet“. Verwendet wurden „Statistiken der öffentlichen Verkehrsunternehmungen und Unterlagen der Gewer-

161 Fremdling 2016b, c.

162 Die Drucklegung verzögerte sich, weil die beauftragte Druckerei im März 1943 „durch Fliegerangriff zerstört wurde.“ Im Tätigkeitsbericht für das Geschäftsjahr 1943/44 wurde die Arbeit als „im zweiten Druck fertiggestellt“ registriert. 
besteuerüberweisungen (Lohnsummen) der Gemeinden. “163 Der Auftraggeber wurde nicht genannt.

Über die acht aufgeführten „Wissenschaftlichen Arbeiten“ hinaus war das RWI „für verschiedene Stellen gutachterlich tätig, erteilte Auskünfte und übernahm Sonderaufträge“, von denen lediglich die „grösseren [vier] Arbeiten“ im Tätigkeitsbericht für 1942/43 auftauchen: Für das DIW wurde ein Bericht über „Gemüse- und Obstversorgung der rheinischen Grossmärkte im Sommer 1942“ verfasst; für das „Provinzialernährungsamt - Bonn“ wurde eine „Analyse“ mit der „Auswertung der Arbeitsbucherhebungen für die Rheinprovinz nach Arbeitsamtsbezirken“ vorgenommen; die „Reichsstelle für Raumordnung - Berlin“ bestellte ein Gutachten über den „Einfluss der steuerpolitischen und sonstigen Massnahmen der Gemeinden des Ruhrbezirks auf die industrielle Ballung“, und die Stadt Essen erteilte einen „Sonderauftrag“ für „Untersuchungen über die wirtschaftlichen und finanziellen Auswirkungen des Generalbebauungsplanes der Stadt Essen“.

Im Archiv des RWI sind aus der Kriegszeit kaum Manuskripte von „Sonderaufträgen“ überliefert: Zwei zusammenhängende, gleichwohl rudimentäre Akten, stellten schematisch die Organisation der Kriegswirtschaft mit den „Systemen Kehrl und Speer“ dar und sind hier im einleitenden Kapitel zum RWI in der Kriegswirtschaft behandelt. ${ }^{164}$ Das im Tätigkeitsbericht für 1942/43 von der „Reichsstelle für Raumordnung - Berlin“ bestellte Gutachten (zur Frage „Haben die Gemeinden des Ruhrgebiets durch finanz- und steuerpolitische Maßnahmen industrielle und andere Unternehmen herangezogen und dadurch die „Ballung“ im Ruhrgebiet vergrößert?“) ist als vollständiges Manuskript überliefert. ${ }^{165}$ Meurer erörtert die finanzpolitischen Maßnahmen (Vorteile beim Grundstückserwerb und der Nutzung von Gebäuden) und steuerpolitischen Vergünstigungen bei der Grund- und Gebäudesteuer sowie der Gewerbesteuer. Nach der vergleichenden quantitativen Untersuchung in langfristiger Perspektive, die in zahlreichen Tabellen dargestellt wurde, schlussfolgerte Meurer, dass sich auf „die eingangs gestellte Frage [...] eine eindeutig negative Antwort“ ergab: Es „waren 1939 beinahe 90 v.H. aller Erwerbstätigen im Ruhrgebiet in Industrien beschäftigt, die hier ihren natürlichen Standort hatten, also nicht durch finanz- oder

163 Im Tätigkeitsbericht des Instituts für das Geschäftsjahr 1943/44 (WWA K1 Nr. 2080) wurde als Heft 6 der „Schriftenreihe des Rheinisch-Westfälischen Instituts für Wirtschaftsforschung Essen“ die entsprechende Arbeit als „gegenwärtig abgeschlossen und ausgegeben“ erwähnt: „Der Personenverkehr, insbesondere der Pendelverkehr der Berufstätigen im Ruhrgebiet.“

164 RWI-Archiv: Aktenband RWI 121: 4, System Kehrl, Mai 1943, Masch. Manuskript und Grafiken zu den Systemen Kehrl und Speer; Akte RWI 121: 5, Ohne Titel, 1943, Masch. Manuskript, Grafiken zu den Systemen Kehrl und Speer und masch. Auszug aus dem Erlass des Reichsministers für Rüstung und Kriegsproduktion über die Aufgabenverteilung in der Kriegswirtschaft vom 20.10.1943.

165 RWI-Archiv: Aktenband RWI 121: 2, Meurer, A. (Autor nach der Unterschrift am Schluss des Gutachtens), Gutachten zu der Frage: Haben die Gemeinden des Ruhrgebiets durch finanz- und steuerpolitische Maßnahmen industrielle und andere Unternehmen herangezogen und dadurch die „Ballung“ im Ruhrgebiet vergrößert? Masch. Manuskript, 23 S. Essen 10.5.43. 
steuerpolitische Maßnahmen der Gemeinden veranlasst wurden, sich im Ruhrgebiet anzusiedeln."

Neben der besonders engen Zusammenarbeit mit dem „Siedlungsverband Ruhrkohlenbezirk - Essen“, „für den auch laufend Statistiken aufgestellt wurden“, verwies der Tätigkeitsbericht darauf, dass das RWI über die „,bestehenden Beziehungen zu Wirtschaft und Verwaltung“ hinaus „besonders solche zu den Organen der totalen Kriegswirtschaft [Hervorhebung R.F.] gepflegt bzw. eingeleitet“ hatte. „Genannt seien die militärischen Stellen, wie der Kommandeur des Rüstungsbereichs, der Rüstungsobmann u.a., ferner einzelne Präsidenten der neuen Gauwirtschaftskammern, die Landesplanungsbehörde der Rheinprovinz, die Landesarbeitsämter Rheinland und Westfalen, die Hochschul-Arbeitsgemeinschaft der Universität Köln.“

Der Tätigkeitsbericht für das Geschäftsjahr 1943/44, ${ }^{166}$ der den Mitgliedern des Verwaltungsausschusses und des Kuratoriums des Rheinisch-Westfälischen Instituts für Wirtschaftsforschung wegen der „Feindeinwirkungen“ (u.a. mehrfache Bombardierung) mit Verspätung erst am 19. September 1944 zuging, führte eine ganze Reihe von bereits „abgeschlossenen und ausgegebenen“ wissenschaftlichen Arbeiten auf. Das war keine sieben Monate vor dem Kriegsende. Der entsprechende Abschnitt des Geschäftsberichtes findet sich vollständig weiter unten. Etliche Arbeiten waren bereits mit dem Geschäftsbericht des Vorjahres aufgeführt und kommentiert worden. Auch sie werden hier für einen vollständigen Gesamtüberblick wiedergegeben. Zudem trugen einige Arbeiten zum Teil deutlich veränderte Titel. Leider verzeichnet der Geschäftsbericht 1943/44 im Gegensatz zum Vorjahr (mit der schon beschriebenen Ausnahme: Nr. 1) nicht die Auftraggeber der Arbeiten. In einem der Einleitung zur Liste vorgeschalteten Absatz wurde die verzögerte Fertigstellung der Arbeiten begründet:

Die wissenschaftliche Tätigkeit des Instituts wurde mithin in wesentlich höherem Maße als zuvor durch die Kriegsereignisse beeinträchtigt. Desgleichen wurde dadurch die Veröffentlichung von Manuskripten erschwert oder verzögert. Die zunehmenden Schwierigkeiten der Drucklegung wirkten sich mehrfach in derselben Richtung aus. Somit verblieb Ende des Geschäftsjahres 1943/ 44 ein erheblicher Überhang, und da inzwischen von dem neuen Geschäftsjahr 1944/45 bereits ein größerer Teil verflossen ist, sei im Folgenden ein Gesamtbericht erstattet. Hierbei seien zunächst diejenigen Arbeiten aufgeführt, die gegenwärtig abgeschlossen und ausgegeben sind.

1. Denkschrift über die wirtschaftliche und verkehrsmäßige Einheit des rheinisch-westfälischen Industriegebietes. Die vom Siedlungsverband Ruhrkohlenbezirk angefertigte und für den Reichskommissar bestimmte Denkschrift mit Tabellen und Karten, an der das Institut mitgearbeitet hatte, wurde im zweiten Druck fertiggestellt. ${ }^{167}$

2. Die Entwicklung der rheinisch-westfälischen Eisenindustrie und des Ruhrkohlenbergbaus seit Kriegsausbruch. Ihre Veröffentlichung erfolgte als Heft 5 des Instituts. ${ }^{168}$

166 WWA K1 Nr. 2080.

167 Nr. 4 im Tätigkeitsbericht für das Geschäftsjahr 1942/43.

168 [Däbritz, Walther], Die Entwicklung der rheinisch-westfälischen Eisenindustrie und des Ruhrkohlenbergbaus seit Kriegsausbruch (Rheinisch-Westfälisches Institut für Wirtschaftsforschung Essen H. 5), hektographiert, Essen 1943. 
Dieses nur 16 Schreibmaschinenseiten umfassende Heft hatte Däbritz selbst geschrieben. Ein Auftraggeber wurde nicht genannt. Bemerkenswert sind die Zahlenangaben bis weit in das Kriegsjahr 1943 hinein. Geschildert wird u. a. zudem, wie schlechtes Wetter die Zufuhr der Rohstoffe (Eisenerz) beeinträchtigte, wie durch den Einsatz von Kriegsgefangenen die Arbeitsproduktivität sank und wie sich die Bombenangriffe auswirkten. Däbritz konnte offensichtlich mit den Produktionsergebnissen in der Kriegswirtschaft auf geheimes Material zugreifen.

3. Der Personenverkehr, insbesondere der Pendelverkehr der Berufstätigen im Ruhrgebiet. Heft $6 .{ }^{169}$

4. Die Struktur der rheinisch-westfälischen Industrie. Eine vergleichende Analyse auf Grund der Produktions- und Absatzstatistik. Heft $\mathbf{7}^{170}$

Diese als „Geheim“ eingestufte Studie - ein Verfasser wird nicht genannt - stützte sich allerdings nicht auf die Originalerhebung, sondern auf die problematische veröffentlichte Version des Industriezensus von 1936. ${ }^{171}$

5. Großbritanniens Kohlenbergbau und Kohlenwirtschaft im gegenwärtigen Kriege. Heft $8 .{ }^{172}$

6. Der Ruhrkohlenbergbau. Ein Vergleich der Entwicklung im ersten und zweiten Weltkrieg. Heft $9 .{ }^{173}$

Diese Arbeit vergleicht Zeitreihen für den Ersten (1914-1918) und Zweiten Weltkrieg (1939-1943), teilweise mit Monats-, Quartals- und Halbjahreszahlen, vor allem über die Steinkohleförderung, Kokserzeugung und Belegschaft.

7. Die Westdeutschen Gaue. Darstellung und Vergleich von Struktur und Bedeutung nach dem Stand der Volks-, Berufs- und Betriebszählung vom 17.5.1939. Heft 10. ${ }^{174}$

169 Nr. 8 im Tätigkeitsbericht für das Geschäftsjahr 1942/43. Wiel, Paul, Der Personenverkehr, insbesondere der Pendelverkehr der Berufstätigen im Ruhrgebiet (Rheinisch-Westfälisches Institut für Wirtschaftsforschung Essen, H. 6), hektographiert, Essen 1944.

170 Schriftenreihe des Rheinisch-Westfälischen Instituts für Wirtschaftsforschung Essen, hektographiert, Essen 1944.

171 RWP 1939. Wichtige Informationen des Industriezensus wurden allerdings gar nicht oder irreführend veröffentlicht, siehe Fremdling/Stäglin 2012.

172 Im Vorwort vom Mai 1944 dieser ebenfalls „nur für den Dienstgebrauch“ (durchnummeriert) zugänglichen Arbeit erwähnte Däbritz, ohne sie genau anzugeben, dass die „darin enthaltenen Angaben [...] zum erheblichen Teil auf vertraulichem Material“ beruhten.

173 Der Ruhrkohlenbergbau. Ein Vergleich der Entwicklung im ersten und zweiten Weltkrieg (Rheinisch-Westfälisches Institut für Wirtschaftsforschung Essen, H. 9), Essen 1944. Nachdem sich die Drucklegung durch „Feindeinwirkung“ verzögert hatte, schrieb Däbritz das Vorwort im Mai 1944.

174 Teilweise dieselbe Datenbasis wie Nr. 2 im Tätigkeitsbericht für das Geschäftsjahr 1942/43. 
Diese als „Geheim“175 eingestufte Studie, verfasst von Else Moldrings, stützte sich teilweise auf unveröffentlichtes Zahlenmaterial der 1939er Zählung, das von der Reichsstelle für Raumordnung zur Verfügung gestellt worden war. ${ }^{176} \mathrm{Im}$ Vorwort erläuterte Däbritz die neue Verwaltungseinteilung in Gaue. Am Schluss erörterte Moldrings strukturelle Veränderungen während des Krieges.

8. Zahlen zu Bevölkerung und Wirtschaft des Ruhrbezirks 1939. Ergebnisse der Volks- und Betriebszählung vom 17.5.1939. Heft $11 .{ }^{177}$

Dieses Heft brachte eine reine Datensammlung in tabellarischer Form. Den Statistiken lagen Vorveröffentlichungen des StRA im Statistischen Jahrbuch des Deutschen Reichs von 1941/42 und in Wirtschaft und Statistik sowie Teilveröffentlichungen in der Statistik des Deutschen Reichs zugrunde. Däbritz schrieb im Vorwort vom Juni 1944 allerdings, dass die „unveröffentlichten Zahlen“ der Betriebsstatistik, die „vertraulich zu behandeln“ seien, durch die Vermittlung der Reichsstelle für Raumordnung dem Institut zur Verfügung gestellt worden seien.

9. Der Steinkohlenbergbau der Niederlande und seine Wettbewerbslage gegenüber dem Ruhrrevier. $\underline{\text { Heft } 12 .} .^{178}$

Nichtgenannter Autor dieser Arbeit, wie auch von Heft 18, war Ferdinand Friedensburg, der nach dem Krieg Ernst Wagemann als Präsidenten des DIW ablöste und diese Funktion von 1945 bis 1968 bekleidete. ${ }^{179}$ Zuvor hatte Friedensburg als Gegner des NS-Regimes lediglich als „Auswärtiger Mitarbeiter“ für das DIW gearbeitet. ${ }^{180}$ In seinen „Lebenserinnerungen“ beschrieb Friedensburg seine damalige Stellung so: „Der Leiter der Zweigstelle des Instituts, Professor Dr. Däbritz, lieh mich für seine Aufgaben aus“, um diese „größere Denkschrift“ zu verfassen. Im Februar 1944 hatte Friedensburg die Zechen in den Niederlanden besucht, wo man ihn in Unkenntnis über seine

175 „Geheim! Dieses Heft ist ein Staatsgeheimnis im Sinne des $\S 88$ RStGB. [...] Es darf nur verschlossen, bei Postbeförderung eingeschrieben, weitergegeben werden. Der Empfänger haftet für eine sichere Aufbewahrung. 53 Seiten Text, 18 Tabellen, 12 Karten, Nummer 8“.

176 Moldrings, E., Die Westdeutschen Gaue. Gaue Düsseldorf, Essen, Köln-Aachen, Moselland, Westfalen-Süd, Westfalen-Nord. Darstellung und Vergleich von Struktur und Bedeutung nach dem Stande der Volks-, Berufs- und Betriebszählung vom 17.5.1939 (Rheinisch-Westfälisches Institut für Wirtschaftsforschung Essen, H. 10), Essen 1944.

177 Zahlen zu Bevölkerung und Wirtschaft des Ruhrbezirks. Ergebnisse der Volks-, Berufs- und Betriebszählung vom 17. Mai 1939 (Rheinisch-Westfälisches Institut für Wirtschaftsforschung Essen, H. 11), hektographiert, Essen 1944. Teilweise handelt es sich um dieselbe Datenbasis wie Nr. 2 im Tätigkeitsbericht für das Geschäftsjahr 1942/43.

178 Schriftenreihe des Rheinisch-Westfälischen Instituts für Wirtschaftsforschung Essen, Essen 1944. 179 Krengel 1986, S. 78 ff.; Roelevink 2015, S. 387 ordnet diese Arbeit irrtümlicherweise Däbritz zu. 180 Friedensburg $(1943,1944)$ publizierte während des Krieges umfangreiche Bücher über die „Rohstoffe und Energiequellen im neuen Europa“ und über die „Bergwirtschaft der Erde, Bodenschätze, Bergbau und Mineralölversorgung der einzelnen Länder“ (mehrere Auflagen, die sechste 1965). 
Regimegegnerschaft mit „wenig verhüllter Abneigung“ empfangen hatte. Er hatte nicht riskieren wollen, seine oppositionelle Haltung $\mathrm{zu}$ offenbaren. ${ }^{181}$

10. Die Landwirtschaft der Niederlande mit besonderer Berücksichtigung ihrer Beziehungen $\mathrm{zu}$ Rheinland und Westfalen. Heft $13 .^{182}$

11. Die Gaue Düsseldorf und Essen in Zahlen nach dem Stand der Berufs- und Betriebszählung vom 17.5.1939. Heft $14 .^{183}$

Unmittelbar vor der Ausgabe standen folgende Arbeiten:

1) Der Güterverkehr des Ruhrgebiets im Kriege. ${ }^{184}$

Im Vorwort vom September 1944 verwies Däbritz auf die schwierige Quellenlage: Aus den „Grundstatistiken“, die vollständig nur bis 1941 vorlagen, und weiteren Zahlen zur Güterbewegung hatte Wiel ${ }^{185}$ detaillierte Versand- und Empfangsstatistiken nach Verkehrsbezirken, z. B. für Kohle in den Jahren 1938 bis 1941, zusammengestellt. Wiel arbeitete u.a. die Verschiebung der Verkehrsströme vom Rhein und den niederländischen Seehäfen (Blockade) zu den deutschen Nordseehäfen sowie die Versorgung Norddeutschlands mit Ruhrkohle heraus. Däbritz: „Eine Ergänzung für den weiteren Kriegsverlauf soll einer späteren Untersuchung vorbehalten bleiben.“ Ein Auftraggeber wurde nicht genannt.

2) Der Arbeitseinsatz in Rheinland-Westfalen während des jetzigen Weltkrieges unter besonderer Berücksichtigung der ausländischen Arbeiter und Kriegsgefangenen. ${ }^{186}$

Däbritz nannte in seinem Vorwort vom September 1944 keinen Auftraggeber. Grundlage der quantitativen Analyse waren die „Arbeitsbucherhebungen und Sondererhebungen über den Kriegsgefangeneneinsatz“ der Landes- bzw. Gauarbeitsämter. In

181 Friedensburg 1969, S. 296. Ein Durchschlag des maschinenschriftlichen Manuskripts der RWISchrift mit Friedensburg als Autor befindet sich in der Bibliothek des DIW. Die Hinweise zu Friedensburg erhielt ich von der Bibliothekarin des DIW, Katharina Zschuppe.

182 Nr. 1 im Tätigkeitsbericht für das Geschäftsjahr 1942/43. Cless, Herta, Die Landwirtschaft der Niederlande unter besonderer Berücksichtigung ihrer Beziehungen zu Rheinland und Westfalen (Schriftenreihe des Rheinisch-Westfälischen Instituts für Wirtschaftsforschung Essen, 12), Essen 1944. 183 Teilweise dieselbe Datenbasis wie Nr. 2 im Tätigkeitsbericht für das Geschäftsjahr 1942/43. Als Heft 14 der Schriftenreihe des Rheinisch-Westfälischen Instituts für Wirtschaftsforschung Essen, hektographiert, 1944 erschienen. Dieses Heft, das offensichtlich eine Ergänzung von Moldrings Studie (Nr. 10) ist, besteht nur aus Tabellen (Stadt-, Landkreise, Gemeinden von mehr als 10.000 Einwohnern). 184 Wiel, Paul, Der Güterverkehr des Ruhrgebietes im Kriege (Rheinisch-Westfälisches Institut für Wirtschaftsforschung Essen, H. 15), hektographiert, Essen 1944.

$185 \mathrm{Zu}$ Paul Wiel siehe Engels 2007, S. 311, Anm. 1411.

186 Odenthal, Matth., Die Entwicklung des Arbeitseinsatzes in Rheinland und Westfalen unter besonderer Berücksichtigung der Ausländer und Kriegsgefangenen 1938-43 (Rheinisch-Westfälisches Institut für Wirtschaftsforschung Essen, H. 16), Essen 1944. 
der erstaunlich sachlich gehaltenen umfangreichen Untersuchung gab Odenthal ${ }^{187}$ auch Einschätzungen zur Arbeitsproduktivität der Kriegsgefangenen wieder, die Däbritz als „subjektive Urteile des Bearbeiters“ qualifizierte. Z. B. schätzte Odenthal die Produktivität der russischen Kriegsgefangenen unter Tage in den Zechen folgendermaßen ein: „Die Leistungen liegen zwischen 60 und 80 v.H. der vergleichbaren deutschen Arbeitskräfte und werden als befriedigend bis gut bezeichnet. Ebenso ihre Arbeitsdisziplin und das sonstige Verhalten.“ Odenthals Datenmaterial und seine Analyse verdienten es, für historische Untersuchungen herangezogen zu werden.

Ferner wurden fortgeführt:

1) Die Konjunkturstatistik (Statistik der wichtigsten Wirtschaftsvorgänge der rheinisch-westfälischen Wirtschaft). ${ }^{188}$

2) Eine Untersuchung über den Gesundheitszustand der Bergarbeiter im ersten und zweiten Weltkrieg.

Vorgesehen waren Untersuchungen über:

1) Die Eisenerzversorgung Europas unter dem Gesichtspunkt des rheinisch-westfälischen Industriebezirks. ${ }^{189}$

2) Eine Untersuchung des Kohlenbergbaus und der Kohlenwirtschaft der USA im gegenwärtigen Weltkrieg ${ }^{190}$ (Gegenstück zu der Untersuchung über den englischen Steinkohlenbergbau in Heft 6).

Im Gesamtbericht und auch in Übersichten nach dem Krieg bleibt eine Arbeit unerwähnt, die als umfängliche (fehlerbehaftete) Korrekturfahne von über siebzig Seiten in der Bibliothek des RWI überliefert ist: „Auswirkungen des gegenwärtigen Krieges auf die Weltkohlenwirtschaft“, Essen 1945. Als „Bearbeiter“ ist handschriftlich „Dr. Friedensburg“ eingetragen. Nach dem Vorwort, das Däbritz im Februar 1945 geschrieben hatte, brachte die „Schrift [...] den ersten Teil einer Untersuchung, die sich zur Aufgabe gestellt hat, dir [sic] durch den jetzigen Krieg bewirkten und noch zu erwartenden Veränderungen innerhalb der Weltkohlenwirtschaft nach ihren mengenmäßigen und zeitlichen Ausmaßen zu ermitteln.“ In diesem vorliegenden Teil wurde die Veränderung der Förderkapazitäten während des Krieges festgestellt, und dem zweiten (nicht vorliegenden) Teil blieb der „Kohlebedarf sowie die voraussichtliche Entwicklung der Weltkohlenwirtschaft in der Nachkriegszeit“ vorbehalten. Die Arbeit legte praktisch für alle kohlefördernden Länder der Welt eine Kurzbeschrei-

$187 \mathrm{Zu}$ Matthias Odenthal siehe Engels 2007, S. 311, Anm. 1411.

188 Vgl. Nr. 3 im Tätigkeitsbericht für das Geschäftsjahr 1942/43.

189 Kurz vor Kriegsende (Vorwort von Däbritz vom Februar 1945) als Heft 18 der Schriftenreihe des Rheinisch-Westfälischen Instituts für Wirtschaftsforschung Essen 1945 unter dem Titel „Neue Aufgaben in der Eisenerzversorgung der europäischen Länder“ erschienen. Der nicht genannte Verfasser war, wie von Heft 12, Ferdinand Friedensburg. Siehe das Verzeichnis von Fontenay 1973.

190 Als Heft 17 der Schriftenreihe des Rheinisch-Westfälischen Instituts für Wirtschaftsforschung Essen 1944 erschienen. 
bung vor, die quantitativ mit Förderzahlen und Außenhandelsdaten für Stichjahre vor und während des Krieges unterbaut waren. Für 1945 wurde jeweils die „Förderung“ von Kohle geschätzt. Es ist unklar, warum die Arbeit nicht mehr als Teil der Schriftenreihe erschienen ist.

Sie wurde auch nicht im folgenden Abschnitt des Gesamtberichtes erwähnt, der die „Themen“ aufführte, die „zurückgestellt oder aufgegeben“ wurden. Genannt waren:

1) Die bereits in Angriff genommenen Kreisbeschreibungen (Grund: nicht kriegswichtig). ${ }^{191}$

2) Untersuchungen über die Wasserwirtschaft des Reviers (Grund: Materialschwierigkeiten).

3) Untersuchungen über den Einsatz der Frauenarbeit im jetzigen Kriege (vielleicht später in Angriff zu nehmen).

4) Regionalplanungen in Kohle und Eisen (Bedenken seitens der beiden Reichsvereinigungen).

Die Bedenken wurden leider nicht spezifiziert. Kohle und Eisen waren für die Kriegswirtschaft nicht nur Vorprodukte für zahlreiche Produktionsprozesse, sondern wegen dieser Eigenschaft auch Schlüsselerzeugnisse, um die Herstellung der nachgelagerten Produktionsstufen über die „Schlüsselgrößen“ (technische bzw. mengenmäßige Input-Output-Koeffizienten) zu steuern. Die dem StRA und dem Planungsamt des Rüstungsministeriums von den Lenkungsbereichen, z. B. der Reichsgruppe Industrie, gelieferten Daten dieser Schlüsselindustrien unterlagen besonderen Geheimhaltungsvorschriften. ${ }^{192}$ Jedoch muss das RWI nach wie vor einen privilegierten Zugang zu „kriegswichtigen“ Daten gehabt haben, um seine Beratungs- und Forschungstätigkeit aufrechterhalten zu können. Der folgende Absatz aus dem Tätigkeitsbericht 1943/44, der im Herbst 1944 verfasst wurde, macht deutlich, dass „Kriegswichtigkeit“ der Zentralbegriff für die Arbeit des Instituts war.

„Auch weiterhin wird sich das Institut der Bearbeitung von Einzel- und Sonderproblemen zu widmen haben. Es bleibt ferner laufend damit befaßt, andere Stellen, die an das Institut herantreten, mit Material zu beliefern, Auskünfte verschiedenster Art zu geben, gutachtliche Äußerungen zu erstatten usw. Im ganzen aber hat das Institut diese Einzeluntersuchungen zurückgestellt und seine Arbeit unter dem Gesichtspunkt der Kriegswichtigkeit straff zusammengefaßt.“ (Hervorhebung R.F.)

Im letzten Teil des Tätigkeitsberichtes für 1943/44 wurden im „Arbeitsplan für das Geschäftsjahr 1944/45“ explizit „Überlegungen“ zur Aufgabe des RWI nach dem Krieg gestellt: Neben den geplanten „Städtemonographien“ ging es um die „Fragen des Wiederaufbaus nach Friedensschluß“.

191 Vgl. Nr. 6 im Tätigkeitsbericht für das Geschäftsjahr 1942/43.

192 Siehe die Rundschreiben des RWM zum Veröffentlichungsverbot bei Kriegsbeginn 1939, BA R3102/3082 F. 28, 30 und passim. Ausführlich zum Planungsprozess in der Kriegswirtschaft Fremdling 2016a und der Abschnitt über das DIW mit seiner Industrieabteilung in der Kriegswirtschaft. 
Für die vorgesehenen „Städtemonographien“ sollte das Institut mit der „Hochschul-Arbeitsgemeinschaft der Universität Köln“ zusammenarbeiten. Der Tätigkeitsbericht für 1942/43 hatte unter den „Organen der totalen Kriegswirtschaft“, zu denen „besondere Beziehungen [...] gepflegt bzw. eingeleitet“ waren, auch diese „Hochschul-Arbeitsgemeinschaft“ bereits aufgeführt. ${ }^{193}$ Mit dem letzten Tätigkeitsbericht des RWI im Krieg für das Geschäftsjahr 1943/44 und dem Arbeitsplan für das Geschäftsjahr 1944/45, ${ }^{194}$ der die Brücke zur Nachkriegszeit bauen sollte, wird die enge Verbindung zur Raumwirtschaftsforschung und zur Universität Köln inhaltlich belegt: So plante man, sich an dem Projekt „Städtemonographien“ zu beteiligen, das die „Reichsarbeitsgemeinschaft für Raumforschung, Berlin“ und die „Hochschularbeitsgemeinschaft für Raumforschung an der Universität Köln“ verfolgten. Geplant waren „systematisch über ganz Deutschland erstreckte Großstadtmonographien“, welche die „historischen, geographischen, sozialen und kulturellen Entwicklungen im Hinblick auf ihre künftige Struktur, ihre zukünftigen Aufgaben und die zu erwartenden Probleme“ darlegten. Daraus sollten „wertvolle grundsätzliche Erkenntnisse für die Neuordnung des deutschen Wirtschaftsraumes abgeleitet werden.“ „Wie immer man über diese Zielsetzung denken“ möge, erschien „es vom Standpunkt des Reviers als erwünscht, daß derartige Untersuchungen, soweit sie das Revier betreffen, an Ort und Stelle vorgenommen“ würden. Aus diesem Grunde schaltete sich das Institut ein und wollte „eine Reihe derartiger Städtemonographien für den rheinischen Teil des Reviers durchführen“. Eingebettet war dieses Forschungsprogramm in die bereits erwähnten breiter angelegten „Fragen des Wiederaufbaus nach Friedensschluß“, die sich das RWI im Herbst 1944 stellte. ${ }^{195}$

Eine Planung der Nachkriegszeit war eigentlich sogar noch in den letzten beiden Kriegsjahren verboten. ${ }^{196}$ Offensichtlich ließ sich dieses Verbot jedoch nicht mehr durchsetzen, sodass die Nachkriegsorientierung des RWI keine Ausnahme bildete. Selbst das RWM beschäftigte sich mit grundlegenden Fragen über die deutsche und europäische Wirtschaft nach dem Krieg.

In dem im Herbst 1943 reorganisierten RWM $^{197}$ übernahm der SS-Brigadeführer Ohlendorf ${ }^{198}$ (Chef des SD-Inland und Hauptabteilungsleiter im RSHA) parallel zu

193 Tätigkeitsbericht des Deutschen Instituts für Wirtschaftsforschung, Abteilung Westen, für das Jahr 1943/43 vom 16.6.1943, RWI-Archiv Akte Chronik: S. 3.

194 WWA K1 Nr. 2080.

195 Das Anschreiben von Däbritz an die „Mitglieder des Verwaltungsausschusses und des Kuratoriums des Rheinisch-Westfälischen Instituts für Wirtschaftsforschung“, denen der Bericht und der Arbeitsplan vorgelegt wurden, datiert vom 19.9.1944, WWA K1 Nr. 2080.

196 Erneut im Führererlass vom 25.7.1944 bekräftigt, Herbst 1982, S. 389. Zu den folgenden Ausführungen siehe ebd. S. 387 ff.; zum Stahl-Kreis siehe mit anderer Akzentuierung als Herbst auch Roth 1996, S. $585 \mathrm{ff}$.

197 Mit der Gründung des Planungsamts und der Übersiedlung der Hauptabteilung II unter der Leitung von Hans Kehrl in das von Speer geleitete Reichsministerium für Rüstung und Kriegsproduktion (RMRuK) büßte das RWM wesentliche der seit Mitte der 1930er Jahre erworbenen Mitwirkungskompetenzen in der Kriegswirtschaft ein. Siehe Führererlass vom 2. September 1943. Boelcke 
seinen bisherigen Funktionen bei der SS als stellvertretender Staatssekretär ab November 1943 die neue Hauptabteilung II, die alle Grundsatzreferate des RWM zusammenfasste. ${ }^{199}$ Mit dem September-Erlass war das RWM zudem für alle annektierten und besetzten Gebiete zuständig und befasste sich unter Ohlendorfs Führung konsequenterweise grundsätzlich auch mit der Wirtschaftspolitik auf europäischer Ebene. ${ }^{200}$ Ordnungspolitisch wurde im RWM ein Gegenpol zur straffen staatlich gelenkten Kriegs- und Planwirtschaft Speerscher Prägung aufgebaut. ${ }^{201}$ Jedoch ging auch das RWM als „Führungsministerium““202 selbstverständlich von einer staatlichen Lenkungskompetenz ${ }^{203}$ unter seiner Federführung bei der Organisation der Nachkriegswirtschaft ${ }^{204}$ aus, sodass erklärbar wird, warum im Ministerium trotz der absehbaren Kriegsniederlage ${ }^{205}$ zukunftsorientiert mit einer „Zentralstelle für Wirtschaftsforschung“206 an einem volkswirtschaftlich-statistischen Informationssystem als wirtschaftspolitischem Lenkungsinstrument geschmiedet wurde. Das RWM sollte zu einem „Wirtschaftsforschungsministerium“ entwickelt werden, um „Aufgaben einer wirklich zentralen Wirtschaftsplanung und Wirtschaftsforschung“ nachzukommen. ${ }^{207}$ Bedeutsamer für die Wirtschaftspolitik in Westdeutschland nach dem Krieg war allerdings die Aktivität Ludwig Erhards, die sich am Ende des Krieges im „StahlKreis“ manifestierte: Im Frühjahr 1944 hatte sich dieser Arbeitskreis unter Federführung des stellvertretenden Leiters der Reichsgruppe Industrie Stahl gebildet, der von

1983, S. 297. Zu den Aufgaben des Planungsamts siehe den Erlass des zuständigen Ministers (Speer) vom 16.9.1943, BA R3102/3589 F. $46 \mathrm{ff}$.

198 Herbst 1982, S. 259, 269 u. passim; Boelcke 1983, S. 300 ff. Nach einer Aktennotiz des RWM vom 13.12.1944 (BA R3101/32119) wird Ohlendorf als „SS-Gruppenführer“ bezeichnet. Er war also in der Rangordnung der SS aufgestiegen.

199 Nach Herbst (1982, S. 187) wurde Ohlendorf heimlicher RWM. Seine Vorgesetzten, der Minister Funk und Staatssekretär Hayler, gelten gemeinhin als schwache Führungsfiguren.

200 Herbst 1982, S. 272. Ohlendorfs Grundsatzreferat hieß: „Grundsätzliche Fragen der Wirtschaftspolitik im Reich und im europäischen Raum“. Ebd. S. 291. Siehe auch Boelcke 1983, S. 305 f.

201 Herbst 1982, S. 276 ff.; siehe auch Roth 1996, S. 580 ff.

202 Siehe Lücks Ausführungen vom 18.8.1944, BA R3101/32131, F. 5.

$203 \mathrm{Zu}$ den ordnungspolitischen Vorstellungen im RWM siehe Herbst 1982, S. $300 \mathrm{ff}$.; $337 \mathrm{ff}$.; $437 \mathrm{ff}$. Dagegen die Auffassung des Planungsamtes (Kehrl), ebd. S. 339; 437 ff. Zur ordnungspolitischen Diskussion und Fortführung der NS-Bewirtschaftungsmaßnahmen nach 1945 in den Westzonen siehe Abelshauser 2004, S. $89 \mathrm{ff}$.

204 „Auch der Ordoliberalismus der Freiburger Schule um Franz Böhm und der Reformliberalismus eines Alfred Müller-Armack oder Ludwig Erhard, der schon 1933 die Umrisse der später so genannten sozialen Marktwirtschaft erkennen ließ, sahen nach der Katastrophe der frühen dreißiger Jahre in einem ,starken Staat' die Voraussetzung, um der von ihnen konzipierten Ordnungspolitik die notwendige Geltung zu verschaffen.“ Abelshauser 2004, S. 59, $92 \mathrm{ff}$.

205 Nach Herbst (1982, S. 346) ging man Mitte 1944 durchaus davon aus, „daß der Apparat des Ministeriums [RWM] im Falle einer totalen Niederlage überleben werde [...]“. Nach Roth (1996, S. 596f.) wurde erst ab Ende Januar/Anfang Februar 1945 mit einer bedingungslosen Kapitulation, alliierter Besetzung und dem Ende einer deutschen Zentralregierung gerechnet.

206 Siehe die Akte BA R3101/32119.

207 Herbst (1982, S. 447) zitiert Ohlendorf aufgrund der Akten im Januar 1945. 
der Denkschrift Ludwig Erhards ausgehend die wirtschaftliche Demobilisierung erörterte. ${ }^{208}$ Ergebnisse des Arbeitskreises wurden führenden Industriellen Ende $\mathrm{Au}$ gust/Anfang September 1944 zugänglich gemacht. ${ }^{209}$ Wegen der untersagten Beschäftigung mit Nachkriegsproblemen hielt sich der Stahl-Kreis zunächst gegenüber Behörden zurück. $\mathrm{Zu}$ tastenden Annäherungen des Kreises an das Reichswirtschaftsministerium und seinen führenden Kopf Ohlendorf ${ }^{210}$ kam es erst im November/Dezember 1944..$^{211}$

Däbritz hielt sich denn auch nicht bedeckt und schrieb bereits im Januar 1944 in der Rheinisch-Westfälischen Zeitung, also für die Öffentlichkeit: ${ }^{212}$ „Es ist selbstverständlich, daß die Arbeiten des Essener Instituts zur Zeit kriegsbedingt sind, daß ihm aber auch nach Kriegsende für den Wiederaufbau und die Friedenswirtschaft ein weites Feld der Tätigkeit offensteht. “ Ausführlicher war der interne Tätigkeitsbericht für 1943/44: „Es gehört zu den wichtigsten Überlegungen, wie sich nach Beendigung der Kriegshandlungen und dem Wiedereintritt friedensähnlicher Verhältnisse die Wirtschaft des Reviers gestalten wird. Diese Frage führt zurück zur Besinnung auf die Struktur des Reviers, seine ökonomischen und insbesondere standortmäßigen Bedingungen. Unter diesem Hauptgesichtspunkt sind eine Reihe von Spezialuntersuchungen in Angriff genommen worden, die zunächst folgenden Wirtschaftszweigen gelten:

1) Ruhrkohlenbergbau

2) Eisen schaffende Industrie

3) Eisen verarbeitende Industrie

4) Verbrauchsgüterindustrien.

Weitere Wirtschaftszweige (Kraftwirtschaft, Wasserwirtschaft, Verkehr u.a.m.) sollen angeschlossen werden.

208 Zur Rolle Ludwig Erhards siehe Herbst (1982, S. 383 ff.) und Roth (1996, S. 548 ff.; zur Denkschrift ebd. S. 556 ff.). Siehe das Protokoll einer Besprechung zwischen Stahl, Erhard und Grünig vom 5.5.1944 (BA R11/2171 F. 431-433): Es ging um eine Stellungnahme zur Erhardschen Denkschrift und Beratung über die „spätere Umstellung der Kriegswirtschaft auf die Friedenswirtschaft.“ In der Akte befindet sich auch ein langer Brief (Kommentar) von Pietzsch (Reichswirtschaftskammer) an seinen Mitarbeiter Grünig über dieses Protokoll (ebd. F. 429f.).

209 Herbst 1982, S. 387. Siehe (ohne Datum) „Reichsgruppe Industrie Programm für die Bearbeitung wirtschaftlicher Nachkriegsprobleme vom Standpunkt der Industrie“ BA R11/2171 F. 434-436 RS. Der zweiseitige Arbeitsplan verzeichnet als „Bearbeiter“ u.a. Erhard und Grünig.

210 Zu den Nachkriegsplanungen Ohlendorfs im RWM siehe Fremdling 2016a.

211 Herbst 1982, S. 389; Roth 1996, S. 588. Stahl leitete im November 1944 weitere Ausarbeitungen der Erhardschen Denkschrift und zusätzliches Material des Arbeitskreises an Ohlendorf und vermittelte direkte Kontakte zwischen Ohlendorf und Erhard. Siehe Brief von Stahl an Ohlendorf vom 14.11.1944, BA R3101/32131 F. 44.

212 RWI-Archiv Akte Chronik: Professor Dr. Däbritz, Essen, „Das Rheinisch-Westfälische Institut für Wirtschaftsforschung“, in: Rheinisch-Westfälische Zeitung, Nr. 12, 13.1.1944. 
Bei diesen Untersuchungen sollen unter den heutigen und den künftigen Gesichtspunkten geklärt werden die natürlichen Voraussetzungen, die geschichtlichen Gegebenheiten, die gegenwärtigen und künftigen Arbeits- und Absatzbedingungen. Es sollen die eingetretenen Kriegsschäden, die vorläufigen und die endgültigen Verlagerungen berücksichtigt werden und aus all diesen Voraussetzungen sollen prognostische Überlegungen abgeleitet werden.

Gleichzeitig sollen damit Beiträge für die Probleme der „Ballung“ bzw. „Entballung“ des Reviers gewonnen werden.“

Der letzte Teil des Tätigkeitsberichtes für 1943/44 und der „Arbeitsplan für das Geschäftsjahr 1944/45“ spannte also den Bogen zum Forschungsprogramm nach dem Krieg. Die Schriftenreihe des RWI mit weiter durchgezählten Heften ${ }^{213}$ wurde ohne Unterbrechung fortgeführt. Es gab keinen radikalen Neuanfang, vielmehr knüpften die meistens eher regional verankerten Themen aus dem rheinisch-westfälischen Raum methodisch routiniert kontinuierlich an die bisherige Forschungspraxis an. Die quantitative Quellenbasis stammte für die ersten Untersuchungen noch aus der NSZeit oder selbst aus davorliegenden Perioden. ${ }^{214}$ Einige im Krieg begonnene Arbeiten wurden erst nach dem Mai 1945 fertiggestellt. ${ }^{215}$ Nicht mehr auf der Agenda stand allerdings die Einordnung des rheinisch-westfälischen Raums in eine großräumliche Entwicklung unter deutscher Oberhoheit. Allenfalls wurde, wie von Däbritz 1948, relativ oberflächlich der europäische Einigungsprozess als wünschenswert herausgestellt. Die Ideen einer Europäischen Wirtschaftsgemeinschaft unter deutscher Führung aus der NS-Zeit unterschlug er kurzerhand, erwähnte hingegen den EuropaGedanken der Zwischenkriegszeit. ${ }^{216}$

Das RWI war weiterhin bestrebt, mit anderen Forschungsinstitutionen zu kooperieren. Doch kam erstaunlicherweise nach dem Krieg anscheinend keine enge Zusammenarbeit mehr mit dem Mutterinstitut in Berlin zustande, obwohl sich das

213 Däbritz 1947, Anlage IV, S. 33-35.

214 Abgesehen von Datenmaterial, welches das RWI selbst gesammelt und archiviert hatte, waren die wichtigsten Statistiken die periodischen Erhebungen des StRA über die Gewerbe-, Berufs- und Volkszählungen von 1925, 1933 und 1939. Hinzu kam der Industriezensus von 1936 als quantitative Quelle, jedoch ausschließlich in der umfangreichen, auch regional gegliederten, veröffentlichten Version von 1939. Aus kriegsstrategischen Erwägungen, die explizit im Vorwort diskutiert wurden, hatte die publizierte Version allerdings irreführende Aggregationen, Zuordnungen oder Auslassungen vorgenommen. Zu den Quellen siehe Fremdling 2005, 2007, 2010, $2016 \mathrm{a}$.

215 Z. B. Siedlungsverband Ruhrkohlenbezirk, Statistische Zusammenstellungen (Rheinisch-Westfälisches Institut für Wirtschaftsforschung Essen, H. 19), Essen 1945.

216 Däbritz, Walther, Europäische Wirtschaftsgemeinschaft (Rheinisch-Westfälisches Institut für praktische Wirtschaftsforschung, Essen, Volkswirtschaftliche Abteilung, H. 39), Essen 1948. Dieses dünne Heft druckte einen Vortrag ab, den Däbritz am 21.1.1948 bei der „Gemeinschaft Europa-Union, Kreisverband Essen“ gehalten hatte. Im dem geschichtlichen Überblick seit dem 19. Jahrhundert über die zentrale Stellung Gesamteuropas im Welthandel hob Däbritz vor allem auf die Verflechtung im intraindustriellen Handel ab, ohne den Begriff zu nennen: Deutschland führte Fertigwaren sowohl aus als auch ein. 
DIW unmittelbar nach dem Krieg noch als Institut für Gesamtdeutschland verstand. ${ }^{217}$ Auf die Frage des Kuratoriumsmitglieds v. Schumann ${ }^{218}$ auf der Sitzung im April 1948, „wie es mit der Zusammenarbeit mit den übrigen Instituten in Westdeutschland stehe, und wie sich die Zusammenarbeit bewähre“, antwortete Friedensburg: „Im November 1947 sei nach Berlin eine Tagung der Institute einberufen worden, die sich mit den gleichen Aufgaben beschäftigen. Diese Tagung habe leider nicht den erwünschten vollen Erfolg gehabt, weil eine Reihe von Vertretern aus politischen Gründen nicht hätte kommen können. Dagegen hätten das Bayerische, Württembergische und Hamburgische Institut an der Tagung teilgenommen, die von den Teilnehmern als wichtig und nützlich empfunden worden sei. Auch mit den Instituten in Essen und Kiel erfolge ein reger Gedanken- und Schriftenaustausch“. ${ }^{219}$ Nach dem Protokoll der Kuratoriumssitzung von Ende November 1948 wurde lediglich noch bekundet, mit den kleineren Instituten in Westdeutschland, ohne deren Namen zu nennen, „Fühlung aufrecht zu erhalten“. Jedoch habe die Zusammenarbeit mit dem Kieler Institut, dessen „besondere Zielsetzung [...] einen störenden Wettbewerb“ ausschließe, eine „erfolgreiche Entwicklung“ genommen. Konkret versuchte das DIW dagegen, mit den „Dienststellen des Vereinigten Wirtschaftsgebietes in Frankfurt/M. [...] eine regelmässige Zusammenarbeit“ herzustellen, „was bisher nicht gelungen sei. [...] Das werde deshalb besonders notwendig sein, weil immer wieder das Gerücht auftauche, in Frankfurt/M. solle ein Institut ähnlichen Charakters geschaffen werden wie in Dahlem.“220 Vorher waren bereits die Bemühungen, selbst eine eigene „Geschäftsstelle“ in Frankfurt zu gründen, gescheitert. ${ }^{221}$ Auch wenn Wagemann bis $1947^{222}$

217 Schon allein aus der umfassenden Mitgliederliste des Kuratoriums ist dies ersichtlich: Im November 1947 hatte das DIW 35 institutionelle Mitglieder, darunter mehrere Abteilungen des Magistrats von Groß-Berlin, den Freien Deutschen Gewerkschaftsbund, mehrere Parteien (SED, SPD, CDU, LDP), fünf Zentralverwaltungen der SBZ, die Deutsche Reichsbahn, drei Industrie- und Handelskammern der SBZ, Landesverwaltungen bzw. Länderministerien (Thüringen, Schleswig-Holstein, Bayern, Hamburg, Hessen, Sachsen-Anhalt), das Verwaltungsamt für Wirtschaft des amerikanischen und britischen Besatzungsgebietes in Minden, den Länderrat des amerikanischen Besatzungsgebietes in Stuttgart, zwei Berliner Unternehmen, das wirtschaftswissenschaftliche Seminar der Universität Halle und den Deutschen Landkreisrat. BA DY34/20402 Liste der Kuratoriumsmitglieder des Deutschen Instituts für Wirtschaftsforschung 14.11.47.

218 Er vertrat das Verwaltungsamt für Wirtschaft des Vereinigten Wirtschaftsgebietes, Frankfurt am Main, und das Land Württemberg-Hohenzollern.

219 Protokoll der Kuratoriumssitzung des DIW, 30.4.1948, BA DY34/20402.

220 „Mit den kleineren Instituten sei in jedem Falle versucht worden, die Fühlung aufrechtzuerhalten. Im Herbst vergangenen Jahres [1947] habe eine Konferenz in Berlin stattgefunden, die erfolgreich verlaufen sei, und diese Zusammenarbeit sehr glücklich eingeleitet habe.“ Protokoll der Kuratoriumssitzung des DIW, 29.11.1948, BA DY34/20402. Auf derselben Sitzung gab der DIW-Präsident Friedensburg bekannt, dass der spätere wissenschaftliche Direktor des RWI „Dr. Bauer [...] einer der drei ältesten und bewährtesten Mitglieder“ das DIW zusammen mit „Dr. Wolf“ und „Diplomkaufmann Nieschlag“ verlassen habe und „einem Ruf nach Westen gefolgt“ sei.

221 Protokoll der Kuratoriumssitzung des DIW, 30.4.1948, BA DY34/20402. 
formell noch Präsident des RWI blieb, dürfte sich die Tochter RWI bereits mit seinem Rückzug als DIW-Präsident zum Kriegsende vom DIW abgenabelt haben. ${ }^{223}$ Und Ferdinand Friedensburg war als Nachfolger Wagemanns ${ }^{224}$ beim DIW trotz seiner zeitweiligen Tätigkeit während des Krieges für das RWI wohl nicht stark an einer Wiederbelebung der Verbindung gelegen. Sie kam erst wieder 1949 mit der Initiative zustande, eine „Arbeitsgemeinschaft Deutscher Wirtschaftswissenschaftlicher Forschungsinstitute“ $\mathrm{zu}$ gründen. ${ }^{225}$

\subsection{Das DIW und das RWI als wissenschaftliche Institute}

Wo verorteten sich das DIW und auch das RWI im Spannungsverhältnis zwischen selbstbestimmter rein wissenschaftlicher Tätigkeit und der Auftragsforschung? Nach $\S 2$ der jeweiligen Satzung verfolgten beide den „ausschließlichen Zweck“ einer am Gemeinnutz ausgerichteten ,wissenschaftlichen Forschungstätigkeit“:226

DIW

Das Institut dient ausschließlich gemeinnützigen wissenschaftlichen Zwecken und hat die Aufgabe, die wirtschaftlichen Bewegungsvorgänge des In- und Auslandes zu erforschen und zu beobachten und auf Grund seiner Arbeiten Wirtschaft, Verwaltung und Wissenschaft durch Herausgabe von Veröffentlichungen sowie durch Erstattung von Gutachten usw. zu beraten. ${ }^{227}$

RWI

Der Verein dient ausschließlich gemeinnützigen Zwecken. Seine Aufgabe ist die wissenschaftliche Forschungstätigkeit mit besonderer Beziehung auf die rheinisch-westfälische Wirtschaft und

222 Er war auf der ersten Kuratoriumssitzung des RWI am 26.2.1943 für fünf Jahre zum Präsidenten gewählt worden. Sein Nachfolger wurde 1947 Kuske. Siehe dazu unten Toni Pierenkemper.

223 Auf der Kuratoriumssitzung des DIW vom 30.4.1948 wurde die Satzung des DIW nach dem Kontrollratsgesetz vom 26.2.1946 „Gesetz zur Regelung und Überwachung der wissenschaftlichen Forschung" entsprechend angepasst, sodass ehemalige NSDAP-Mitglieder, wie Wagemann, auch nach der Entnazifizierung kein Amt mehr im DIW hätten bekleiden können. Siehe Tagesordnungsvorschlag und Protokoll der Kuratoriumssitzung des DIW, 30.4.1948, BA DY34/20402.

224 Wagemann hatte bereits vor dem Ende des Krieges Wagenführ als seinen Stellvertreter mit der Amtsführung in Berlin betraut. Unmittelbar nach dem Krieg, Wagemann war nicht in Berlin, übertrug Wagenführ seine Vollmachten auf Friedensburg, der auf der ersten Kuratoriumssitzung des DIW nach dem Krieg, die faktisch eine Neukonstituierung des DIW war, am 14.7.1945 zum Präsidenten gewählt wurde. Krengel (1986, S. 74, 78f., 83ff.) schreibt allerdings nichts über eine formale Abwahl oder Entlassung Wagemanns als Präsident des DIW.

225 Siehe dazu unten Toni Pierenkemper.

226 Möglicherweise hatte der Verweis auf den Gemeinnutz rein steuerrechtliche Gründe (Abzugsfähigkeit von Spenden).

227 Bei der Gründung des IfK 1925 war das Institut laut Satzung formaljuristisch als ein „unselbständiges Zweckvermögen“ konzipiert. Siehe oben Gliederungspunkt 1.2.2. Zur Satzung des IfK von 1935 siehe Krengel 1986, S. 11. 
Verwaltung, ferner die Abfassung einschlägiger Arbeiten, Berichte und Gutachten sowie die Herausgabe von Veröffentlichungen.228

Mit dem Verhältnis zwischen selbstbestimmter wissenschaftlicher Tätigkeit und Auftragsforschung setzte sich der Reichsminister für Wissenschaft, Erziehung und Volksbildung in einem Schreiben an den $\mathrm{RWM}^{229}$ vom 12. August 1941 auseinander. ${ }^{230}$ Anlass war die Umbenennung des IfK in DIW und eine entsprechende Namensänderung des DIW-Tochterunternehmens in Prag. Damit verbunden war die Frage, welches Ministerium für das DIW und seine Ableger zuständig sei. In einem Vermerk des Wissenschaftsministeriums aus dem Jahr 1941, ${ }^{231}$ der bis unmittelbar vor Kriegsende, u.a. am 15. April 1945, dem zuständigen Referenten und höheren Beamten $^{232}$ mehrfach ,wiedervorgelegt“ worden war, wurde ausgehend von der Satzungsbestimmung, dass das Institut „ausschließlich gemeinnützigen wissenschaftlichen Zwecken“ diene, festgestellt, diese „Zweckbestimmung müsste von Rechts wegen zur Folge haben, dass das Institut dem hiesigen Zuständigkeitsbereich [des Wissenschaftsministeriums] angehört. “ Allerdings wird sodann der zweite Satzteil von § 2 der Satzung zitiert, der dem DIW auch eine „besondere Aufgabenstellung“ zuweist. Diese sei von der ersten „geschieden“ zu interpretieren und wurde, „wenn man die bisherige Entwicklung des Instituts für Konjunkturforschung überblickt, [...] als die entscheidendere“ Aufgabe gesehen: „Tatsächlich bedient sich der Reichswirtschaftsminister des Instituts als einer eigenen Forschungsstelle, die ihm auftragsweise das erforderliche Material für die von ihm zu treffenden Entscheidungen liefert. ${ }^{233}$ Ein Institut, das auftragsweise tätig ist, kann freilich nicht mehr als rein wissenschaftliches Institut angesehen werden und infolgedessen nicht in den Zuständigkeitsbereich unseres

228 Nach der von Wagemann im Februar 1944 für alle Regionalinstitute entworfenen Präambel war die „Aufgabe der Regional-Institute [...] die Pflege der empirischen Wirtschaftsforschung und die wirtschaftswissenschaftliche Beratung von Verwaltung und Wirtschaft.“ Zitiert nach Däbritz 1950, S. 36.

229 Aus dem Etat des RWM wurde auch der Mitgliedsbeitrag des Reichs bezahlt. Protokoll der Kuratoriumssitzung und die Satzung: Registergericht beim Amtsgericht Berlin-Charlottenburg: Vereinsregister Gesch.Nr. 581. Merkwürdigerweise war das RWM nicht für das Reich im Kuratorium, also in der Mitgliederversammlung, vertreten, sondern das Reichsarbeitsministerium und das Reichsernährungsministerium nahmen diese Funktion wahr. Später, 1944, war das RWM mit Ohlendorf im Verwaltungsausschuss des DIW tätig, siehe den Brief Wagemanns an „Ministerialdirektor Ohlendorf“" vom 25.4.1944, BA R3101/32126 F. 25.

230 BA R4901/15234 F. 1-6.

231 Das erste Datum „Wiedervorgelegt 21.4.1941“, so der Stempel, kann nicht stimmen, da der Vermerk sich auf den neuen Namen „Deutsches Institut für Wirtschaftsforschung“ bezieht, der erst auf der Kuratoriumssitzung des Instituts vom 18.6.1941 beschlossen worden war, BA R11/111.

232 Nach dem angehängten Briefentwurf an „Ministerialdirigent Dr. Südhof“ war die Sache vielleicht sogar dem Staatssekretär vorgelegt worden. BA R4901/15234 F. 3 RS.

233 Im April 1941, als der Vermerk geschrieben wurde, war die Industrieabteilung des DIW mit Wagenführ an der Spitze noch gar nicht vom RWM und danach vom Speerschen Planungsamt in die operationale Lenkung der Kriegswirtschaft eingebunden. Ausführlich dazu Fremdling 2016a. 
Ministeriums gehören, denn im engeren Bereich der Wissenschaft muss die Auftragsarbeit vollständig ausgeschaltet und die interessierte Praxis lediglich auf Anregungen und Wünsche beschränkt bleiben, denen die Wissenschaft auf Grund eigenen pflichtgemässen Ermessens entsprechen kann oder nicht.“ Es sei deshalb nicht anzustreben, das DIW der „Aufsicht des Wirtschaftsministeriums zu entziehen und dem hiesigen Zuständigkeitsbereich einzuverleiben.“ Es werde aber „Wert darauf gelegt werden müssen, das Institut eindeutig als eine Institution der Praxis zu kennzeichnen und einen deutlichen Trennungsstrich zwischen ihm und wissenschaftlichen Instituten im eigentlichen Sinne zu ziehen.“ Dem RWM wurde vorgehalten, dass bei der Satzungsänderung bzw. der „Neuorganisation“ des Instituts das Wissenschaftsministerium hätte beteiligt werden müssen, „umso mehr, als der neue Name des Instituts „Deutsches Institut für Wirtschaftsforschung“ in sehr viel stärkerem Masse als der frühere Name „Institut für Konjunkturforschung“ geeignet ist, in der Öffentlichkeit den Eindruck einer echten wissenschaftlichen Einrichtung hervorzurufen.“

Auch wenn man diese Einschätzung des Wissenschaftsministeriums über den wissenschaftlichen Status des DIW und davon abgeleitet auch des RWI nicht teilt, bleibt festzuhalten, dass diese Charakterisierung erfolgte, bevor beide Institute den Höhepunkt ihrer Arbeiten für die deutsche Kriegswirtschaft erreicht hatten. Beim RWI lässt schon allein die mehrfach geäußerte Zuordnung seiner Aktivitäten als „kriegswichtig“234 in den von Däbritz verfassten schriftlichen Quellen keine andere Interpretation als die des Wissenschaftsministeriums zu. ${ }^{235}$ Die umfangreiche Arbeit von Stäglin/Fremdling ${ }^{236}$ über die „Wirtschaftsforschung und wirtschaftspolitische Beratung“ des DIW während des Zweiten Weltkriegs belegt detailliert seine Teilhabe am nationalsozialistischen Herrschaftssystem und mit dieser Auftragsforschung seine Einbindung in die Kriegswirtschaft.

Im Haushaltsjahr 1934/35, als der Etat der Essener Zweigstelle zum letzten Mal als Teil des IfK-Haushalts ausgewiesen wurde, verzeichnete das IfK Einnahmen aus Mitgliedsbeiträgen von 300.546 RM. Davon entfielen auf Essen mit 32.825 RM gut zehn Prozent. Zusammen mit den sonstigen Einnahmen des IfK wurden damit insgesamt Ausgaben von 638.893 RM finanziert. ${ }^{237}$ Im letzten Kriegshaushaltsjahr 1944/45 hatte sich der veranschlagte Etat des DIW, ohne die Tochterinstitute, auf 1.576.900 RM mehr als verdoppelt. ${ }^{238}$ Das RWI hatte für dasselbe Haushaltsjahr ein Volumen von 224.900 RM veranschlagt, wovon 150.000 RM aus Mitgliedsbeiträgen stammen sollten.

234 „Im ganzen aber hat das Institut [...] seine Arbeit unter dem Gesichtspunkt der Kriegswichtigkeit straff zusammengefaßt. “ Tätigkeitsbericht für das Geschäftsjahr 1943/44 und Arbeitsplan für das Geschäftsjahr 1944/45 vom 19.9.1944, WWA K1 Nr. 2080.

235 Bei den einzelnen im Krieg herausgegebenen Heften ist allerdings nicht immer deutlich, ob es einen direkten Auftraggeber gab.

236 Stäglin/Fremdling 2016a.

237 Haushaltsplan des IfK 1935/36, siehe BA R2501/6835 F. 413-414. Der Rechnungshof hatte moniert, dass dieser durchlaufende Posten im IfK-Haushalt ausgewiesen wurde. Ebd., F. 419.

238 Haushaltsplan des DIW 1944/45, BA R3601/216 F. 28-31. 
Es hatte seinen Etat in den zehn Jahren also noch stärker als das Mutterinstitut in Berlin gesteigert. ${ }^{239}$ Wagemanns Institutsgeflecht, er war schließlich in Personalunion Präsident der Muttergesellschaft DIW und aller im ganzen deutschen Herrschaftsgebiet gegründeten Tochterinstitute, expandierte durch die kriegswirtschaftlichen Aufträge enorm: Ohne inhaltlich auf die Tätigkeiten abzustellen, wird diese Tatsache allein durch die gewaltig gesteigerten Haushaltsvolumina während der NS-Zeit belegt, und dies in besonderem Maße beim RWI.

Wagemanns persönliche Stellung und die Einbindung seiner Institute (damit auch des RWI) in das Machtgefüge der NS-Herrschaft erreichte ihren Höhepunkt mit seiner Ernennung zum Leiter der „Arbeitsgemeinschaft für empirische Wirtschaftsforschung im Reichsforschungsrat“ durch Göring ${ }^{240}$ im August 1944:241 „Hiermit beauftrage ich Sie, die von mir gegründete Arbeitsgemeinschaft für empirische Wirtschaftsforschung im Reichsforschungsrat $\mathrm{zu}$ übernehmen und als mein Bevollmächtigter zu leiten. Ich bitte Sie, das von Ihnen geleitete Deutsche Institut für Wirtschaftsforschung mit seinen ihm angeschlossenen Zweiginstituten als Basis für Ihren neuen Arbeitsauftrag anzusehen und entsprechend auszugestalten. Als Bevollmächtigter für das Gebiet der empirischen Wirtschaftsforschung unterstehen Sie mir unmittelbar.“ Diese Ernennung, die eine zusätzliche „personelle und sachliche Unterstützung“ einschloss, wurde von Wagemann in einer Serie von gleichlautenden Briefen Kuratoriumsmitgliedern und mit dem DIW verbundenen Reichsbehörden mitgeteilt, z.B. dem „Herrn Präsidenten Kehrl, Planungsamt beim Generalbevollmächtigten für die Rüstung, [...]. Hiermit teile ich ergebenst mit, daß durch Erlaß vom 26.8.1944 [...] der Herr Reichsmarschall des Großdeutschen Reichs mich beauftragt hat, die neugegründete Arbeitsgemeinschaft für empirische Wirtschaftsforschung im Reichsforschungsrat zu übernehmen und als sein Bevollmächtigter zu leiten. In diesem Zusammenhang ist mir aufgegeben worden, das Deutsche Institut für Wirtschaftsforschung als Basis für diesen neuen Arbeitsauftrag anzusehen, und entsprechend auszugestalten.“242

Der 1937 gegründete Reichsforschungsrat sollte parallel zum Vierjahresplan die Forschung, zunächst vor allem auf natur- und technikwissenschaftlichem Gebiet,

239 Tätigkeitsbericht für das Geschäftsjahr 1943/44 und Arbeitsplan für das Geschäftsjahr 1944/45 vom 19.9.1944, WWA K1 Nr. 2080, S. $10 \mathrm{f}$.

240 Vor allem mit seiner Ernennung zum Beauftragten des Vierjahresplans im Oktober 1936 konnte Göring neben seinen zahlreichen anderen Ämtern und Funktionen auch formal in allen Wirtschaftsbereichen seine Pläne und Vorstellungen durchsetzen.

241 Brief des Reichsmarschalls des Grossdeutschen Reiches (gez. Göring) vom 26.8.1944 an den Präsidenten des DIW, Professor Dr. Ernst Wagemann, BA R3/156 F. 27.

242 Wagemann an Kehrl vom 21.10.1944 BA R3/156. Der Erlass Görings war als Abschrift beigefügt. Siehe die gleichen Briefe an „Ministerialrat Dr. Lorenz, Reichsministerium für Ernährung und Landwirtschaft“ vom 30.10.1944 (BA R3601/216); „Ministerialdirektor Dr. Körner, Reichspostministerium“ vom 30.10.1944 (R4701/13655 (2) F. 386); den „Leitenden Geschäftsführer der Reichswirtschaftskammer Dr. Erdmann“ und den „Abteilungsleiter der Reichswirtschaftskammer Hickmann“ vom 31.10.1944 (BA R11/111). 
verstärkt auf die Kriegsvorbereitung ausrichten. Der Reichsforschungsrat, der nahezu sämtliche Grundlagenforschung wie auch die angewandte Forschung zentral planen sollte, war mit der Deutschen Forschungsgemeinschaft verknüpft. Nach der Reorganisation im Jahr 1942 wurde er unter der Leitung Görings organisatorisch dem Speerschen Rüstungsministerium zugeordnet und entwickelte sich in der Endphase des Zweiten Weltkrieges zur bedeutendsten staatlichen Forschungsförderungsstelle. ${ }^{243}$

Wagemanns Ernennung fiel unter die Anordnung Görings vom 24. August 1944 zum „Erlass des Führers über die Konzentration der Rüstungs- und Kriegsproduktion“: ${ }^{244}$ Um „neben der auch im Kriege unbedingt zu betreibenden Grundlagenforschung möglichst viele für die Kriegsentscheidung wesentliche Forschungsergebnisse kurzfristig zu erhalten“, ordnete Göring an, dass „zu diesem Zweck [...] sämtliche staatlichen forschungstreibenden Institute namentlich in einer Wehrforschungs - Gemeinschaft innerhalb des Reichsforschungsrates zusammenzuschließen“ seien. U.a. zur „Überwachung und Konzentration der Forschung auf vordringlichste durch Erfordernisse der künftigen Kriegführung diktierte Aufgaben“ sollte sich der „Präsident des Reichsforschungsrats eines wissenschaftlichen Führungsstabes [...] aus den vorhandenen und in nächster Zeit noch zu berufenden Fachspartenleitern, Bevollmächtigten und Sonderbeauftragten des Reichsforschungsrates“ bedienen. Mit der Anordnung Görings wurde auch der „Führerbefehl, zur Sicherstellung der für die Kriegführung unentbehrlichen Forschung 5000 Fachkräfte aus der Truppe zu entlassen“, bekräftigt. Nach der Denkschrift „Aufgaben des Deutschen Instituts für Wirtschaftsforschung“ von November 1944 glaubte Wagemann, die zusätzlichen Ressourcen könnten auch zu erweiterter Grundlagenforschung verhelfen: ${ }^{245}$ So interpretierte „die Institutsleitung den neuen Forschungsauftrag, der ihr im Rahmen des Reichsforschungsrates übertragen“ wurde, in „Analogie zu der Grundlagenforschung bei den Naturwissenschaften, deren Daseinsberechtigung im Kriege unbestritten“ sei.

Wagemann konnte sich auf jeden Fall auf konkrete Zusagen im Ernennungsbrief stützen: „Die notwendigen Mittel für die Durchführung Ihrer Forschungsarbeiten sowie sonstige personelle und sachliche Unterstützung stehen Ihnen beim Leiter des Geschäftsführenden Beirats, Ministerialdirektor Professor Dr. Mentzel, zur Verfügung. “246 Mit dem Brief Görings in der Hand gelang es Wagemann, noch in den letzten Kriegsmonaten den Reichsforschungsrat als neues Mitglied des DIW-Kuratoriums $\mathrm{zu}$ gewinnen und umfangreiche Forschungsgelder über den Reichsforschungsrat direkt für das DIW zu mobilisieren: ${ }^{247}$ Als jährlicher Mitgliedsbeitrag wa-

243 Flachowsky 2008, S. 9-11, 232f., 280 ff.; Federspiel 2002, S. 76 - 81; Engels 2007, S. 346.

244 Siehe die Anordnung vom „Reichsmarschall des Großdeutschen Reiches“ vom 24.8.1944, BA R26/III-51 F. $15 \mathrm{f}$.

245 BA R3601/216, F. 57.

246 26.8.1944, Göring an Wagemann, BA R3/156 F. 27.

247 Siehe den Briefwechsel: Wagemann (Antrag) an Mentzel (Leiter des Geschäftsführenden Beirates des Reichsforschungsrates) vom 8.10.1944; Mentzel an Wagemann vom 27.1.1945; Mentzel an Görnnert 
ren RM 100.000 vorgesehen. „Daneben bitte ich [Wagemann], für das Institut im Wege des Werkvertrages einen weiteren Betrag von RM 150.000,- bereitzustellen. ${ }^{248}$ Zur Begründung darf ich ausführen: Der Reichsmarschall hat mich zugleich mit meiner Ernennung zum Bevollmächtigten für empirische Wirtschaftsforschung gebeten, in erster Linie das Deutsche Institut für Wirtschaftsforschung als Basis für den neuen mir erteilten Arbeitsauftrag zu benutzen und zu diesem Zweck entsprechend auszugestalten. Ich bitte, diesen Auftrag zum Gegenstand des vorgeschlagenen Werkvertrages zu machen und für die dadurch erwachsenen neuen Ausgaben den genannten Betrag vorzusehen.“ Da „nach den Bestimmungen der Reichshaushaltsordnung die Hortung von Reichsgeldern untersagt“ war, sollten nur Beträge angefordert werden, „die etwa im Zeitraum eines Vierteljahres benötigt“ wurden. Obwohl im März 1945 die technische Abwicklung (Einrichtung eines Bewilligungskontos) noch nicht vollzogen war, wurden die von DIW-Direktor Pusch als „dringend“ angemahnten RM 75.000 „im Rahmen der jetzt laufenden Überweisungsaktion des Reichsforschungsrates“ als Vorschuss am 24. März 1945 bewilligt.

Mit der Bevollmächtigung Wagemanns im August 1944 waren die Weichen gestellt, dass das DIW mit seinen Tochterinstituten (wie dem RWI) die Kontrolle über die gesamte mit Staatsgeldern geförderte empirische Wirtschaftsforschung übernehmen und „für die Kriegführung fruchtbar gestalten“249 sollte. Mit den Mitteln des Reichsforschungsrates war ein Schritt dazu bereits getan. Allerdings war die NSHerrschaft neun Monate nach der Bevollmächtigung Wagemanns zu Ende.

Wagemann ${ }^{250}$ hatte durchgesetzt, dass nicht nur das DIW als Institut, sondern er als Person als „kriegswichtig“ eingestuft wurde: Dies geschah, obwohl der Leiter der Partei-Kanzlei, Martin Bormann, Wagemann im Einklang mit dem Reichsführer SS und Chef der deutschen Polizei, Heinrich Himmler, noch 1943 nach unbedachten Äußerungen Wagemanns „das Recht, Leiter eines bedeutenden Wirtschaftswissenschaftlichen Institutes zu sein" abgesprochen hatte. Nach einem Bericht der Gauleitung Süd-HannoverBraunschweig vom September 1943 soll Wagemann nach einem Vortrag im Rahmen einer kleinen Gesellschaft geäußert haben, „daß es jetzt richtig wäre, Frieden zu schließen. Wir würden dann halb Polen, halb Italien und den Balkan behalten und könnten im übrigen auf die Ukraine verzichten. Es ist nicht das erste Mal, daß sich Prof. Wagemann in dieser bezw. ähnlicher Weise äussert“. RWM Funk lehnte den von Bor-

(Stabsamt Görings) vom 27.1.1945; Reichsforschungsrat an Wagemann (Bewilligung) vom 27.1.1945; Reichsforschungsrat an Wagemann (Vorschuss) vom 23.3.1945, BA R73/15434.

248 Zusammen also mehr als 15 Prozent des veranschlagten DIW-Haushalts für das Haushaltsjahr $1944 / 45$.

249 Im Erlass Hitlers vom 9.6.1942 lautete der ganze Satz: „Führende Männer der Wissenschaft sollen auf ihren Sondergebieten in Gemeinschaftsarbeit in erster Reihe die Forschung für die Kriegführung fruchtbar gestalten." Siehe Flachowsky 2008, S. 288.

250 Ausführlich zu den Quellen siehe Fremdling/Stäglin 2018; hier wird hingegen i.d.R. nur bei längeren Zitaten auf die Quelle verwiesen. Siehe zudem die Sichtweise eines Mitarbeiters von Wagemann, Wissler 1954. 
mann geforderten Rauswurf Wagemanns ab: „Nach einer eingehenden Prüfung der Verhältnisse und der Aufgaben des von Professor Wagemann gegründeten Institutes für deutsche Wirtschaftsforschung komme ich zu dem Ergebnis, dass die vorhandenen personellen und materiellen Kräfte des Institutes von den verschiedenen Reichsressorts für kriegswichtige Zwecke so völlig eingespannt sind, dass das Institut lediglich durch die Autorität und die Wirkungskraft des Professor Wagemann zusammengehalten wird“. ${ }^{251}$

Mit dem Kriegsende verlor Wagemann seine Funktion im DIW. Schon im Februar 1945 war er, nachdem er die Institutsleitung stellvertretend an Wagenführ übergeben hatte, mit einigen Mitarbeitern nach Clausthal-Zellerfeld gezogen. Der Harz war mit seinen Bergwerken in den letzten Kriegsmonaten Ausweichquartier zahlreicher Reichsbehörden geworden. Nach der Entnazifizierungsentscheidung vom 11. Oktober 1948 wohnte Wagemann noch dauerhaft in Clausthal-Zellerfeld. Der „EntnazifizierungsHauptausschuß der Stadt Göttingen“ stufte ihn in „Kategorie V“ ein, als „entlastet festgestellt“. Die vorhandene Aktenkopie führt etliche Entlastungsgründe auf, ohne seine Rolle als Präsident des IfK/DIW als kriegswichtiges Institut zu erwähnen: Hervorgehoben wurde seine internationale Reputation bei Fachkollegen (1936 war er Vizepräsident des Internationalen Statistischen Instituts gegen „die Stimmen der Nationalsozialisten“ geworden). Der Ausschuss hielt ihm ferner zugute, dass die Gestapo ihn verhört bzw. überwacht hatte. Erwähnt wurde der bereits beschriebene aktenkundige Vorfall seiner unbedachten Äußerungen in Braunschweig im September 1943, weswegen „eine Verweisung auf einige Wochen in das KZ Dachau vom Reichssicherheitshauptamt in Aussicht genommen" worden war. Der Ausschuss stellte zwar Wagemanns Mitgliedschaft in der NSDAP fest, schenkte aber seiner Aussage Glauben, dass er „von einem jungen Beamten seines Amtes, wie er angibt, ohne sein Wissen und Wollen, bei der Partei gemeldet worden“ sei. Zugunsten Wagemanns wurde weiterhin angeführt: „Er hat kein Amt in der Partei bekleidet und hat keiner ihrer Gliederungen angehört.“ „Seiner inneren ablehnenden Einstellung zu dem Nationalsozialismus“ hat Wagemann „im engeren Kreis seiner Mitarbeiter sehr häufig Ausdruck verliehen [...]“. Der Ausschuss schlussfolgerte, dass Wagemann „nur dem Namen nach der Partei angehört hat“, dass er sogar „von der Partei als Gegner erkannt“ worden sei und eine „ablehnende äussere Haltung der Partei gegenüber" gezeigt habe. Darüber hinaus wurde Wagemann zugute gehalten, dass im IfK/DIW Führungskräfte beschäftigt wurden, die „durch die NSDAP von ihren Staatsämtern entfernt worden“ waren. Dazu gehörte der ehemalige deutsche Botschafter in Rom, Ulrich von Hassel (1861-1944), „der im Verlauf der Ereignisse des 20. Juli 1944 als führendes Mitglied der deutschen Widerstandsbewegung hingerichtet worden ist. “252

1948 gründete Wagemann das ,Instituto de Economia' in Chile. Von 1949 bis 1953 war er Professor an der Universität in Santiago de Chile. Nach Deutschland zurückge-

251 BA NS19/20531; Stäglin/Fremdling 2016a, b. 252 BA R9361/V 153574. 
kehrt, lebte er in Frankfurt, Hamburg und Kiel, bevor er 1955 nach Bad Godesberg übersiedelte. Dort starb er am 20. März 1956.

Die insgesamt offenkundige Verkettung des IfK/DIW und seiner Tochterinstitute mit dem NS-System wurde im Nachhinein in Selbstdarstellungen des DIW bis heute heruntergespielt. Bezeichnend dafür ist die „Übersicht über die Entwicklungsgeschichte des Instituts“, ${ }^{253}$ die Rudolf Pusch ${ }^{254}$ am 15. Januar 1949 an das DIW-Mitglied, den „Bundesvorstand des Freien Deutschen Gewerkschaftsbundes für die sowjetische Zone“, schickte. Die Arbeit des DIW in der NS-Zeit wird darin folgendermaßen beschrieben:

Von 1933 an und später etwa bis zum Kriege fand die Tätigkeit des Instituts hauptsächlich in dessen Veröffentlichungen ihren Niederschlag. Seit Ausbruch des Krieges traten die Veröffentlichungen jedoch mehr und mehr in den Hintergrund, da auch die damalige Institutsleitung nicht zu den Konzessionen bereit war, die in Hinblick auf die politische Prüfung des gesamten deutschen Veröffentlichungswesens hätten gemacht werden müssen und wiederholt vom Institut gefordert worden waren. Das Schwergewicht der Arbeit wurde statt dessen auf die interne Forschungsarbeit und auf Materiallieferungen für die verschiedenen planwirtschaftlichen Stellen gelegt. Die internen Forschungsarbeiten während des Krieges hatten u.a. Probleme der Bevölkerungsentwicklung der letzten Jahrhunderte, die Theorie der Verkehrspolitik, Fragen der mathematischen Statistik und die Stellung des Einzelhandels im Rahmen der Gesamtwirtschaft zum Gegenstand.

Nach dem „Arbeitsbericht des Deutschen Instituts für Wirtschaftsforschung (April 1943 bis Juni 1944)“, den Pusch kannte und möglicherweise selber geschrieben hatte, las sich die „interne Forschungsarbeit“ schon im ersten Satz ganz anders: „Im Zeichen des totalen Krieges war das Institut im Berichtszeitraum wieder ganz überwiegend für die Ausführung unmittelbar kriegswichtiger Aufträge der wirtschaftspolitisch interessierten obersten Reichsbehörden und Wehrmachtsdienststellen eingesetzt.“255 Ei-

253 BA DY34/21459. Es wird kein Verfasser genannt, auf dem Schreibmaschinenmanuskript steht unten links „Ki.“. Im gleichen Jahr erklärte der FDGB allerdings seinen Austritt aus dem DIW, siehe den Brief von Friedensburg an den FDGB vom 4.2.1949, ebd.

254 Bis 1952 langjähriger Mitarbeiter des DIW, u.a. als einer der drei Direktoren unter Wagemann (Verwaltungsdirektor, Krengel 1986, S. 45), und enger Vertrauter Wagemanns. Auf der Kuratoriumssitzung zur Umwandlung des IfK in einen eingetragenen Verein stellte „Oberregierungsrat Pusch“ die Satzungsänderungen und den Haushaltsplan für das Geschäftsjahr 1935/36 vor. Er fungierte auch bei längerer Abwesenheit Wagemanns als sein Vertreter, siehe Protokoll der Kuratoriumssitzung vom 29.11. 1935, Registergericht beim Amtsgericht Berlin-Charlottenburg: Vereinsregister Gesch.Nr. 581. Pusch war als Oberregierungsrat im StRA eng mit Wagemann verbunden, als dieser noch bis 1933 das StRA und das IfK in Personalunion leitete (siehe den Bericht des Reichssparkommissars vom 1.4.1933, BA R2301/ 2234 F. 230). Pusch gehörte auch zu den hohen Beamten des StRA, die im März 1933 vom Kommissar des RWM, „Frhr. von Massenbach“, im Gefolge der Beurlaubung Wagemanns ebenfalls beurlaubt wurden. Siehe die Verfügung Platzers „für den beurlaubten Präsidenten“vom 29.3.1933, BA R3102/6210 F. 232. Zu Massenbachs Rolle im StRA siehe Fisch 2016, S. 25-29.

255 BA R3/156 F. 9-25. Siehe dort detailliert die Beschreibung der Aktivitäten des DIW im Berichtsjahr 1943/44 und das „Arbeitsprogramm vom Juli 1944“ für das „nächste“ Jahr. Der Bericht wurde Mitte Juli 1944 an die Mitglieder des Verwaltungsausschusses geschickt. 
nige Monate später, im November 1944, beschrieb das DIW in der Denkschrift über „Die Aufgaben des Deutschen Instituts für Wirtschaftsforschung“ in der Exekutive des NS-Staates seine Funktionen: ${ }^{256}$ Dem DIW sei „die Rolle eines ,wirtschaftswissenschaftlichen Referenten' der staatlichen Wirtschaftsführung zugefallen. In dieser Eigenschaft steht es besonders seit Kriegsbeginn in einem Arbeitsverhältnis mit den Reichsressorts, die wirtschaftliche Belange wahrzunehmen haben. $\mathrm{Zu}$ seinen Auftraggebern gehören während der letzten Jahre insbesondere das Stabsamt des Reichsmarschalls, das Reichsministerium für Ernährung und Landwirtschaft, der Generalbevollmächtigte für die Rüstung (Planungsamt), das Reichsministerium für Rüstung und Kriegsproduktion, das Reichswirtschaftsministerium, die Deutsche Reichsbank, das Oberkommando der Wehrmacht, das Reichsministerium für Volksaufklärung und Propaganda (bzw. der Werberat der deutschen Wirtschaft), das Reichsverkehrsministerium, das Auswärtige Amt und das Reichspostministerium.“ Neben den Auftraggebern wurde die inhaltliche Einbindung in einer umfangreichen Anlage mit 40 ausgewählten Projekten von den „zurzeit in Bearbeitung befindlichen Themen“ spezifiziert. ${ }^{257}$

Der langjährige DIW-Mitarbeiter Rolf Krengel führte die Veränderung und schließlich die Einstellung der Vierteljahrshefte zur Konjunkturforschung (seit dem 12. Jahrgang 1937/38 „Vierteljahrshefte zur Wirtschaftsforschung“) in seiner Institutsgeschichte „auf die immer rigoroser gehandhabte Zensur“ des Propagandaministeriums zurück. ${ }^{258}$ Krengel ließ dabei das vom RWM erlassene Veröffentlichungsverbot außer Acht, das die Publikation statistischer Daten beschränkte oder ganz verbot. ${ }^{259}$ Diese Einschränkung aber dürfte wichtiger für die Auszehrung der Institutsreihe gewesen sein als die Zensur des Propagandaministeriums. Das Veröffentlichungsverbot galt natürlich auch für die Wochenberichte des Instituts, die ebenfalls im Krieg eingestellt wurden - 1943 erschien nur noch ein Heft. ${ }^{260}$ Um diese Publikation in der NS-Zeit überhaupt zu ermöglichen, habe Wagemann nach Krengel bereits im August 1933 mit einer Erklärung im Wochenbericht, „vom Propagandaministerium gezwungen [...] dem Hitler-Regime Treue und Gehorsam schwören“ müssen. ${ }^{261}$ „An die Stelle der - zensierten - Publikationen traten immer mehr interne und im Krieg geheime Gutachten“. ${ }^{262}$ Krengel konnte auf die DIW-Tätigkeit in der Kriegswirtschaft allerdings nur summarisch eingehen, weil ihm bei der Forschung zu seinem Buch kein internes Archivmaterial vorlag. Das war im letzten Kriegsjahr verloren gegangen. Und zu Archivalien aus der „Gegenüberlieferung“, also zu Dokumenten, welche die Auf-

256 BA R3601/216, F. 53.

257 BA R3601/216, F. $58 \mathrm{f}$.

258 Krengel 1986, S. 53 f.

259 „Beschränkungen und Verbote von Statistischen Veröffentlichungen wirtschaftlicher Art“, BA R3102/3082.

260 Fremdling/Stäglin 2008; Krengel 1986, S. 61-63.

261 Krengel (1986, S. 54 f.) zitiert den längeren Abschnitt.

262 Krengel 1986, S. 61. 
traggeber oder die Kuratoriumsmitglieder vom DIW erhielten, verschaffte er sich kaum Zugang. ${ }^{263}$ Auf Rolf Wagenführ, der mit der gesamten Industrieabteilung des DIW 1942 zunächst im RWM und dann ab 1943 im Planungsamt des Rüstungsministeriums für die zur Lenkung der Kriegswirtschaft erforderliche Planstatistik ${ }^{264}$ verantwortlich war, geht Krengel aber immerhin mit Selbstzeugnissen Wagenführs und den „Erinnerungen“ Hans Kehrls ${ }^{265}$ ein. ${ }^{266}$

In der aus einer Ausstellung im Foyer des DIW in der Berliner Mohrenstraße hervorgegangenen Broschüre zur 90-Jahrfeier des Instituts im Jahr 2015 fehlt ein Hinweis auf Wagenführ. ${ }^{267}$ Trotz dieses Versäumnisses wird unter der allerdings verharmlosenden Überschrift „Opportunismus im Zweiten Weltkrieg“268 die Einbindung des DIW in die Kriegswirtschaft und Eroberungspolitik Deutschlands durchaus herausgearbeitet. Doch kann diese Broschüre natürlich nicht eine historisch-kritische Bestandsaufnahme der Geschichte des DIW in der NS-Zeit ersetzen. Wie eng das DIW auch formal und personell tatsächlich in der Kriegswirtschaft mit den Machtzentren des NS-Staates verflochten war, zeigt die Zusammensetzung eines Unterausschusses des Verwaltungsausschusses ${ }^{269}$ des DIW, der am 30. März 1944 gebildet wurde. Folgende Personen bzw. Institutionen gehörten ihm an: $:^{270}$

263 Diese Lücke haben Stäglin/Fremdling 2016b mit einer umfangreichen Materialsammlung aus der „Gegenüberlieferung“, vor allem aus dem Bundesarchiv geschlossen. Dazu haben sie 2014 eine umfassende Expertise (Findbuch mit ausführlichen Zitaten und Paraphrasierungen aus unterschiedlichen Akten und überlieferten Aktenbeständen hauptsächlich verschiedener Ministerien) erarbeitet. Diese Materialien zur Geschichte des IfK/DIW sind über „researchgate“ im Internet und als Broschüre in der Bibliothek des DIW zugänglich, wo auch die Kopien der aufgespürten Archivalien lagern. Zugleich erschienen die Materialien als MPRA (Munich Personal RePEc Archive) Paper No. 76217. http://Econ Papers.repec.org/RePEc:pra:mprapa:76217

264 Das DIW erhob die statistischen Daten nicht selbst (wie manchmal der Eindruck erweckt wird, DIW 2015, S. 21); sie kamen vielmehr von den privatwirtschaftlichen Lenkungsbereichen und aus Erhebungen des StRA. Die Statistische Leitstelle im StRA lieferte sie an das Planungsamt, wo sie unter Wagenführs Leitung für den Planungsprozess aufbereitet wurden. Siehe Fremdling 2016a.

265 Kehrl leitete das Planungsamt, die Kommandozentrale der deutschen Kriegswirtschaft. Zur Rolle Wagenführs und zur Planstatistik ausführlich Fremdling 2016a; siehe auch Tooze 2001, S. 261-282.

266 Krengel 1986, S. 65-72.

267 DIW 2015.

268 Mit dem verbrämenden Begriff „Opportunismus“ schließt sich der Kreis von der ersten zitierten Selbstdarstellung von 1949 über Krengel bis zur heutigen Broschüre: Nach wie vor weist sich das DIW eine eher passive Rolle zu. „Das DIW arrangierte sich zu sehr mit dem NS-Staat“, und „Im Zweiten Weltkrieg ließ sich das Institut zum Unterstützer des nationalsozialistischen Vernichtungskrieges machen“ (so der Vorstand des DIW im Vorwort zur Jubiläumsbroschüre). Eine historisch-kritische Bestandsaufnahme dagegen würde ohne Beschönigungen wie „Arrangement“ und „Unterstützung“ nüchtern feststellen, dass der NS-Staat funktionierte, weil Institutionen wie das DIW und Menschen wie sein damaliger Präsident aktiver, integraler Bestandteil des Regimes waren.

269 Der Verwaltungsausschuss bildete nach der Satzung unter dem Vorsitz des Präsidenten das erweiterte Exekutivorgan des DIW. „Die Mitglieder des Verwaltungsausschusses des Deutschen Instituts für Wirtschaftsforschung bekleiden durchweg führende und besonders verantwortungsvolle Posten in Staat, Partei, und Wirtschaft.“ Zitat aus dem Brief des RWM (gez. Dr. Rollenhagen) an den Präsidenten 


\begin{abstract}
Ministerialdirektor Ohlendorf vom RWM als Vorsitzender
Ministerialrat Dr. Schrötter als Vertreter des Stabsamts des Reichsmarschalls

Staatsminister Riecke als Vertreter des Reichsministeriums für Ernährung und Landwirtschaft Präsident Kehrl als Vertreter des Planungsamts im Reichsministerium für Rüstung und Kriegsproduktion

Ministerialdirektor Dr. Körner als Vertreter des Reichspostministeriums

Ein noch zu benennender Vertreter des Propaganda-Ministeriums

Ministerialrat Fröhling als Vertreter der Parteikanzlei
\end{abstract}

Als von Göring ernannter Leiter der „Arbeitsgemeinschaft für empirische Wirtschaftsforschung im Reichsforschungsrat" hatte Wagemann den Reichsforschungsrat für das DIW als neues Kuratoriumsmitglied und seinen faktischen Leiter Mentzel als Mitglied des Verwaltungsausschusses gewonnen. Im entsprechenden Brief an Mentzel vom 8. Oktober $1944^{271}$ führte Wagemann die im Verwaltungsausschuss, „dem entscheidenden Gremium des Instituts [...] vertretenen Körperschaften“ mit ihren Mitgliedsbeiträgen auf:

\author{
Reichsernährungsministerium \\ Reichspostministerium \\ Reichswirtschaftsministerium \\ Parteikanzlei \\ Deutsche Arbeitsfront \\ Reichsbank \\ IG-Farben \\ (sowie für einen Werkvertrag) \\ Speer-Ministerium \\ (sowie für einen Werkvertrag ${ }^{272}$ ) \\ Geplant: \\ Reichsforschungsrat \\ (sowie für einen Werkvertrag)
}

$$
\begin{array}{ll}
\text { RM } 270.000,- \\
\text { RM } 150.000,- \\
\text { RM } 140.000,- \\
\text { RM } 100.000,- \\
\text { RM } \quad 60.000,- \\
\text { RM } 50.000,- \\
\text { RM } 25.000,- \\
\text { RM } 25.000,- \\
\text { RM } 20.000,- \\
\text { RM } 280.000,- \\
\text { RM } 100.000,- \\
\text { RM } 150.000,-
\end{array}
$$

Die von Stäglin/Fremdling erschlossenen Quellen würden mit ihrer umfangreichen Überlieferung eine umfassendere historisch-kritische Bestandsaufnahme der Geschichte des DIW in der NS-Zeit erlauben, als sie hier für das weitaus kleinere, weniger gut dokumentierte RWI nur begrenzt möglich war. Allerdings konnten in Analogie mit Quellen über das Mutterhaus des RWI in Berlin zahlreiche Lücken geschlossen werden. Wegen ihrer exemplarischen Bedeutung für die Töchter wurden

des DIW vom 20.12.1944 (BA R3/146 F. 168), in dem es darum ging, wegen der Arbeitsüberlastung regulärer Mitglieder einen „Beauftragten“ einzusetzen.

270 Brief Wagemanns an Körner, Reichspostministerium vom 15.6.1944, BA R4701/13655 (2) F. 321. Siehe auch das Protokoll über die Sitzung des Verwaltungsausschusses vom 30.3.1944, auf der die Einrichtung dieses Unterausschusses und seine Zusammensetzung diskutiert wurde, BA R3/156 F .4-7. 271 Wagemann an Mentzel vom 8.10.1944, BA R73/15434. Zu Mentzel siehe Flachowsky 2008, S. 300. 272 Wohl Vergütung für die Dienstleistung der Industrieabteilung des DIW (Wagenführ) für das Planungsamt. 
also einige Themen für die Berliner Mutter behandelt, die sowohl für das IfK/DIW selbst wie für seine Zweigstellen stehen.

Die in diesem Abschnitt eingangs gestellte Frage zum Spannungsverhältnis zwischen selbstbestimmter rein wissenschaftlicher Tätigkeit und der Auftragsforschung während der NS-Zeit lässt sich m. E. eindeutig beantworten: Der ganz überwiegende Teil der Arbeiten des DIW und RWI während der NS-Zeit waren Auftragsarbeiten. Die empirische Wirtschaftsforschung beider Institute trug zum Funktionieren des nationalsozialistischen Herrschaftssystems und der Kriegswirtschaft bei und war direkt oder indirekt dessen integraler Bestandteil. ${ }^{273}$

273 Zwischen „wahrer und guter“ Grundlagenforschung auf der einen Seite und einer dem Regime dienenden Anwendungsforschung auf der anderen Seite trennen zu können, ist ein Wunschdenken, in dem nach 1945 weite Bereiche der Forschungstätigkeit in der NS-Zeit entlastet werden sollten. Flachowsky (2008, S. 10) bringt diese irreführende Immunisierung in seiner Arbeit über die Wissenschaftspolitik während der NS-Zeit auf den Punkt: „Das Dogma einer nur erkenntnisgeleiteten deutschen Wissenschaft und der damit einhergehende Topos von ihrem Missbrauch durch die Nationalsozialisten verstellen jedoch den Blick auf eine hochgradige „Selbstmobilisierung der Wissenschaft“ für die verbrecherischen Ziele des Nationalsozialismus.“ 
